Cochrane Database of Systematic Reviews

\title{
Pharmacotherapies that specifically target ammonia for the prevention and treatment of hepatic encephalopathy in adults with cirrhosis (Review)
}

Zacharias HD, Zacharias AP, Gluud LL, Morgan MY

Zacharias HD, Zacharias AP, Gluud LL, Morgan MY.

Pharmacotherapies that specifically target ammonia for the prevention and treatment of hepatic encephalopathy in adults with cirrhosis. Cochrane Database of Systematic Reviews 2019, Issue 6. Art. No.: CD012334.

DOI: 10.1002/14651858.CD012334.pub2.

www.cochranelibrary.com

Pharmacotherapies that specifically target ammonia for the prevention and treatment of hepatic encephalopathy in adults with cirrhosis 


\section{TABLE OF CONTENTS}

HEADER

ABSTRACT

PLAIN LANGUAGE SUMMARY

. . . . . . . . . . . . . . . . . . . . . . . . . . . . . . 2

SUMMARY OF FINDINGS FOR THE MAIN COMPARISON ．．．．．．．．． . . . . . . . . . . . 4

BACKGROUND . . . . . . . . . . . . . . . . . . . . . . . . . . . . . . . . . . . . 13

OBJECTIVES . . . . . . . . . . . . . . . . . . . . . . . . . . . . . . . . . . . . . 15

METHODS . . . . . . . . . . . . . . . . . . . . . . . . . . . . . . . . . . . . . . 15

RESULTS . . . . . . . . . . . . . . . . . . . . . . . . . . . . . . . . . . . . 19

Figure 1. . . . . . . . . . . . . . . . . . . . . . . . . . . . . . . . . 20

Figure 2. . . . . . . . . . . . . . . . . . . . . . . . . . . . . . . . . . . . . . .

Figure 3. . . . . . . . . . . . . . . . . . . . . . . . . . . . . . . . . . . . . 424

DISCUSSION . . . . . . . . . . . . . . . . . . . . . . . . . . . . . . . . . . . . . . . . . . . . . . . .

AUTHORS' CONCLUSIONS . . . . . . . . . . . . . . . . . . . . . . . . . . . . . . . . . . . . . . . . . $\quad 29$

ACKNOWLEDGEMENTS . . . . . . . . . . . . . . . . . . . . . . . . . . . . . . . . . . . . . . . . . . 2

REFERENCES . . . . . . . . . . . . . . . . . . . . . . . . . . . . . . . . . . . . . . . . 30

CHARACTERISTICS OF STUDIES . . . . . . . . . . . . . . . . . . . . . . . . . . . . . . . . . . . . 36

DATA AND ANALYSES . . . . . . . . . . . . . . . . . . . . . . . . . . . . . . . . . . . . 61

Analysis 1.1. Comparison 1 Pharmacotherapies that specifically target ammonia versus placebo, lactulose, or lactitol,

Outcome 1 Mortality. . . . . . . . . . . . . . . . . . . . . . . . . . . . . . . .

Analysis 1.2. Comparison 1 Pharmacotherapies that specifically target ammonia versus placebo, lactulose, or lactitol,

Outcome 2 Hepatic encephalopathy.

Analysis 1.3. Comparison 1 Pharmacotherapies that specifically target ammonia versus placebo, lactulose, or lactitol,

Outcome 3 Serious adverse events.

Analysis 1.4. Comparison 1 Pharmacotherapies that specifically target ammonia versus placebo, lactulose, or lactitol,

Outcome 4 Non-serious adverse events. . . . . . . . . . . . . . . . . . . . . . . . . . . . . . . . . .

Analysis 1.5. Comparison 1 Pharmacotherapies that specifically target ammonia versus placebo, lactulose, or lactitol,

Outcome 5 Ammonia. . . . . . . . . . . . . . . . . . . . . . . . . . . . . . . . 68

ADDITIONAL TABLES . . . . . . . . . . . . . . . . . . . . . . . . . . . . . . . . . . . . . . . . . . . .

APPENDICES . . . . . . . . . . . . . . . . . . . . . . . . . . . . . . . . . . . . . . . . . . . . .

WHAT'S NEW . . . . . . . . . . . . . . . . . . . . . . . . . . . . . . . . . . . . . . 76

HISTORY . . . . . . . . . . . . . . . . . . . . . . . . . . . . . . . . . . . . . . . . 76

CONTRIBUTIONS OF AUTHORS . . . . . . . . . . . . . . . . . . . . . . . . . . . . . . . . . . . . . . . . . . .

DECLARATIONS OF INTEREST . . . . . . . . . . . . . . . . . . . . . . . . . . . . . . . . . . 76

SOURCES OF SUPPORT . . . . . . . . . . . . . . . . . . . . . . . . . . . . . . . . . . . . . . . . . . . . . . . 76

DIFFERENCES BETWEEN PROTOCOL AND REVIEW . . . . . . . . . . . . . . . . . . . . . . . . . . . . .

Pharmacotherapies that specifically target ammonia for the prevention and treatment of hepatic encephalopathy in adults with cirrhosis 


\title{
[Intervention Review]
}

\section{Pharmacotherapies that specifically target ammonia for the prevention and treatment of hepatic encephalopathy in adults with cirrhosis}

\author{
Harry D Zacharias ${ }^{1}$, Antony P Zacharias ${ }^{1}$, Lise Lotte Gluud ${ }^{2}$, Marsha Y Morgan ${ }^{1}$ \\ ${ }^{1}$ UCL Institute for Liver \& Digestive Health, Division of Medicine, Royal Free Campus, University College London, London, UK. \\ ${ }^{2}$ Gastrounit, Medical Division, Copenhagen University Hospital Hvidovre, Hvidovre, Denmark \\ Contact address: Marsha Y Morgan, UCL Institute for Liver \& Digestive Health, Division of Medicine, Royal Free Campus, University \\ College London, London, NW3 2PF, UK. marsha.morgan@ucl.ac.uk.
}

Editorial group: Cochrane Hepato-Biliary Group.

Publication status and date: Edited (no change to conclusions), published in Issue 7, 2019.

Citation: Zacharias HD, Zacharias AP, Gluud LL, Morgan MY. Pharmacotherapies that specifically target ammonia for the prevention and treatment of hepatic encephalopathy in adults with cirrhosis. Cochrane Database of Systematic Reviews 2019, Issue 6. Art. No.: CD012334. DOI: 10.1002/14651858.CD012334.pub2.

Copyright (C) 2019 The Cochrane Collaboration. Published by John Wiley \& Sons, Ltd.

\begin{abstract}
A B S T R A C T
Background

Hepatic encephalopathy is a common complication of cirrhosis, with high related morbidity and mortality. Its presence is associated with a wide spectrum of change ranging from clinically obvious neuropsychiatric features, known as 'overt' hepatic encephalopathy, to abnormalities manifest only on psychometric or electrophysiological testing, 'minimal' hepatic encephalopathy. The exact pathogenesis of the syndrome is unknown but ammonia plays a key role. Drugs that specifically target ammonia include sodium benzoate, glycerol phenylbutyrate, ornithine phenylacetate, AST-120 (spherical carbon adsorbent), and polyethylene glycol.
\end{abstract}

\section{Objectives}

To evaluate the beneficial and harmful effects of pharmacotherapies that specifically target ammonia versus placebo, no intervention, or other active interventions, for the prevention and treatment of hepatic encephalopathy in people with cirrhosis.

\section{Search methods}

We searched the Cochrane Hepato-Biliary Controlled Trials Register, CENTRAL, MEDLINE, Embase, and three other databases to March 2019. We also searched online trials registries such as ClinicalTrials.gov, European Medicines Agency, WHO International Clinical Trial Registry Platform, and the Food and Drug Administration for ongoing or unpublished trials. In addition, we searched conference proceedings, checked bibliographies, and corresponded with investigators.

\section{Selection criteria}

We included randomised clinical trials comparing sodium benzoate, glycerol phenylbutyrate, ornithine phenylacetate, AST-120, and polyethylene glycol versus placebo or non-absorbable disaccharides, irrespective of blinding, language, or publication status. We included participants with minimal or overt hepatic encephalopathy or participants who were at risk of developing hepatic encephalopathy.

\section{Data collection and analysis}

Two review authors independently extracted data from the included reports. The primary outcomes were mortality, hepatic encephalopathy, and serious adverse events. We undertook meta-analyses and presented results using risk ratios (RR) or mean differences (MD), both with $95 \%$ confidence intervals (CIs), and $\mathrm{I}^{2}$ statistic values as a marker of heterogeneity. We assessed bias control using the Cochrane Hepato-Biliary domains and the certainty of the evidence using GRADE.

Pharmacotherapies that specifically target ammonia for the prevention and treatment of hepatic encephalopathy in adults with cirrhosis 


\section{Main results}

Eleven randomised clinical trials fulfilled our inclusion criteria. Two trials evaluated the prevention of hepatic encephalopathy while nine evaluated the treatment of hepatic encephalopathy. The trials assessed sodium benzoate (three trials), glycerol phenylbutyrate (one trial), ornithine phenylacetate (two trials), AST-120 (two trials), and polyethylene glycol (three trials). Overall, 499 participants received these pharmacotherapies while 444 participants received a placebo preparation or a non-absorbable disaccharide. We classified eight of the 11 trials as at 'high risk of bias' and downgraded the certainty of the evidence to very low for all outcomes.

Eleven trials, involving 943 participants, reported mortality data, although there were no events in five trials. Our analyses found no beneficial or harmful effects of sodium benzoate versus non-absorbable disaccharides (RR 1.26, 95\% CI 0.49 to 3.28; 101 participants; 2 trials; $\mathrm{I}^{2}=0 \%$ ), glycerol phenylbutyrate versus placebo (RR 0.65, 95\% CI 0.11 to 3.81; 178 participants; 1 trial), ornithine phenylacetate versus placebo (RR 0.73, 95\% CI 0.35 to $1.51 ; 269$ participants; 2 trials; $\mathrm{I}^{2}=0 \%$ ), AST-120 versus lactulose (RR $1.05,95 \%$ CI 0.59 to $1.85 ; 41$ participants; 1 trial), or polyethylene glycol versus lactulose (RR 0.50, 95\% CI 0.09 to $2.64 ; 190$ participants; 3 trials; $\mathrm{I}^{2}=$ $0 \%)$.

Seven trials involving 521 participants reported data on hepatic encephalopathy. Our analyses showed a beneficial effect of glycerol phenylbutyrate versus placebo (RR $0.57,95 \%$ CI 0.36 to $0.90 ; 178$ participants; 1 trial; number needed to treat for an additional beneficial outcome (NNTB) 6), and of polyethylene glycol versus lactulose (RR 0.19, 95\% CI 0.08 to $0.44 ; 190$ participants; 3 trials; NNTB 4). We did not observe beneficial effects in the remaining three trials with extractable data: sodium benzoate versus nonabsorbable disaccharides (RR 1.22, 95\% CI 0.51 to 2.93; 74 participants; 1 trial); ornithine phenylacetate versus placebo (RR 2.71, 95\% CI 0.12 to 62.70; 38 participants; 1 trial); or AST-120 versus lactulose (RR 1.05, 95\% CI 0.59 to 1.85; 41 participants; 1 trial).

Ten trials, involving 790 participants, reported a total of 130 serious adverse events. Our analyses found no evidence of beneficial or harmful effects of sodium benzoate versus non-absorbable disaccharides (RR 1.08, 95\% CI 0.44 to 2.68 ; 101 participants; 2 trials), glycerol phenylbutyrate versus placebo (RR $1.63,95 \%$ CI 0.85 to 3.13; 178 participants; 1 trial), ornithine phenylacetate versus placebo (RR 0.92 , 95\% CI 0.62 to $1.36 ; 264$ participants; 2 trials; $\mathrm{I}^{2}=0 \%$ ), or polyethylene glycol versus lactulose (RR $0.57,95 \%$ CI 0.18 to 1.82; 190 participants; 3 trials; $\mathrm{I}^{2}=0 \%$ ). Likewise, eight trials, involving 782 participants, reported a total of 374 non-serious adverse events and again our analyses found no beneficial or harmful effects of the pharmacotherapies under review when compared to placebo or to lactulose/lactitol.

Nine trials, involving 733 participants, reported data on blood ammonia. We observed significant reductions in blood ammonia in placebo-controlled trials evaluating sodium benzoate $(\mathrm{MD}-32.00 \mu \mathrm{g} / \mathrm{dL}, 95 \% \mathrm{CI}-46.85$ to $-17.15 ; 16$ participants; 1 trial), glycerol phenylbutyrate (MD $-12.00 \mu \mathrm{mol} / \mathrm{L}^{*}$ week, $95 \% \mathrm{CI}-23.37$ to $-0.63 ; 178$ participants; 1 trial), ornithine phenylacetate (MD -27.10 $\mu \mathrm{mol} / \mathrm{L}, 95 \% \mathrm{CI}-48.55$ to $-5.65 ; 231$ participants; 1 trial), and AST-120 (MD $-22.00 \mu \mathrm{g} / \mathrm{dL}, 95 \%$ CI -26.75 to -17.25 ; 98 participants; 1 trial). However, there were no significant differences in blood ammonia concentrations in comparison with lactulose/ lactitol with sodium benzoate (MD 9.00, 95\% CI - 1.10 to 19.11; 85 participants; 2 trials; $\mathrm{I}^{2}=0 \%$ ), AST-120 (MD 5.20 units not specified, $95 \% \mathrm{CI}-2.75$ to 13.15 ; 35 participants; 1 trial), and polyethylene glycol (MD $-29.28 \mu \mathrm{mol} / \mathrm{L}, 95 \% \mathrm{CI}-95.96$ to 37.39 ; 90 participants; 2 trials; $\left.\mathrm{I}^{2}=88 \%\right)$.

Five trials received support from pharmaceutical companies while four did not; two did not provide this information.

\section{Authors' conclusions}

There is insufficient evidence to determine the effects of these pharmacotherapies on the prevention and treatment of hepatic encephalopathy in adults with cirrhosis. They have the potential to reduce blood ammonia concentrations when compared to placebo, but their overall effects on clinical outcomes of interest and the potential harms associated with their use remain uncertain. Further evidence is needed to evaluate the potential beneficial and harmful effects of these pharmacotherapies in this clinical setting.

\section{PLAIN LANGUAGESUMMARY}

\section{Drug treatments that specifically target ammonia for adults with cirrhosis and hepatic encephalopathy}

\section{Background}

Cirrhosis is a chronic disorder of the liver. People with cirrhosis may develop hepatic encephalopathy, a condition that results in poor brain functioning. Some people with hepatic encephalopathy show clear evidence of brain dysfunction and are said to have 'overt' hepatic encephalopathy. They may have a poor memory, difficulty concentrating, speech problems, a tremor, particularly of their hands,

Pharmacotherapies that specifically target ammonia for the prevention and treatment of hepatic encephalopathy in adults with cirrhosis 2 (Review)

Copyright $($ C 2019 The Cochrane Collaboration. Published by John Wiley \& Sons, Ltd. 
or stiffness of their limbs. These changes may occur in bouts or may be persistent. Other people with cirrhosis may not show any obvious signs of brain dysfunction, but some aspects of their brain function, such as attention and the ability to perform complex tasks are found to be impaired when tested. They are said to have 'minimal' hepatic encephalopathy. The reason why people develop hepatic encephalopathy is complex, but the build up in the blood of toxins from the gut, particularly of a compound called ammonia, plays a key role. Certain drugs have been developed specifically to lower blood ammonia levels and may help prevent people from developing hepatic encephalopathy and have beneficial effects in those already suffering from this disorder. However, the evidence that they are beneficial is unclear. The five drugs (pharmacotherapies) considered in this review are sodium benzoate, glycerol phenylbutyrate, ornithine phenylacetate, AST-120 (spherical carbon adsorbent), and polyethylene glycol.

\section{Review question}

We investigated the use of five pharmacotherapies that specifically target ammonia for the prevention and treatment of hepatic encephalopathy in people with cirrhosis. We did this by reviewing clinical trials in which people with cirrhosis were randomly allocated to treatment with one of these drugs or to an inactive dummy (placebo), to no treatment or to other drugs that are also used to manage this condition, such as, lactulose and lactitol (these are non-absorbable disaccharides). We included people with cirrhosis who had minimal or overt hepatic encephalopathy and people who were at risk of developing this complication.

\section{Search date}

5 March 2019

\section{Study funding sources}

Five of the 11 randomised clinical trials we included in the review received support from pharmaceutical companies. Two trials did not provide information on potential financial support or links to pharmaceutical companies. Four trials did not receive funding or other support from this source.

\section{Study characteristics}

We identified 11 randomised clinical trials comparing drugs that specifically target ammonia with inactive placebo or a non-absorbable disaccharide; two trials evaluated prevention of hepatic encephalopathy while nine trials evaluated treatment of hepatic encephalopathy. The trials assessed sodium benzoate (three trials), glycerol phenylbutyrate (one trial), ornithine phenylacetate (two trials), AST-120 (two trials) and polyethylene glycol (three trials). Participants were treated for varying periods ranging from five days to 16 weeks.

\section{Key results}

Sodium benzoate, glycerol phenylbutyrate, ornithine phenylacetate, and AST-120 lowered blood ammonia levels when compared to placebo, but none of the drugs lowered the blood ammonia levels when compared to a non-absorbable disaccharide. Glycerol phenylbutyrate seemed to have a beneficial effect on hepatic encephalopathy when compared to placebo, as did polyethylene glycol when compared to lactulose. None of the drugs appeared to affect the risk of death and did not have any notable adverse effects.

\section{Quality of the evidence}

The evidence we found was very uncertain, and so we are not confident that these drugs are useful for preventing or treating hepatic encephalopathy in people with cirrhosis. There were very few trials available, and not all of them provided sufficient data for us to include in our analyses. In addition, many of the published trials received support from the pharmaceutical industry which introduces an element of bias. Thus, we need more information to obtain a better idea if these drugs are useful and safe for use in this context.

Pharmacotherapies that specifically target ammonia for the prevention and treatment of hepatic encephalopathy in adults with cirrhosis 


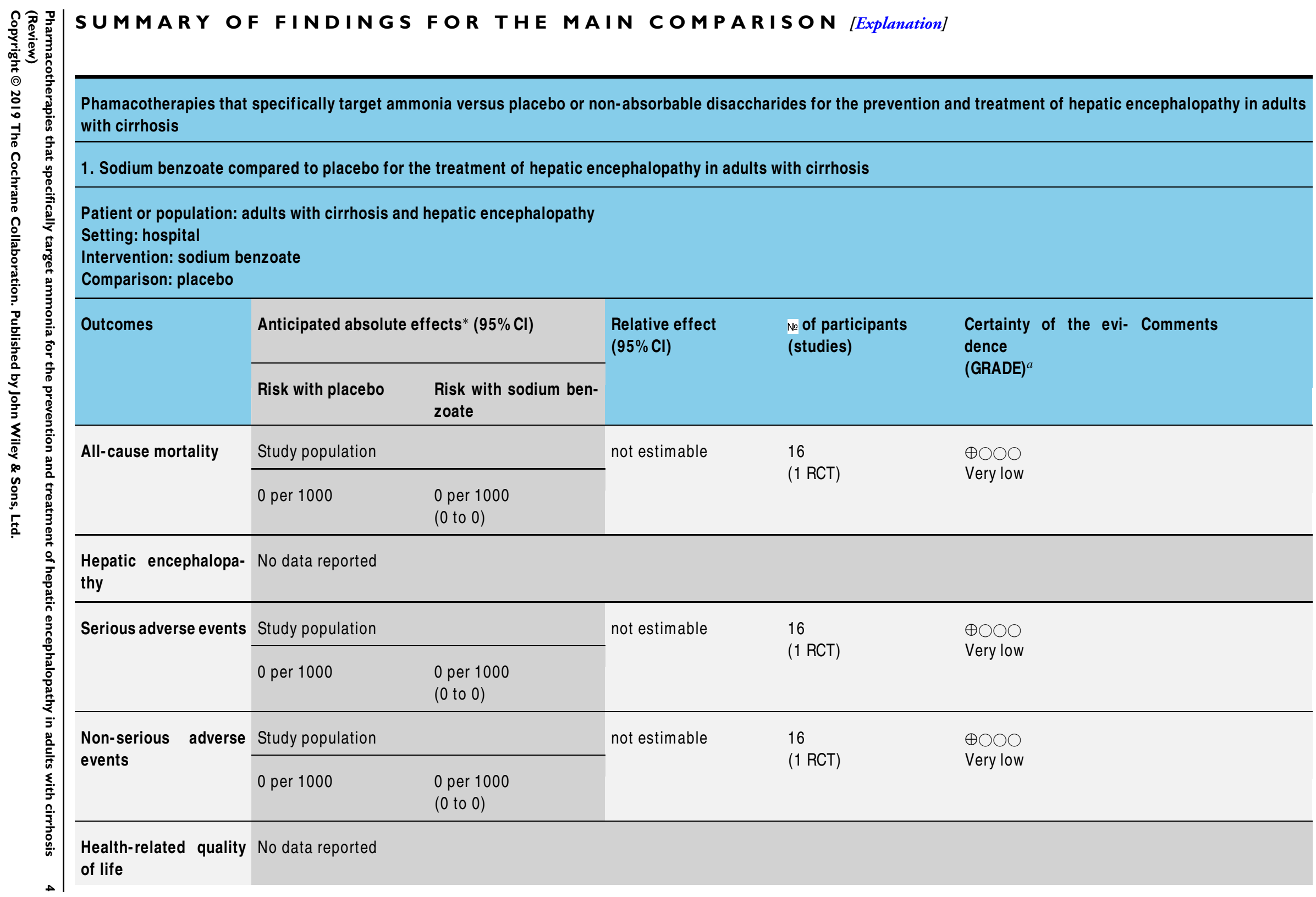




$\begin{array}{llll}\begin{array}{l}\text { Blood ammonia con- } \\ \text { centrations }(\mu \mathrm{g} / \mathrm{dL})\end{array} & \begin{array}{l}\text { MD } 32 \text { lower } \\ (46.85 \text { lower to } 17.15\end{array} & \begin{array}{l}16 \\ (1 \mathrm{RCT})\end{array} & \text { Very low } \\ & \text { lower) }\end{array}$

2. Sodium benzoate compared to non-absorbable disaccharides for the prevention and treatment of hepatic encephalopathy in adults with cirrhosis

Participants: people with cirrhosis and hepatic encephalopathy Setting: hospital

Intervention: sodium benzoate

Comparison: non-absorbable disaccharides (lactulose or lactitol)

\begin{tabular}{|c|c|c|c|c|c|}
\hline \multirow[t]{2}{*}{ Outcomes } & \multicolumn{2}{|c|}{ Anticipated absolute effects* $(95 \% \mathrm{Cl})$} & \multirow{2}{*}{$\begin{array}{l}\text { Relative effect } \\
(95 \% \mathrm{Cl})\end{array}$} & \multirow{2}{*}{$\begin{array}{l}\text { № of participants } \\
\text { (studies) }\end{array}$} & \multirow{2}{*}{$\begin{array}{l}\text { Certainty of the evi- Comments } \\
\text { dence } \\
\text { (GRADE) }^{b}\end{array}$} \\
\hline & $\begin{array}{l}\text { Risk with lactulose/ } \\
\text { lactitol }\end{array}$ & $\begin{array}{l}\text { Risk with sodium ben- } \\
\text { zoate }\end{array}$ & & & \\
\hline \multirow[t]{2}{*}{ All-cause mortality } & Study population & & \multirow{2}{*}{$\begin{array}{l}\text { RR } 1.26 \\
(0.49 \text { to } 3.28)\end{array}$} & \multirow{2}{*}{$\begin{array}{l}101 \\
\text { (2 RCTs) }\end{array}$} & \multirow{2}{*}{$\begin{array}{l}\oplus \bigcirc \bigcirc \bigcirc \\
\text { Very low }\end{array}$} \\
\hline & 118 per 1000 & $\begin{array}{l}148 \text { per } 1000 \\
(58 \text { to } 386)\end{array}$ & & & \\
\hline \multirow{2}{*}{$\begin{array}{l}\text { Hepatic encephalopa- } \\
\text { thy }\end{array}$} & Study population & & \multirow{2}{*}{$\begin{array}{l}\text { RR } 1.22 \\
-(0.51 \text { to } 2.93)\end{array}$} & \multirow{2}{*}{$\begin{array}{l}74 \\
(1 \mathrm{RCT})\end{array}$} & \multirow{2}{*}{$\begin{array}{l}\oplus \circ \bigcirc \bigcirc \\
\text { Very low }\end{array}$} \\
\hline & 194 per 1000 & $\begin{array}{l}237 \text { per } 1000 \\
(99 \text { to } 570)\end{array}$ & & & \\
\hline \multirow[t]{2}{*}{ Serious adverse events } & Study population & & \multirow{2}{*}{$\begin{array}{l}\text { RR } 1.08 \\
-(0.44 \text { to } 2.68)\end{array}$} & \multirow{2}{*}{$\begin{array}{l}101 \\
(2 \mathrm{RCTs})\end{array}$} & \multirow{2}{*}{$\begin{array}{l}\oplus \circ \bigcirc \bigcirc \\
\text { Very low }\end{array}$} \\
\hline & 137 per 1000 & $\begin{array}{l}148 \text { per } 1000 \\
(60 \text { to } 368)\end{array}$ & & & \\
\hline \multirow{2}{*}{$\begin{array}{l}\text { Non-serious adverse } \\
\text { events }\end{array}$} & Study population & & \multirow[t]{2}{*}{ RR 1.13 (0.96 to 1.32$)$} & \multirow{2}{*}{$\begin{array}{l}182 \\
\text { (2 RCTs) }\end{array}$} & \multirow{2}{*}{$\begin{array}{l}\oplus \bigcirc \bigcirc \bigcirc \\
\text { Very low }\end{array}$} \\
\hline & 469 per 1000 & $\begin{array}{l}530 \text { per } 1000 \\
(450 \text { to } 619)\end{array}$ & & & \\
\hline
\end{tabular}




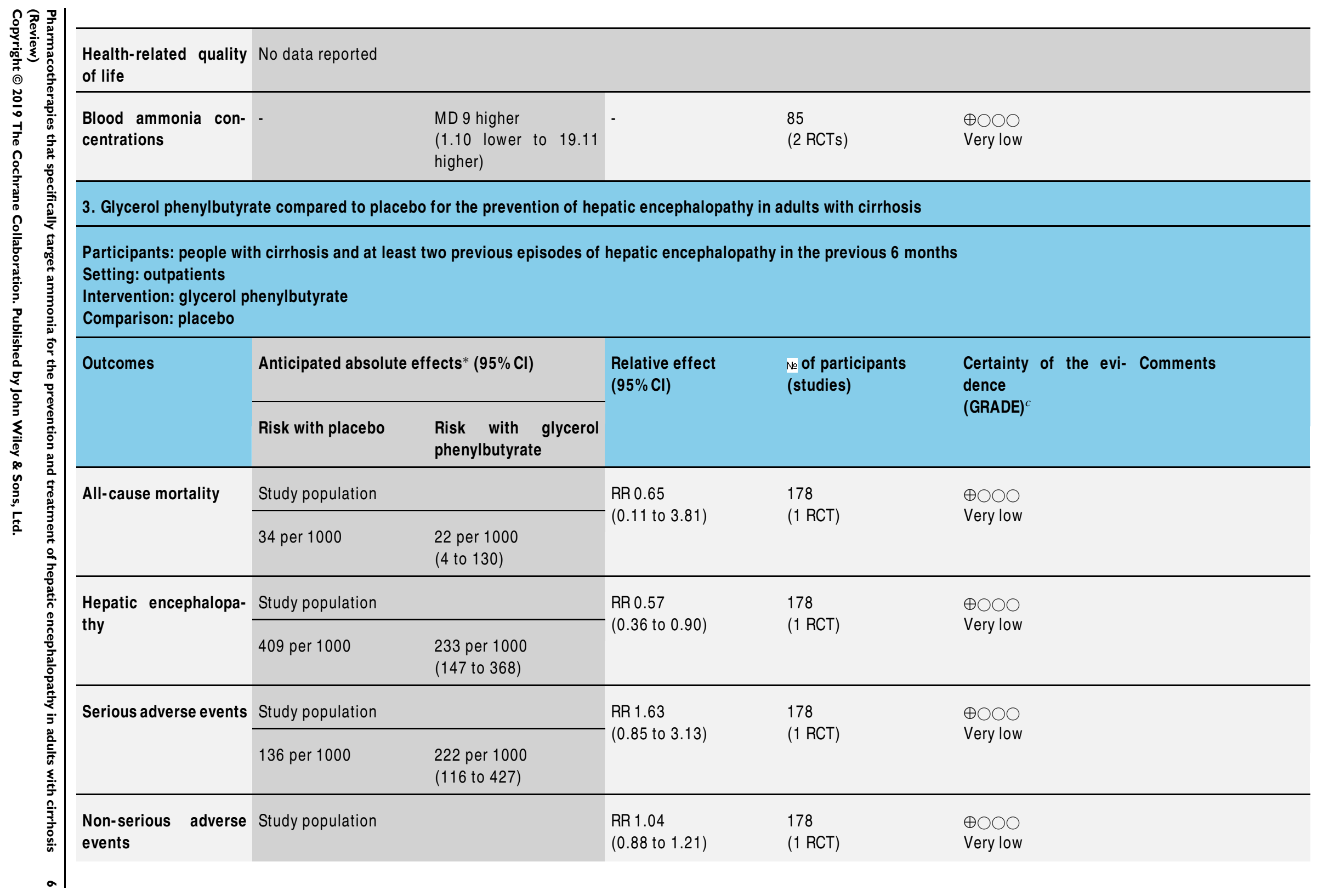




\begin{tabular}{|c|c|c|c|c|c|}
\hline & 761 per 1000 & $\begin{array}{l}792 \text { per } 1000 \\
(670 \text { to } 921)\end{array}$ & & & \\
\hline $\begin{array}{l}\text { Health-related quality } \\
\text { of life }\end{array}$ & \multicolumn{4}{|l|}{ No data reported } & \\
\hline $\begin{array}{l}\text { Blood ammonia } \\
\text { concentrations ( } \mu \mathrm{mol} / \\
L^{*} \text { week) }\end{array}$ & - & $\begin{array}{l}\text { MD } 12 \text { lower } \\
\text { (23.37 lower to } 0.63 \\
\text { lower) }\end{array}$ & - & $\begin{array}{l}178 \\
(1 \mathrm{RCT})\end{array}$ & $\begin{array}{l}\oplus \bigcirc \bigcirc \bigcirc \\
\text { Very low }\end{array}$ \\
\hline \multicolumn{6}{|c|}{ 4. Ornithine phenylacetate compared to placebo for the prevention and treatment of hepatic encephalopathy in adults with cirrhosis and hepatic encephalopath } \\
\hline \multicolumn{6}{|c|}{$\begin{array}{l}\text { Participants: adults with cirrhosis and } \\
\text { bleeding } \\
\text { Setting: hospital } \\
\text { Intervention: ornithine phenylacetate } \\
\text { Comparison: placebo }\end{array}$} \\
\hline \multirow[t]{2}{*}{ Outcomes } & \multicolumn{2}{|c|}{ Anticipated absolute effects* $(95 \% \mathrm{CI})$} & \multirow{2}{*}{$\begin{array}{l}\text { Relative effect } \\
(95 \% \mathrm{Cl})\end{array}$} & \multirow{2}{*}{$\begin{array}{l}\text { № of participants } \\
\text { (studies) }\end{array}$} & \multirow{2}{*}{$\begin{array}{l}\text { Certainty of the evi- Comments } \\
\text { dence } \\
\text { (GRADE) }^{d}\end{array}$} \\
\hline & Risk with placebo & $\begin{array}{l}\text { Risk with ornithine } \\
\text { phenylacetate }\end{array}$ & & & \\
\hline \multirow[t]{2}{*}{ All-cause mortality } & Study population & & \multirow{2}{*}{$\begin{array}{l}\text { RR } 0.73 \\
-(0.35 \text { to } 1.51)\end{array}$} & \multirow{2}{*}{$\begin{array}{l}269 \\
(2 \mathrm{RCTs})\end{array}$} & \multirow{2}{*}{$\begin{array}{l}\oplus \bigcirc \bigcirc \bigcirc \\
\text { Very low }\end{array}$} \\
\hline & 113 per 1000 & $\begin{array}{l}82 \text { per } 1000 \\
(39 \text { to } 170)\end{array}$ & & & \\
\hline \multirow{2}{*}{$\begin{array}{l}\text { Hepatic encephalopa- } \\
\text { thy }\end{array}$} & Study population & & \multirow{2}{*}{$\begin{array}{l}\text { RR } 2.71 \\
-(0.12 \text { to } 62.70)\end{array}$} & \multirow{2}{*}{$\begin{array}{l}38 \\
(1 \mathrm{RCT})\end{array}$} & \multirow{2}{*}{$\begin{array}{l}\oplus \bigcirc \bigcirc \bigcirc \\
\text { Very low }\end{array}$} \\
\hline & 0 per 1000 & $\begin{array}{l}0 \text { per } 1000 \\
(0 \text { to } 0)\end{array}$ & & & \\
\hline Serious adverse events & Study population & & $\begin{array}{l}\text { RR } 0.92 \\
(0.62 \text { to } 1.36)\end{array}$ & $\begin{array}{l}264 \\
(2 \mathrm{RCTs})\end{array}$ & $\begin{array}{l}\oplus \bigcirc \bigcirc \bigcirc \\
\text { Very low }\end{array}$ \\
\hline
\end{tabular}




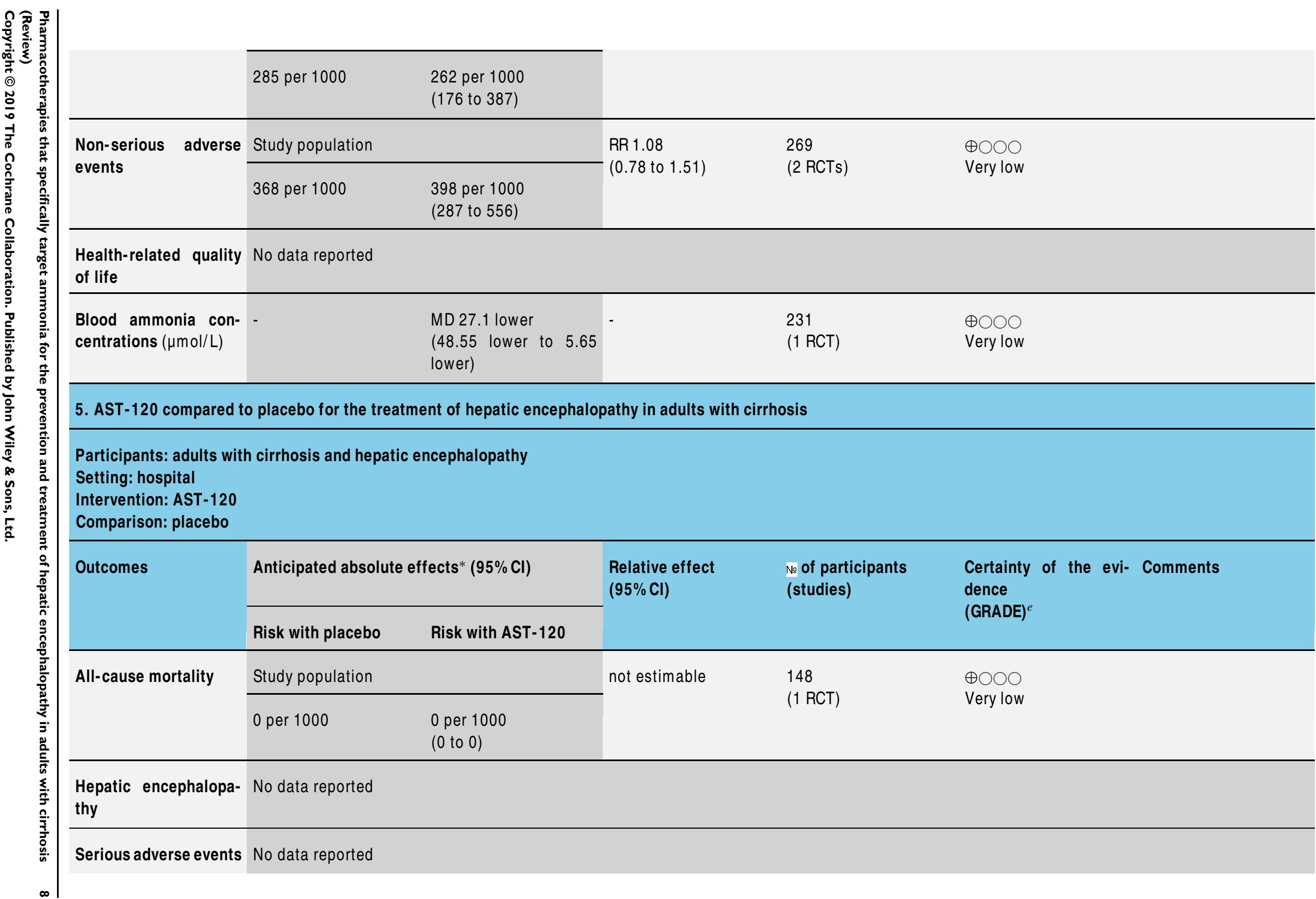


Non-serious adverse No data reported

events

Health-related quality No data reported

of life

\begin{tabular}{|c|c|c|c|c|}
\hline $\begin{array}{l}\text { Blood ammonia con- } \\
\text { centrations }(\mu \mathrm{g} / \mathrm{dL})\end{array}$ & $\begin{array}{l}\text { MD } 22 \text { lower } \\
\text { ( } 26.75 \text { lower to } 17.25 \\
\text { lower) }\end{array}$ & $\begin{array}{l}98 \\
(1 \mathrm{RCT})\end{array}$ & $\begin{array}{l}\oplus \circ \bigcirc \bigcirc \\
\text { Very low }\end{array}$ & $\begin{array}{l}\text { We were not able } \\
\text { to gather data on } \\
\text { blood ammonia con- } \\
\text { centration separately } \\
\text { for the two treatment } \\
\text { groups }\end{array}$ \\
\hline
\end{tabular}

6. AST-120 compared to non-absorbable disaccharide (lactulose) for the treatment of hepatic encephalopathy in adults with cirrhosis

Patient or population: adults with cirrhosis and hepatic encephalopathy

Setting: hospital

Intervention: AST-120

Comparison: lactulose

\begin{tabular}{|c|c|c|c|c|c|}
\hline \multirow[t]{2}{*}{ Outcomes } & \multicolumn{2}{|c|}{ Anticipated absolute effects* $(95 \% \mathrm{Cl})$} & \multirow{2}{*}{$\begin{array}{l}\text { Relative effect } \\
(95 \% \mathrm{Cl})\end{array}$} & \multirow{2}{*}{$\begin{array}{l}\text { № of participants } \\
\text { (studies) }\end{array}$} & \multirow{2}{*}{$\begin{array}{l}\text { Certainty of the evi- Comments } \\
\text { dence } \\
\text { (GRADE) }^{f}\end{array}$} \\
\hline & Risk with lactulose & Risk with AST-120 & & & \\
\hline \multirow[t]{2}{*}{ All-cause mortality } & Study population & & \multirow[t]{2}{*}{ RR 1.05 (0.59 to 1.85$)$} & \multirow{2}{*}{$\begin{array}{l}41 \\
(1 \mathrm{RCT})\end{array}$} & \multirow{2}{*}{$\begin{array}{l}\oplus \circ \bigcirc \bigcirc \\
\text { Very low }\end{array}$} \\
\hline & 524 per 1000 & $\begin{array}{l}550 \text { per } 1000 \\
(0 \text { to } 0)\end{array}$ & & & \\
\hline \multirow{2}{*}{$\begin{array}{l}\text { Hepatic encephalopa- } \\
\text { thy }\end{array}$} & \multicolumn{2}{|l|}{ Study population } & \multirow{2}{*}{$\begin{array}{l}\text { RR } 1.05 \\
(0.59 \text { to } 1.85)\end{array}$} & \multirow{2}{*}{$\begin{array}{l}41 \\
(1 \mathrm{RCT})\end{array}$} & \multirow{2}{*}{$\begin{array}{l}\oplus \bigcirc \bigcirc \bigcirc \\
\text { Very low }\end{array}$} \\
\hline & 524 per 1000 & $\begin{array}{l}550 \text { per } 1000 \\
(309 \text { to } 969)\end{array}$ & & & \\
\hline Serious adverse events & Study population & & not estimable & $\begin{array}{l}41 \\
(1 \mathrm{RCT})\end{array}$ & $\begin{array}{l}\oplus \bigcirc \bigcirc \bigcirc \\
\text { Very low }\end{array}$ \\
\hline
\end{tabular}




\begin{tabular}{|c|c|c|c|c|c|c|}
\hline & & & & & \\
\hline & 0 per 1000 & $\begin{array}{l}0 \text { per } 1000 \\
(0 \text { to } 0)\end{array}$ & & & & \\
\hline $\begin{array}{l}\text { Non-serious adverse } \\
\text { events }\end{array}$ & \multicolumn{6}{|l|}{ No data reported } \\
\hline $\begin{array}{l}\text { Health-related quality } \\
\text { of life }\end{array}$ & \multicolumn{6}{|l|}{ No data reported } \\
\hline $\begin{array}{l}\text { Blood ammonia con- } \\
\text { centrations (units un- } \\
\text { specified) }\end{array}$ & - & $\begin{array}{l}\text { MD } 5.2 \text { higher } \\
\text { (2.75 lower to } 13.15 \\
\text { higher) }\end{array}$ & - & $\begin{array}{l}35 \\
(1 \mathrm{RCT})\end{array}$ & $\begin{array}{l}\oplus \bigcirc \bigcirc \bigcirc \\
\text { Very low }\end{array}$ & $\begin{array}{l}\text { We were only able } \\
\text { to gather data on } \\
\text { blood ammonia con- } \\
\text { centrations on a sub- } \\
\text { group of participants }\end{array}$ \\
\hline \multicolumn{7}{|c|}{ 7. Polyethylene glycol compared non-absorbable disaccharide (lactulose) for the treatment of hepatic encephalopathy in adults with cirrhosis } \\
\hline \multicolumn{7}{|c|}{$\begin{array}{l}\text { Participants: adults with cirrhosis and hepatic encephalopathy } \\
\text { Setting: hospital } \\
\text { Intervention: polyethylene glycol } \\
\text { Comparison: lactulose }\end{array}$} \\
\hline \multirow[t]{2}{*}{ Outcomes } & \multicolumn{2}{|c|}{ Anticipated absolute effects* $(95 \% \mathrm{Cl})$} & \multirow[t]{2}{*}{$\begin{array}{l}\text { Relative effect } \\
(95 \% \mathrm{Cl})\end{array}$} & \multirow[t]{2}{*}{$\begin{array}{l}\text { № of participants } \\
\text { (studies) }\end{array}$} & \multirow{2}{*}{$\begin{array}{l}\text { Certainty of the evi- } \\
\text { dence } \\
\text { (GRADE) }^{g}\end{array}$} & Comments \\
\hline & Risk with lactulose & $\begin{array}{l}\text { Risk with polyethylene } \\
\text { glycol }\end{array}$ & & & & \\
\hline \multirow[t]{2}{*}{ All-cause mortality } & \multicolumn{2}{|l|}{ Study population } & \multirow{2}{*}{$\begin{array}{l}\text { RR } 0.50 \\
(0.09 \text { to } 2.64)\end{array}$} & \multirow{2}{*}{$\begin{array}{l}190 \\
\text { (3 RCTs) }\end{array}$} & \multirow{2}{*}{$\begin{array}{l}\oplus \bigcirc \bigcirc \bigcirc \\
\text { Very low }\end{array}$} & \\
\hline & 43 per 1000 & $\begin{array}{l}21 \text { per } 1000 \\
(4 \text { to } 112)\end{array}$ & & & & \\
\hline $\begin{array}{l}\text { Hepatic encephalopa- } \\
\text { thy }\end{array}$ & Study population & & $\begin{array}{l}\text { RR } 0.19 \\
(0.08 \text { to } 0.44)\end{array}$ & $\begin{array}{l}190 \\
\text { (3 RCTs) }\end{array}$ & $\begin{array}{l}\oplus \bigcirc \bigcirc \bigcirc \\
\text { Very low }\end{array}$ & \\
\hline
\end{tabular}




\begin{tabular}{|c|c|c|c|c|c|}
\hline & 330 per 1000 & $\begin{array}{l}63 \text { per } 1000 \\
(26 \text { to } 145)\end{array}$ & & & \\
\hline \multirow[t]{2}{*}{ Serious adverse events } & Study population & & \multirow{2}{*}{$\begin{array}{l}\text { RR } 0.57 \\
-(0.18 \text { to } 1.82)\end{array}$} & \multirow{2}{*}{$\begin{array}{l}190 \\
\text { (3 RCTs) }\end{array}$} & \multirow{2}{*}{$\begin{array}{l}\oplus \bigcirc \bigcirc \bigcirc \\
\text { Very low }\end{array}$} \\
\hline & 74 per 1000 & $\begin{array}{l}42 \text { per } 1000 \\
(13 \text { to } 136)\end{array}$ & & & \\
\hline \multirow{2}{*}{$\begin{array}{l}\text { Non-serious } \\
\text { events }\end{array}$} & \multicolumn{2}{|l|}{ Study population } & \multirow{2}{*}{$\begin{array}{l}\text { RR } 0.71 \\
-(0.40 \text { to } 1.27)\end{array}$} & \multirow{2}{*}{$\begin{array}{l}117 \\
\text { (2 RCTs) }\end{array}$} & \multirow{2}{*}{$\begin{array}{l}\oplus \bigcirc \bigcirc \bigcirc \\
\text { Very low }\end{array}$} \\
\hline & 191 per 1000 & $\begin{array}{l}136 \text { per } 1000 \\
(77 \text { to } 243)\end{array}$ & & & \\
\hline $\begin{array}{l}\text { Health-related quality } \\
\text { of life }\end{array}$ & No data reported & & & & \\
\hline $\begin{array}{l}\text { Blood ammonia levels } \\
(\mu \mathrm{mol} / \mathrm{L})\end{array}$ & - & $\begin{array}{l}\text { MD } 29.28 \text { lower } \\
\text { (95.96 lower to } 37.39 \\
\text { higher) }\end{array}$ & - & $\begin{array}{l}90 \\
(2 \text { RCTs) }\end{array}$ & $\begin{array}{l}\oplus \bigcirc \bigcirc \bigcirc \\
\text { Very low }\end{array}$ \\
\hline
\end{tabular}

${ }^{*}$ The risk in the intervention group (and its $95 \%$ confidence interval) is based on the assumed risk in the comparison group and the relative effect of the intervention (and its $95 \% \mathrm{Cl})$.

Cl: confidence interval; MD: mean difference; RR: risk ratio; $\mathbf{R C T}$ : randomised clinical trial

\section{GRADE Working Group grades of evidence}

High certainty: we are very confident that the true effect lies close to that of the estimate of the effect.

Moderate certainty: we are moderately confident in the effect estimate: the true effect is likely to be close to the estimate of the effect, but there is a possibility that it is substantially different.

Low certainty: our confidence in the effect estimate is limited: the true effect may be substantially different from the estimate of the effect.

Very low certainty: we have very little confidence in the effect estimate: the true effect is likely to be substantially different from the estimate of effect

${ }^{a}$ We downgraded the evidence by three levels because of the serious risk of bias (two levels) and uncertainty; only one small

trial is included in the analysis and there were no reported events (one level).

${ }^{b}$ We downgraded the evidence by three levels because of the serious risk of bias; only one of the two trials had a low risk of bias (two levels) and uncertainty; only two small trials are included in the analysis (one level).

${ }^{c}$ We downgraded the evidence by three levels because of the serious risk of bias (two levels) and uncertainty; only one small

$=$ trial is included in the analysis (one level). 


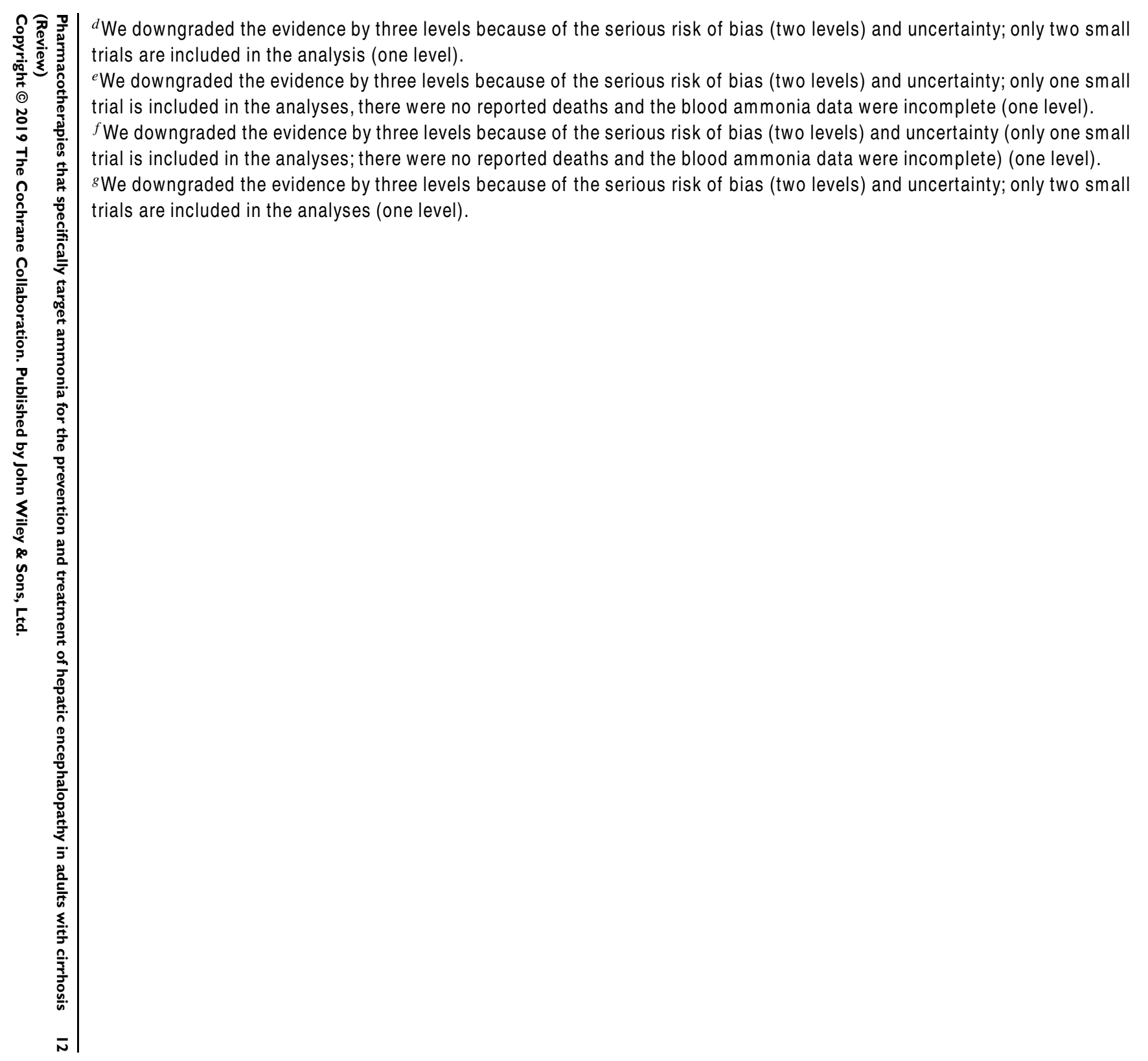




\section{B A C K G R O U N D}

\section{Description of the condition}

The term 'hepatic encephalopathy' is used to describe the spectrum of neuropsychiatric change that can arise in people with cirrhosis. The joint guideline from the European Association for the Study of the Liver (EASL) and the American Association for the Study of Liver Diseases (AASLD) defines hepatic encephalopathy as, "brain dysfunction associated with liver insufficiency or portal-systemic shunting" (AASLD/EASL 2014; Vilstrup 2014).

Clinically apparent or 'overt' hepatic encephalopathy manifests as a neuropsychiatric syndrome encompassing a wide spectrum of mental and motor disorders (Ferenci 2002; Weissenborn 1998). It may develop over a period of hours or days, apparently spontaneously, or else, in $50 \%$ to $70 \%$ of instances, follow an identifiable precipitating event such as gastrointestinal bleeding, infection, dehydration, or constipation (Pantham 2017). Episodes may recur. Between episodes, people may return to their baseline neuropsychiatric status or retain a degree of impairment (Bajaj 2010). Less frequently, people present with persistent neuropsychiatric abnormalities, which are always present to some degree, but which may fluctuate in severity (Ferenci 2002). The changes in mental state in people with overt hepatic encephalopathy range from subtle alterations in personality, intellectual capacity and cognitive function to deep coma. The changes in motor function may include asterixis (flapping tremor), rigidity, speech disorders, tremor, and delayed diadochocinetic movements (Cadranel 2001; Victor 1965; Weissenborn 1998). People with overt hepatic encephalopathy may show other associated abnormalities, including: impaired psychomotor performance (Schomerus 1998); disturbed neurophysiological function (Chu 1997; Parsons-Smith 1957); altered cerebral neurochemical/neurotransmitter homeostasis (Taylor-Robinson 1994); reductions in global and regional cerebral blood flow and metabolism (O'Carroll 1991); and changes in cerebral fluid homeostasis (Haussinger 2000). In general, the degree of impairment in these variables increases with the severity of the underlying liver disease (Bajaj 2009). 'Minimal' hepatic encephalopathy, in the older literature referred to as 'subclinical' or 'latent' hepatic encephalopathy, is the term applied to people with cirrhosis with no clinical neuropsychiatric abnormalities who, nevertheless, show abnormalities in neuropsychometric or neurophysiological performance, when tested (Ferenci 2002; Guérit 2009). Recently, the term covert hepatic encephalopathy has been introduced to encompass patients with minimal hepatic encephalopathy and those with low-grade overt hepatic encephalopathy. While this approach may be pragmatic, it is not clear how informative or valuable it is in clinical and particularly research settings. Indeed, it has already been shown that patients classified as having covert hepatic encephalopathy behave, when tested, as two relatively independent groups (Montagnese 2014; Zacharias 2017).
There is no gold standard test for the diagnosis of hepatic encephalopathy (AASLD/EASL 2014; Montagnese 2004; Vilstrup 2014), but rather a range of diagnostic tests that can be used singly or in combination. A detailed neuropsychiatric history and examination (Montagnese 2004), should be undertaken with particular attention paid to changes in memory, concentration, cognition, and consciousness. Clinicians and researchers often use the West Haven Criteria to grade mental status (Conn 1977), and the Glasgow Coma Score to grade the level of consciousness (Teasdale 1974). The history and examination will identify the clinical features suggestive of hepatic encephalopathy, which are often subtle, or confirm their absence. Further, they will allow exclusion of other causes of neuropsychiatric abnormalities, such as certain neurological disorders and other metabolic encephalopathies, including those associated with diabetes, renal failure, and chronic pulmonary insufficiency. People with hepatic encephalopathy also show impaired performance on a range of psychometric tests (Montagnese 2004; Randolph 2009). Those with minimal hepatic encephalopathy show deficits in attention, visuospatial abilities, fine motor skills, and memory, while other cognitive functions are relatively well preserved. People with overt hepatic encephalopathy show additional disturbances in psychomotor speed, executive function, and concentration. Several paper and pencil psychometric tests are used in the evaluation of cognitive performance in people suspected of having hepatic encephalopathy. These tests are either used individually or are grouped together into test batteries or systems. Of the tests used singly, Number Connection Tests A and B are the best known (Ferenci 2002). The Psychometric Hepatic Encephalopathy Score (PHES), which comprises five paper and pencil tests covering the domains of attention, visual perception, and visuo-constructive abilities, is the most widely used psychometric test battery and has high diagnostic specificity (Schomerus 1998; Weissenborn 2001). PHES test scores have to be normalised to take account of factors such as age, sex, and educational level. At present, normative databases are available in several countries, including Germany, Italy, Spain, Mexico, Korea, Romania, India, and the UK. In countries where levels of illiteracy are high, Figure Connection Tests A and B are often used either alone or as part of the PHES battery (Dhiman 1995). People with hepatic encephalopathy may also show several neurophysiological abnormalities (Guérit 2009). The electroencephalogram (EEG), which primarily reflects cortical neuronal activity, may show progressive slowing of the background activity and abnormal wave morphology (Parsons-Smith 1957). Recent advances in electroencephalogram analysis provide better quantifiable and more informative data (Jackson 2016; Olesen 2016). The brain responses, or evoked potentials, to stimuli such as light and sound may show abnormal slowing or wave forms, or both (Chu 1997; Guérit 2009). Other potential diagnostic techniques, such as the Critical Flicker Fusion Frequency (Kircheis 2002), the Inhibitory Control Test (Bajaj 2008), and the Stroop test (Allampati 2016), need further validation. Blood ammonia concentrations

Pharmacotherapies that specifically target ammonia for the prevention and treatment of hepatic encephalopathy in adults with cirrhosis 
are not routinely measured to diagnose hepatic encephalopathy (Blanco Vela 2011; Lockwood 2004), but are often monitored in clinical trials.

\section{Description of the intervention}

We assessed five separate pharmacotherapies that specifically target ammonia. These differed in their formulation, routes of administration, and modes of action (Table 1).

\section{How the intervention might work}

The exact pathogenesis of hepatic encephalopathy is unknown but ammonia is known to play a key role (Butterworth 2013; Morgan 2018). Ammonia is produced in the intestine from dietary protein, deamination of glutamine via glutaminase and bacterial action in the colon. It is absorbed by non-ionic diffusion but specific ammonia transporters may also be involved; ammonia concentrations in the portal vein are ten-fold higher than in arterial blood. The hepatic extraction rate is high. The ammonia in portal blood, together with the ammonia derived from hepatic amino acid metabolism, is taken up primarily by periportal hepatocytes and metabolised to urea via the urea cycle. The kidneys and muscles also play a role in ammonia homeostasis (Wright 2011). In skeletal muscle, ammonia is transformed into glutamine through the action of glutamine synthetase. In the kidneys, ammonia is generated from the deamination of glutamine. In people with cirrhosis, blood ammonia levels increase primarily because of a reduction in first-pass metabolism of ammonia as a result of portal systemic shunting and a loss of hepatic metabolic capacity. As a result, gut-derived ammonia is not effectively cleared from the blood by the liver; it consequently enters the systemic circulation and impinges on the brain where it has both direct and indirect effects on cerebral function. Treatment is aimed, primarily, at reducing the production and absorption of ammonia from the gastrointestinal tract and this is usually affected by use of non-absorbable disaccharides and non-absorbable antibiotics.

Hyperammonaemia is also a major consequence of genetic disorders of the urea cycle enzymes. In these conditions the increase in blood ammonia concentrations results directly from failure of hepatic ammonia metabolism. Treatment is based on providing alternative pathways for the removal of nitrogen waste (Berry 2014). A small number of drugs, so-called 'ammonia scavengers', have been developed for use in urea cycle disorders. The best known of these agents are sodium benzoate, and sodium/glycerol phenylbutyrate. Both decrease ammonia concentrations by serving as alternatives to urea for the excretion of waste nitrogen. Benzoate conjugates with glycine to form hippuric acid while phenylacetate conjugates with glutamine in the liver and kidneys to form phenylacetylglutamine. Hippuric acid and phenylacetylglutamine are subsequently excreted in the urine (Table 1 ). These 'ammonia scaveng- ing agents' have also been used to treat hepatic encephalopathy in people with cirrhosis (Campollo 1992; Efrati 2000; Gonzalez 1994; Mendenhall 1986; Misel 2013; Rockey 2014; Sushma 1992; Uribe 1990; Weiss 2018). Ornithine phenylacetate was specifically developed for the treatment of hepatic encephalopathy in people with cirrhosis; the L-ornithine moiety acts as a substrate for the synthesis of glutamine from ammonia in skeletal muscle, while the phenylacetate moiety combines with glutamine to form phenylacetylglutamine, which is excreted in the urine (Jalan 2007; Rahimi 2016; Rose 2012; STOP-HE 2017; Ventura-Cots 2016). This agent is not intended for use in the treatment of urea cycle enzyme disorders (Rahimi 2016). AST-120 is a carbon microsphere adsorbent that differs structurally from activated charcoal in that it has a selective binding surface. It exhibits superior adsorption of low molecular weight organic compounds such as ammonia from the lumen of the lower gastrointestinal tract, which are then excreted in the faeces (Bajaj 2013; Bosoi 2011; Pockros 2009). Polyethylene glycol (PEG) is a cathartic; it causes rapid clearance of the gut bacteria that synthesize ammonia, thereby reducing its production (Naderian 2017; Rahimi 2014; Rahimi 2016). The adverse events associated with the use of these drugs are mainly gastrointestinal and include diarrhoea, constipation, dry mouth, and changes in appetite (Lee 2010; Rahimi 2016).

\section{Why it is important to do this review}

Hepatic encephalopathy is a common and debilitating complication of cirrhosis. Approximately $10 \%$ to $14 \%$ of people with cirrhosis have overt hepatic encephalopathy when they are first diagnosed with liver disease (Saunders 1981). In people with decompensated cirrhosis, the prevalence of overt hepatic encephalopathy at presentation is about 20\% (D'Amico 1986; De Jongh 1992; Zipprich 2012). In people with cirrhosis who have no evidence of neuropsychiatric impairment, the risk of developing an episode of overt hepatic encephalopathy within five years of presentation varies from $5 \%$ to $25 \%$, depending on the presence or absence of other risk factors; the cumulative incidence of overt hepatic encephalopathy is as high as 40\% (Bajaj 2011a; Randolph 2009). The prevalence of minimal hepatic encephalopathy may be more than $50 \%$ in people with previous overt hepatic encephalopathy (Lauridsen 2011; Sharma 2010).

The presence of hepatic encephalopathy, whether minimal or overt, is associated with significant impairment in the performance of complex tasks, such as driving (Kircheis 2009; Schomerus 1981), and a detrimental effect on quality of life (Groeneweg 1998), and safety (Roman 2011). In addition, the presence of overt hepatic encephalopathy pre-transplantation has a detrimental effect on neurocognitive function post-transplantation (Sotil 2009), and on survival (Bustamante 1999; D'Amico 2006; Jepsen 2010; Stewart 2007). The one-year survival rate in people who have hepatic encephalopathy at presentation is $36 \%$, with a fiveyear survival rate of $15 \%$ (Jepsen 2010), while the survival prob-

Pharmacotherapies that specifically target ammonia for the prevention and treatment of hepatic encephalopathy in adults with cirrhosis 14 (Review)

Copyright ( 2019 The Cochrane Collaboration. Published by John Wiley \& Sons, Ltd. 
ability after a first episode of hepatic encephalopathy is $42 \%$ at one year but only 23\% at three years (Bustamante 1999). Overt hepatic encephalopathy also poses a substantial burden for the affected families (Bajaj 2011b), and a significant financial burden on healthcare systems (Poodad 2007; Stepanova 2012).

Strategies to prevent and treat hepatic encephalopathy in people with cirrhosis are clearly needed (Morgan 2018). At present, treatment is directed primarily at reducing the production and absorption of gut-derived neurotoxins, particularly ammonia, mainly through dietary manipulation, bowel cleansing, non-absorbable disaccharides and non-absorbable antibiotics (AASLD/ EASL 2014; Vilstrup 2014). Interventions that specifically target the metabolism and elimination of ammonia may provide new treatment options (Jover-Cobos 2013; McGuire 2010; Rahimi 2016; Rose 2012). There are several potential candidates (Table 1). Some, for example, sodium benzoate and glycerol phenylbutyrate, are used to treat the hyperammonaemia associated with urea cycle enzyme deficiencies; they serve as 'ammonia scavengers', providing alternative, non-urea cycle pathways for removal of ammonia. Ornithine phenylacetate is also an ammonia scavenger; it was developed specifically for the treatment of hepatic encephalopathy in people with cirrhosis. AST-120 and polyethylene glycol speed elimination of ammonia or ammonia-generating bacteria via the large intestine (Table 1). None of these pharmacotherapies are currently licensed for the indication of hepatic encephalopathy, although several are undergoing phase IIB and III clinical trials. Thus, presently these agents do not have a place in routine clinical practice.

Very little is known about the potential beneficial and harmful effects of these pharmacotherapies. We have, therefore, conducted a systematic review with meta-analyses of the available randomised clinical trials of five pharmacotherapeutic agents that specifically target ammonia for the prevention and treatment of hepatic encephalopathy in people with cirrhosis, following recommendations for best practice.

\section{O B J E C T I VES}

To evaluate the beneficial and harmful effects of pharmacotherapies that specifically target ammonia versus placebo, no intervention, or other active interventions, for the prevention and treatment of hepatic encephalopathy in people with cirrhosis.

\section{METHODS}

\section{Criteria for considering studies for this review}

\section{Types of studies}

We included randomised clinical trials, irrespective of blinding, language, or publication status in our primary analyses. If, during the selection of trials, we identified observational studies, for example, quasi-randomised studies, cohort studies or patient reports that described adverse events caused by or associated with use of the interventions under review, then we included these data in our qualitative analyses. We did not specifically search for observational studies for inclusion in this review, which is a known limitation.

\section{Types of participants}

We included adults with cirrhosis and minimal or overt hepatic encephalopathy, or adults who were at risk of developing overt hepatic encephalopathy. We included participants in our primary analyses irrespective of age, sex, the aetiology and severity of the underlying liver disease, or the presence or absence of precipitating factors. We excluded trials involving people with hepatic encephalopathy associated with acute liver failure. We included trials involving people with hepatic encephalopathy associated with either cirrhosis or non-cirrhotic portal hypertension provided that subgroup analyses were available or else the proportion of participants with non-cirrhotic portal hypertension was very small.

\section{Types of interventions}

We evaluated drugs that specifically target ammonia, including sodium benzoate, glycerol phenylbutyrate, ornithine phenylacetate, spherical carbon adsorbents (AST-120), and polyethylene glycol versus placebo, no treatment or interventions that have a potentially beneficial effect on hepatic encephalopathy, such as the non-absorbable disaccharides (Gluud 2016). We included trials irrespective of the dose, treatment duration, or mode of administration of the drugs under review. We allowed co-interventions if they were administered equally to all comparison groups.

We did not include trials involving use of L-ornithine L-aspartate as these are the subject of a separate Cochrane Review (Goh 2018).

\section{Types of outcome measures}

We assessed all outcomes at the maximum duration of follow-up.

\section{Primary outcomes}

1. All-cause mortality.

2. Hepatic encephalopathy. We assessed this outcome using the primary investigators' overall assessment of: i) the number of participants who developed hepatic encephalopathy, and ii) the number of participants without a clinically-relevant improvement in hepatic encephalopathy.

3. Serious adverse events. We defined adverse events as any untoward medical occurrence (ICH-GCP 1997) and considered adverse events as serious if they resulted in death; were lifethreatening; required inpatient hospitalisation or prolongation of

Pharmacotherapies that specifically target ammonia for the prevention and treatment of hepatic encephalopathy in adults with cirrhosis (Review)

Copyright ( 2019 The Cochrane Collaboration. Published by John Wiley \& Sons, Ltd. 
existing hospitalisation; or resulted in persistent or significant disability or incapacity. In this review, serious adverse events included mortality and hepatic encephalopathy, and they were analysed as a composite outcome.

\section{Secondary outcomes}

1. Non-serious adverse events. We considered as non-serious all adverse events that did not fulfil the criteria for serious adverse events, as described above (ICH-GCP 1997).

2. Health-related quality of life.

3. Blood ammonia.

\section{Search methods for identification of studies}

We combined the electronic and manual searches.

\section{Electronic searches}

We searched the Cochrane Hepato-Biliary Specialised Register (March 2019: hbg.cochrane.org/specialised-register), the Cochrane Central Register of Controlled Trials (CENTRAL; 2019, Issue 3) in the Cochrane Library; MEDLINE Ovid (1946 to March 2019); Embase Ovid (1974 to March 2019); LILACs (Bireme; 1982 to March 2019); Science Citation Index Expanded (Web of Science; 1900 to March 2019); and Conference Prodeedings Citation Index - Science (Web of Science; 1990 to March 2019; Royle 2003) using the strategies outlined in Appendix 1. We did not have access to Chinese, Russian, or Japanese databases, but we plan to search these in future updates should they become available to us via the Cochrane Hepato-Biliary Group.

\section{Searching other resources}

We searched the reference lists of papers identified in the electronic searches and wrote to authors of the identified clinical trials and relevant pharmaceutical companies for additional data, if required. We searched the conference proceedings of the annual meetings of the British Society of Gastroenterology (BSG), the European Association for the Study of the Liver (EASL), the United European Gastroenterology Week (UEGW), the American Gastroenterological Association (AGA), and the American Association for the Study of Liver Diseases (AASLD) from 2000 to 2018/9. We searched online trials registries such as ClinicalTrials.gov ( clinicaltrials.gov/); European Medicines Agency (EMA; www.ema.europa.eu/ema/); the World Health Organization ( WHO) International Clinical Trials Registry Platform ( www.who.int/ictrp), and the Food and Drug Administration (FDA; www.fda.gov) in March 2019. We also searched Google Scholar using the search terms cirrhosis AND ammonia scavenging agents; and pharmaceutical company sources for ongoing or unpublished trials with no date restriction.

\section{Data collection and analysis}

We performed the review following the recommendations in the Cochrane Handbook for Systematic Reviews of Interventions (Higgins 2011), Cochrane Hepato-Biliary information for authors ( hbg.cochrane.org/), and the Methodological Expectations of Cochrane Intervention Reviews (MECIR) guidelines (MECIR 2018).

\section{Selection of studies}

Three review authors (HDZ, APZ, and MYM), working independently, read the electronic search output, performed additional manual searches, and listed potentially eligible trials. All review authors read the potentially eligible trials and participated in the final selection of trials for inclusion. If trial data were reported in more than one publication, we selected the report with the largest number of participants and the longest duration of followup as our primary reference. We listed details of all the included trials in the Characteristics of included studies table, and listed all the excluded trials with the reasons for their exclusion in the Characteristics of excluded studies table. A fourth review author (LLG) acted as ombudsman in case of disagreements on trial suitability for inclusion or exclusion. We resolved contrary opinions through discussion.

\section{Data extraction and management}

All review authors independently extracted data and evaluated bias. We requested missing data and other information from the published trial reports from the corresponding authors of the included trials. We sought information and data from identified but unpublished trials or ongoing trials from the principal investigators and sponsors. We gathered the following data from the included trials.

- Trials: design (cross-over or parallel); settings (number of clinical sites; outpatient or inpatient; inclusion period); country of origin; publication status; funding sources;

- Participants: mean age; proportion of men; aetiology and severity of the liver disease; type of hepatic encephalopathy (diagnostic criteria and definitions/terminology); previous history of hepatic encephalopathy;

- Interventions: type, dose, duration of therapy, mode of administration; co-interventions;

- Outcomes: including definitions used in the assessment and duration of follow-up; number of participants included in the assessment of outcomes (number of losses to follow-up/ withdrawals); outcomes included in the meta-analyses.

\section{Assessment of risk of bias in included studies}

We followed Cochrane Hepato-Biliary recommendations for assessing the risk of bias in the included trials, based on the definitions described below ( hbg.cochrane.org/information-authors).

Pharmacotherapies that specifically target ammonia for the prevention and treatment of hepatic encephalopathy in adults with cirrhosis 16 (Review)

Copyright ( 2019 The Cochrane Collaboration. Published by John Wiley \& Sons, Ltd. 
We assessed each domain separately as recommended in the Cochrane Handbook for Systematic Reviews of Interventions (Higgins 2017) and combined the domains to provide an overall assessment of bias control for both mortality and non-mortality outcomes. We classified trials as low risk of bias only if none of the domains was designated as being at unclear or high risk of bias.

\section{Allocation sequence generation}

- Low risk of bias: sequence generation achieved using computer random number generation or a random number table. Drawing lots, tossing a coin, shuffling cards, or throwing dice were adequate if performed by an independent person not otherwise involved in the trial.

- Unclear risk of bias: the method of sequence generation was not specified.

- High risk of bias: sequence generation method was not random.

\section{Allocation concealment}

- Low risk of bias: the participant allocations could not have been foreseen in advance of, or during, enrolment; allocation was controlled by a central and independent randomisation unit or similar adequate method (e.g. serially numbered opaque sealed envelopes) to ensure that the allocation sequence was unknown to the investigators (Savović 2012a; Savović 2012b).

- Unclear risk of bias: the method used to conceal the allocation was not described so that intervention allocations may have been foreseen in advance of, or during, enrolment.

- High risk of bias: allocation sequence was likely to be known to the investigators who assigned the participants.

\section{Blinding of participants and personnel}

- Low risk of bias: blinding of participants and personnel performed adequately using a placebo. We defined lack of blinding as not likely to affect the evaluation of mortality (Savović 2012a; Savović 2012b).

- Unclear risk of bias: insufficient information to assess blinding.

- High risk of bias: no blinding or incomplete blinding.

\section{Blinding of outcome assessors}

- Low risk of bias: blinding of outcome assessors performed adequately using a placebo. We defined lack of blinding as not likely to affect the evaluation of mortality (Savović 2012a; Savović 2012b).

- Unclear risk of bias: there was insufficient information to blinding.

- High risk of bias: no blinding or incomplete blinding.

\section{Incomplete outcome data}

- Low risk of bias: missing data were unlikely to make treatment effects depart from plausible values. The investigators used sufficient methods, such as intention-to-treat analyses with multiple imputations or carry-forward analyses to handle missing data.

- Unclear risk of bias: there was insufficient information to assess whether missing data in combination with the method used to handle missing data were likely to induce bias on the results.

- High risk of bias: the results were likely to be biased due to missing data.

\section{Selective outcome reporting}

- Low risk of bias: the trial reported clinically relevant outcomes (all-cause mortality, hepatic encephalopathy, and serious adverse events). If we had access to the original trial protocol, the outcomes selected should be those called for in the protocol. If we obtained information from a trial registry (such as www.clinicaltrials.gov), we only used that information if the investigators registered the trial before inclusion of the first participant.

- Unclear risk of bias: predefined relevant outcomes were not reported fully or the reporting was unclear.

- High risk of bias: one or more predefined outcomes were not reported.

\section{Other bias}

- Low risk of bias: the trial appeared free of other biases including: medicinal dosing, medicinal problems, or follow-up (as defined below)

- Unclear risk of bias: the trial may or may not have been free of other domains that could put it at risk of bias.

- High risk of bias: there were other factors in the trial that could put it at risk of bias such as inappropriate treatments being given to the controls (e.g. an inappropriate dose) or follow-up (e.g. the trial included different follow-up schedules for participants in the allocation groups).

\section{Overall bias assessment}

- Low risk of bias: all domains were low risk of bias using the definitions above.

- High risk of bias: one or more of the bias domains was of unclear or high risk of bias.

\section{Measures of treatment effect}

We analysed dichotomous outcomes using risk ratios (RR) and continuous outcomes using mean differences (MD), both with

Pharmacotherapies that specifically target ammonia for the prevention and treatment of hepatic encephalopathy in adults with cirrhosis 17

(Review)

Copyright @ 2019 The Cochrane Collaboration. Published by John Wiley \& Sons, Ltd. 
95\% confidence intervals (CI). For primary outcomes, we calculated the number needed to treat for an additional beneficial outcome (NNTB) as 1 / risk difference (RD) based on the highestquality evidence (randomised clinical trials with a low risk of bias where available).

\section{Unit of analysis issues}

We included randomised clinical trials using a parallel-group design. We did not identify any multi-armed trials, however, if we identify any such trials in future updates, then we will undertake separate pair-wise comparisons of the treatments of interest. We did not identify any cross-over trials, however, if we identify any such trials in future updates, we will only use data from the first treatment period (Deeks 2017).

\section{Dealing with missing data}

We collected data on all participants randomised and included all participants irrespective of compliance or follow-up. We planned to evaluate the influence of missing data (Higgins 2008), by undertaking best-case scenario, worst-case scenario, and extreme worstcase scenario analyses ( hbg.cochrane.org/information-authors). However, we did not identify any randomised clinical trials with missing outcome data.

\section{Assessment of heterogeneity}

We expressed heterogeneity as $\mathrm{I}^{2}$ statistic values using the following thresholds: $0 \%$ to $40 \%$ (unimportant), $40 \%$ to $60 \%$ (moderate), $60 \%$ to $80 \%$ (substantial), and more than $80 \%$ (considerable). We used this information when describing and interpreting our analyses and included the information in the 'Summary of findings' table.

\section{Assessment of reporting biases}

We evaluated reporting bias based on the definition and reporting of key outcomes (the most clinically relevant) and by comparing protocols, online trial registrations, and trial publications if available. We planned to use visual inspection of funnel plots and regression analyses to evaluate reporting biases if our analysis included at least 10 trials with reported events for an individual pharmacotherapy (Egger 1997; Harbord 2006), however, our review did not reach this number threshold.

\section{Data synthesis}

We performed the analysis in Review Manager 5 (Review Manager 2014) and STATA version 14 (Stata 2015).

\section{Meta-analyses}

We analysed trials for each of the drugs that specifically target ammonia separately, using fixed-effect and random-effects metaanalyses (Deeks 2017). The individual meta-analyses included a small number of trials, and we did not identify differences between the two models. We chose to report random-effects meta-analyses based on an expected clinical difference between trials.

In the case that estimates of the random-effects and fixed-effect meta-analyses are similar in future updates, then we will assume that any small-study effect had little effect on the intervention effect estimate. If the random-effects estimate is more beneficial, we will re-evaluate whether it is reasonable to conclude that the intervention was more effective in the smaller trials. If the larger trials tend to be those conducted with greater methodological rigour, or conducted in circumstances more typical of the use of the intervention in practice, then we will report the results of meta-analyses restricted to the larger, more rigorous trials. Based on the expected clinical heterogeneity, we anticipated that a number of analyses would display statistical between-trial heterogeneity $\left(\mathrm{I}^{2}>0 \%\right)$.

\section{Subgroup analysis and investigation of heterogeneity}

We planned to perform subgroup analyses to determine the influence of:

- risk of bias;

- type of encephalopathy;

- aetiology of the liver disease (alcohol or hepatitis).

We were not able to undertake subgroup analyses because the number of trials was too small.

\section{Sensitivity analysis}

We planned to undertake worst-case scenario analyses, as described in Dealing with missing data. However, outcome data sets were complete in the intervention and control groups in all of the included trials.

\section{Trial Sequential Analysis}

We planned to perform Trial Sequential Analyses of our primary outcomes to evaluate the risk of random error associated with sparse data and cumulative testing, and to evaluate futility (Higgins 2008; Wetterslev 2008). However, the number of events, participants, and trials were clearly insufficient, so we did not undertake these analyses.

In future updates of our review, if the data allow, we plan to undertake Trial Sequential Analyses with alpha 3\%, power 90\%, and the results of the random-effects meta-analyses (upper 95\% CI) in order to determine the relative risk reduction and the control group event.

Pharmacotherapies that specifically target ammonia for the prevention and treatment of hepatic encephalopathy in adults with cirrhosis 


\section{Certainty of evidence, GRADE}

We used the GRADE system to evaluate the certainty of the evidence for all outcomes reported in the review, considering the within-study risk of bias (methodological quality), directness of evidence, heterogeneity, precision of effect estimate, and risk of publication bias (Schünemann 2013).

\section{'Summary of findings' tables}

We used GradePro 2015 to generate a 'Summary of findings' table with information about outcomes, risk of bias, and the results of the meta-analyses (Summary of findings for the main comparison).

\section{RE S U L T S}

\section{Description of studies}

We included 11 randomised clinical trials (Characteristics of included studies), and excluded three observational trials, one randomised clinical trial comparing two agents that specifically target ammonia, and one randomised clinical trial in which the drug of interest was used as adjuvant therapy to another active agent (Characteristics of excluded studies). In addition, we identified two ongoing trials that may be eligible for inclusion in future updates (NCT00558038; NCT03448770). We did not have access to data from these ongoing trials. Four of the 11 trials were published in abstract form only (Bajaj 2013; Gonzalez 1994; Pockros 2009; STOP-HE 2017), while the remaining seven trials were published as full papers (Naderian 2017; Rahimi 2014; Rockey 2014; Shehata 2018; Sushma 1992; Uribe 1990; Ventura-Cots 2016).

We included 11 trials in our quantitative and qualitative analyses (Bajaj 2013; Gonzalez 1994; Naderian 2017; Pockros 2009; Rahimi 2014; Rockey 2014; Shehata 2018; STOP-HE 2017; Sushma 1992; Uribe 1990; Ventura-Cots 2016).

\section{Results of the search}

We identified 513 potentially relevant records from electronic databases, and 10 additional records through manual searches and enquires (Figure 1). After removing duplicate references and references that were irrelevant to this review, we identified 17 records reporting 11 randomised clinical trials that fulfilled our inclusion criteria (Bajaj 2013; Gonzalez 1994; Naderian 2017; Pockros 2009; Rahimi 2014; Rockey 2014; Shehata 2018; STOP-HE 2017; Sushma 1992; Uribe 1990; Ventura-Cots 2016). In five of the 11 trials the control group received a placebo preparation (Bajaj 2013; Gonzalez 1994; Rockey 2014; STOP-HE 2017; Ventura-Cots 2016); in the remaining six trials they received a nonabsorbable disaccharide (Naderian 2017; Pockros 2009; Rahimi 2014; Shehata 2018; Sushma 1992; Uribe 1990). We did not identify any trials that compared these drugs with no treatment or with interventions that might potentially benefit hepatic encephalopathy, other than the non-absorbable disaccharides. 
Figure I. Study flow diagram

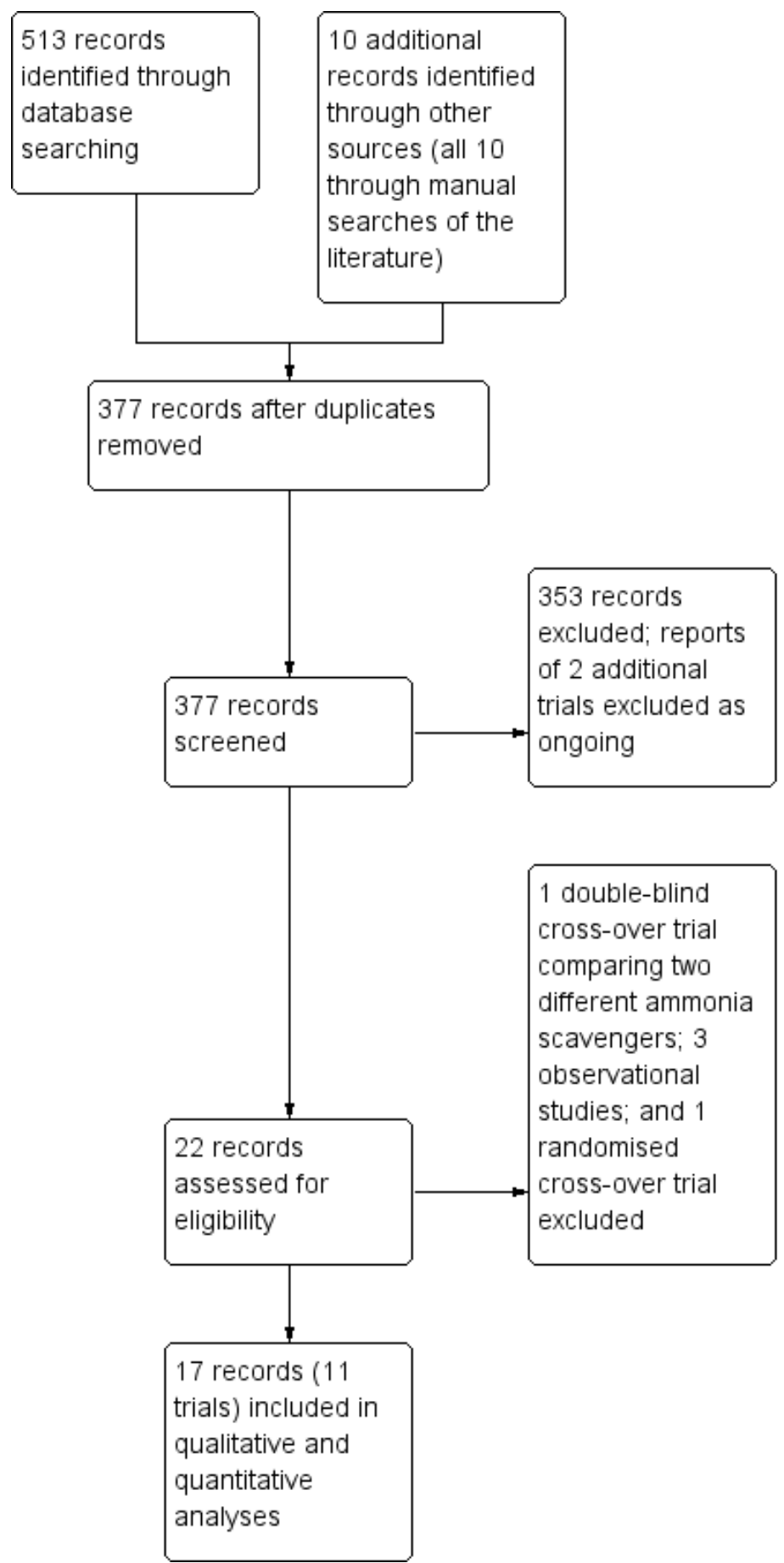

Pharmacotherapies that specifically target ammonia for the prevention and treatment of hepatic encephalopathy in adults with cirrhosis 
The countries of origin were Egypt (Shehata 2018), India (Sushma 1992), Iran (Naderian 2017), Mexico (Gonzalez 1994; Uribe 1990), Spain (Ventura-Cots 2016), and the USA (Bajaj 2013; Pockros 2009; Rahimi 2014). One study was undertaken in centres in the USA, Ukraine, and Russia (Rockey 2014); one study was undertaken in centres in Australia, Austria, Belgium, Bulgaria, Czech Republic, Denmark, Estonia, France, Germany, Hungary, Israel, Italy, Netherlands, New Zealand, Russia, Spain, and the USA (STOP-HE 2017).

\section{Included studies}

\section{Participants}

In total, 499 participants received pharmacotherapies that specifically target ammonia and 444 participants received placebo or a non-absorbable disaccharide. The mean age of participants in the included trials ranged from 35.6 to 59.6 years and the proportion of men from $41.7 \%$ to $79.0 \%$. The proportion of participants with cirrhosis secondary to hepatitis $\mathrm{B}$ or $\mathrm{C}$ infection ranged from $4 \%$ to $100 \%$; the proportion with alcohol-related cirrhosis ranged from $4.8 \%$ to $70 \%$.

One trial, involving 38 participants with cirrhosis, evaluated prevention of hepatic encephalopathy following an upper gastrointestinal bleed (Ventura-Cots 2016); six participants had overt hepatic encephalopathy at the time of inclusion while the remaining 32 participants did not. One trial evaluated the secondary prevention of hepatic encephalopathy in participants who had had at least two previous episodes of hepatic encephalopathy Grade 2 or greater in the previous six months (Rockey 2014).

The remaining nine trials included participants with current hepatic encephalopathy which was classified as covert (minimal and Grade 1) in one trial (Bajaj 2013), and as overt (Grades 1 to 4) in eight (Gonzalez 1994; Naderian 2017; Pockros 2009; Rahimi 2014; Shehata 2018; STOP-HE 2017; Sushma 1992; Uribe 1990).

\section{Interventions}

Three trials evaluated sodium benzoate in doses of 5.6 to $10 \mathrm{~g}$ a day given orally or via a nasogastric tube (Gonzalez 1994; Sushma 1992; Uribe 1990); one trial evaluated oral glycerol phenylbutyrate $12 \mathrm{~mL}$ a day (Rockey 2014); two trials evaluated intravenous ornithine phenylacetate in doses ranging from $5 \mathrm{~g}$ to $20 \mathrm{~g}$ a day (STOP-HE 2017; Ventura-Cots 2016); two trials evaluated oral AST-120 in doses ranging from $6 \mathrm{~g}$ to $12 \mathrm{~g}$ a day (Bajaj 2013; Pockros 2009); and three trials evaluated polyethylene glycol given orally or via a nasogastric tube at a dose of 280 grams in 4 litres of water daily (Naderian 2017; Rahimi 2014), or three to four sachets at 64 grams per sachet dissolved in one litre of water, given orally over three to four hours or via nasogastric tube at a rate of 20 to 30 millilitres per minute (Shehata 2018).

\section{Comparisons}

The control groups received either a placebo preparation (Bajaj 2013; Gonzalez 1994; Rockey 2014; STOP-HE 2017; VenturaCots 2016), or a non-absorbable disaccharide in a dose adjusted to produce two to three semi-soft stools per day (Naderian 2017; Pockros 2009; Rahimi 2014; Sushma 1992; Uribe 1990), or a fixed dose of 20-30 millilitres orally or via nasogastric tube, given as 3 doses over 24 hours with 200 millilitres as a retention enema every four hours (Shehata 2018).

\section{Co-interventions}

The majority of trials used co-interventions. It is unclear if one study used additional active agents, which included rifaximin, Lornithine L-aspartate and lactulose, in similar proportions of participants in the treatment and placebo groups (STOP-HE 2017). Three trials did not report the use of co-interventions (Bajaj 2013; Naderian 2017; Shehata 2018). The remaining seven trials used co-interventions in similar proportions of participants in the treatment and control groups.

\section{Outcomes}

All 11 trials reported on mortality although there were no events in one trial (Gonzalez 1994). Ten trials reported the other primary outcomes (Bajaj 2013; Naderian 2017; Pockros 2009; Rahimi 2014; Rockey 2014; Shehata 2018; STOP-HE 2017; Sushma 1992; Uribe 1990; Ventura-Cots 2016). Investigators assessed hepatic encephalopathy using several different methods. Seven of 10 trials assessed mental status using West Haven Criteria (Bajaj 2013; Gonzalez 1994; Pockros 2009; Rockey 2014; Sushma 1992; Uribe 1990; Ventura-Cots 2016). They also used several composite assessment techniques (Table 2) including the Portal-Systemic Encephalopathy Sum and Index (Gonzalez 1994; Sushma 1992; Uribe 1990); the Hepatic Encephalopathy Scoring Algorithm (HESA) (Naderian 2017; Pockros 2009; Rahimi 2014; Shehata 2018; STOP-HE 2017); the Clinical Hepatic Encephalopathy Staging Scale (CHESS) (Ventura-Cots 2016); and the Repeatable Battery for the Assessment of Neuropsychological Status (RBANS) (Bajaj 2013). One trial used visual, auditory, and somatosensoryevoked potentials as an additional test moiety (Sushma 1992), while the only trial that included participants with minimal hepatic encephalopathy used the Psychometric Hepatic Encephalopathy Score (PHES) test battery (Bajaj 2013).

Ten trials measured blood ammonia concentrations (Bajaj 2013; Gonzalez 1994; Naderian 2017; Pockros 2009; Rahimi 2014;

Pharmacotherapies that specifically target ammonia for the prevention and treatment of hepatic encephalopathy in adults with cirrhosis 2 
Rockey 2014; STOP-HE 2017; Sushma 1992; Uribe 1990; Ventura-Cots 2016). However, we could not extract the data from one trial as they were displayed in graph form in the published paper and the corresponding data were not included separately in the text (Ventura-Cots 2016). Blood ammonia concentrations were measured variously in venous and arterial blood; the timing of the blood sampling varied between trials as did the laboratory measurement techniques and the expression of the results (Table 3)

\section{Excluded studies}

We excluded five trials (Campollo 1992; Ghabril 2013; Mendenhall 1986; Panella 1993; Weiss 2018). See Characteristics of excluded studies.

We excluded one trial because it did not meet our inclusion criteria in that it compared two oral interventions that specifically target ammonia: sodium benzoate or sodium phenylacetate (Mendenhall 1986); both agents were effective at improving or maintaining participants' mental status. We excluded one further trial because it did not meet our inclusion criteria in that it assessed sodium benzoate as an adjuvant to branched chain amino acids for the treatment of chronic stable hepatic encephalopathy versus placebo (Panella 1993); participants receiving adjuvant sodium benzoate showed a significantly greater reduction in blood ammonia concentrations compared to the group receiving placebo and a trend to a greater reduction in Number Connection Test times and the Portal-Systemic Encephalopathy Index.

We excluded three trials because they were observational. The first included 18 participants with cirrhosis and chronic persistent hepatic encephalopathy, given sodium benzoate in a mean dose of 6.4 grams daily for six months (Campollo 1992). Three participants were withdrawn within the first month of treatment with nausea and abdominal pain. The remaining 15 participants showed improvement in their Portal-Systemic Encephalopathy Sum and Index (Table 2). The second included 18 participants with overt hepatic encephalopathy and hyperammonaemia admitted to an intensive care unit, given sodium phenylbutyrate $200 \mathrm{mg} / \mathrm{kg}$ per day orally or via a nasogastric tube (Weiss 2018). They compared outcomes with those in an historical control group (matched for age, sex, MELD (Model for End-stage Liver Disease) score, and severity of hepatic encephalopathy using West Haven Criteria), managed in the same unit, using the same guidelines. Blood ammonia concentrations were lower at 12 and 48 hours in those receiving sodium phenylbutyrate, while survival on discharge from the intensive care unit was significantly higher. Several side effects were recorded in the participants who received sodium phenylbutyrate including ascites (two), leucopenia (one), pancreatitis (one), herpes simplex infection (one), and renal tubulopathy (one). In the control group, one participant developed ascites and one developed a maculopapular eruption. The third observational study included 15 participants with cirrhosis and a history of at least two previous episodes of overt hepatic encephalopathy within the previous six months, given $6 \mathrm{~mL}$ of glycerol phenylbutyrate twice daily for one week followed by $9 \mathrm{~mL}$ twice daily for three weeks to assess tolerability and the effect on blood ammonia concentrations (Ghabril 2013). The lower of the two doses effectively reduced blood ammonia concentrations compared with baseline and was better tolerated.

\section{Risk of bias in included studies}

We based our 'Risk of bias' assessment on the published descriptions combined with additional information from the investigators and from ClinicalTrials.gov (Figure 2; Figure 3). 
Figure 2. 'Risk of bias' graph: review authors' judgements about each 'Risk of bias' item presented as percentages across all included studies

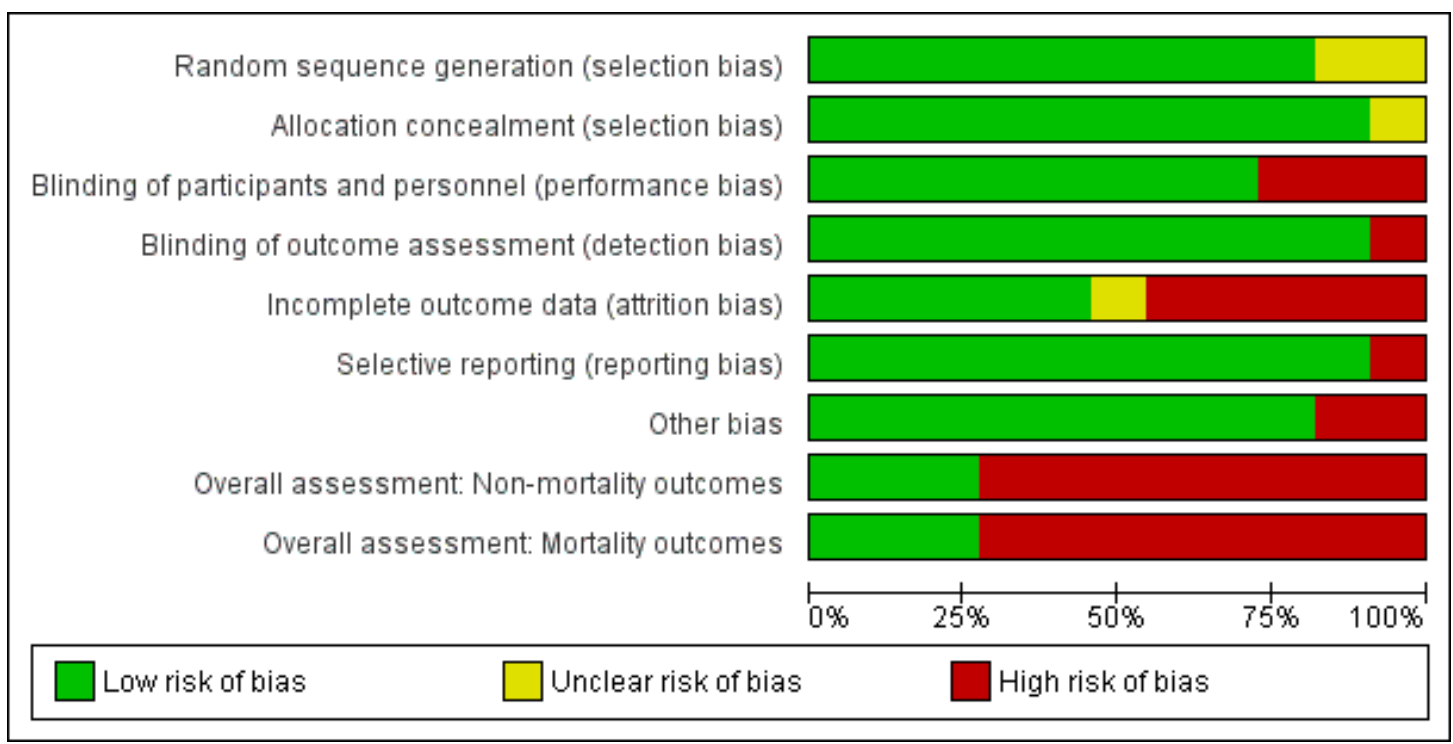

Pharmacotherapies that specifically target ammonia for the prevention and treatment of hepatic encephalopathy in adults with cirrhosis 
Figure 3. 'Risk of bias' summary: review authors' judgements about each 'Risk of bias' item for each included study

\begin{tabular}{|c|c|c|c|c|c|c|c|c|c|}
\hline & 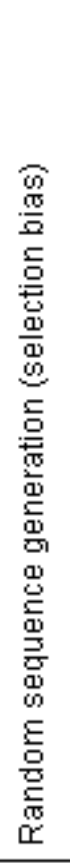 & 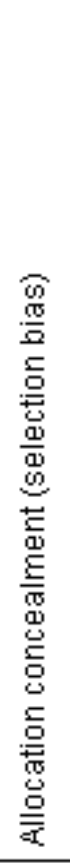 & 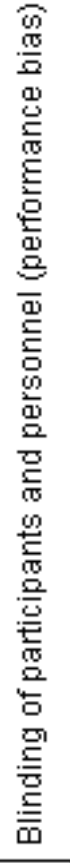 & 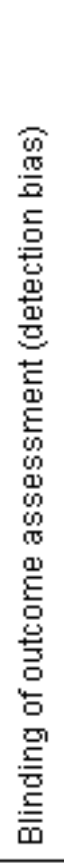 & 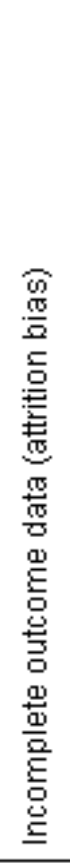 & 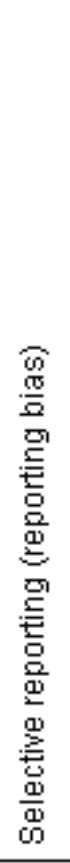 & 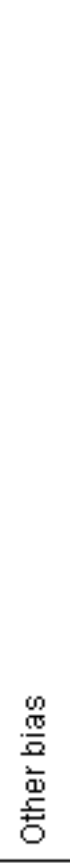 & 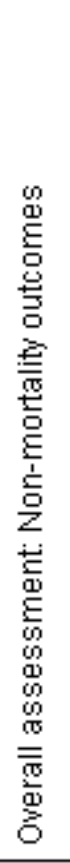 & 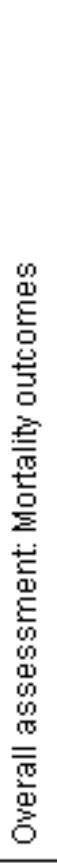 \\
\hline \multicolumn{10}{|l|}{ Bajaj 2013} \\
\hline Gonzalez 1994 & $?$ & $?$ & + & + & - & + & + & & \\
\hline Naderian 2017 & + & + & + & $\oplus$ & 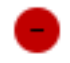 & + & + & & \\
\hline Pockros 2009 & + & + & - & - & 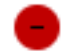 & + & + & & \\
\hline Rahimi 2014 & + & + & - & $\oplus$ & 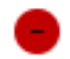 & + & & & \\
\hline Rockey 2014 & + & + & + & + & $?$ & + & + & & \\
\hline Shehata 2018 & + & + & - & + & + & + & + & & \\
\hline STOP-HE 2017 & + & + & + & + & + & & & & \\
\hline Sushma 1992 & $?$ & + & + & $\oplus$ & & + & + & & \\
\hline Uribe 1990 & + & + & + & $\odot$ & + & + & + & + & + \\
\hline Ventura-Cots 2016 & + & + & + & $\oplus$ & + & + & + & + & + \\
\hline
\end{tabular}

Pharmacotherapies that specifically target ammonia for the prevention and treatment of hepatic encephalopathy in adults with cirrhosis 24 (Review)

Copyright $\odot 2019$ The Cochrane Collaboration. Published by John Wiley \& Sons, Ltd. 


\section{Allocation}

In nine of the 11 trials investigators generated the allocation sequence based on computer-generated random numbers (Bajaj 2013; Naderian 2017; Pockros 2009; Rahimi 2014; Rockey 2014; Shehata 2018; STOP-HE 2017; Uribe 1990; Ventura-Cots 2016). Two trials did not specify the method of sequence generation (Gonzalez 1994; Sushma 1992).

Four trials concealed the allocation of participants using sealed envelopes (Rahimi 2014; Shehata 2018; Sushma 1992; Ventura-Cots 2016). Four trials used central allocation (Bajaj 2013; Pockros 2009; Rockey 2014; Uribe 1990). One trial confirmed concealment of allocation, but not the specific method used (STOP-HE 2017). One trial utilized different personnel to ensure allocation was concealed (Naderian 2017). One study lacked information regarding the blinding of allocation (Gonzalez 1994).

We graded nine trials as having a low risk of selection bias (Bajaj 2013; Naderian 2017; Pockros 2009; Rahimi 2014; Rockey 2014; Shehata 2018; STOP-HE 2017; Uribe 1990; Ventura-Cots 2016) and two as having an unclear risk of selection bias (Gonzalez 1994; Sushma 1992).

\section{Blinding}

We graded eight trials as having a low risk of performance and detection bias (Bajaj 2013; Gonzalez 1994; Naderian 2017; Rockey 2014; STOP-HE 2017; Sushma 1992; Uribe 1990; Ventura-Cots 2016). We graded three trials as having a high risk of bias, as they were open-label trials without blinding (Pockros 2009; Rahimi 2014; Shehata 2018).

\section{Incomplete outcome data}

We graded five trials as having a low risk of attrition bias, as they used an intention-to-treat analysis, or included all participants in the analyses (Bajaj 2013; Shehata 2018; STOP-HE 2017; Uribe 1990; Ventura-Cots 2016). Five trials did not evaluate all randomised participants, and so we graded these as at high risk of attrition bias (Gonzalez 1994; Naderian 2017; Pockros 2009; Rahimi 2014; Sushma 1992). In one study the risk of attrition bias was unclear (Rockey 2014).

\section{Selective reporting}

Ten trials reported predefined, clinically relevant outcome measures, suggesting a low risk of selective reporting (Bajaj 2013; Gonzalez 1994; Naderian 2017; Pockros 2009; Rahimi 2014; Rockey 2014; Shehata 2018; Sushma 1992; Uribe 1990; VenturaCots 2016). We classified the remaining trial as having a high risk of reporting bias as it did not report the primary outcome of a change from baseline in hepatic encephalopathy stage (STOP-HE 2017).

\section{Other potential sources of bias}

We found no other potential sources of bias in nine trials (Bajaj 2013; Gonzalez 1994; Naderian 2017; Pockros 2009; Rockey 2014; Shehata 2018; Sushma 1992; Uribe 1990; Ventura-Cots 2016). We classified two trials as at high risk in respect of other potential bias: in one study, baseline blood urea nitrogen concentration was significantly higher in participants in the treatment group compared to the control group (Rahimi 2014), while in another trial we observed differences, some of them significant, in baseline characteristics, the severity of the underlying liver disease, the precipitant factors, and use of additional anti-encephalopathy treatments between participants recruited in the USA and elsewhere in the world (STOP-HE 2017).

\section{Overall risk of bias}

We classified eight trials at high risk of bias for all outcomes ( Gonzalez 1994; Naderian 2017; Pockros 2009; Rahimi 2014; Rockey 2014; Shehata 2018; STOP-HE 2017; Sushma 1992), and three trials as at low risk of bias for all outcomes (Bajaj 2013; Uribe 1990; Ventura-Cots 2016).

\section{Effects of interventions}

See: Summary of findings for the main comparison Phamacotherapies that specifically target ammonia versus placebo or non-absorbable disaccharides for the prevention and treatment of hepatic encephalopathy in adults with cirrhosis

\section{Primary outcomes}

\section{All-cause mortality}

We were able to gather mortality data from 11 trials involving 943 participants (Analysis 1.1). Our analyses found no beneficial or harmful effects of sodium benzoate versus non-absorbable disaccharides (RR 1.26, 95\% CI 0.49 to 3.28; 101 participants; 2 trials; $\mathrm{I}^{2}=0 \%$ ), glycerol phenylbutyrate versus placebo (RR $0.65,95 \%$ CI 0.11 to $3.81 ; 178$ participants; 1 trial), ornithine phenylacetate versus placebo (RR $0.73,95 \%$ CI 0.35 to $1.51 ; 269$ participants; 2 trials; $\mathrm{I}^{2}=0 \%$ ), AST-120 versus lactulose (RR 1.05, 95\% CI 0.59 to 1.85 ; 41 participants; 1 trial), or polyethylene glycol versus lactulose (RR 0.50, 95\% CI 0.09 to 2.64; 190 participants; 3 trials; $\left.\mathrm{I}^{2}=0 \%\right)$. There were no events in the trial of sodium benzoate versus placebo.

Pharmacotherapies that specifically target ammonia for the prevention and treatment of hepatic encephalopathy in adults with cirrhosis 


\section{Hepatic encephalopathy}

Seven trials involving 521 participants reported data on hepatic encephalopathy (Analysis 1.2). Our analyses showed a beneficial effect of glycerol phenylbutyrate versus placebo (RR 0.57, 95\% CI 0.36 to $0.90 ; 178$ participants; 1 trial; NNTB 6), and of polyethylene glycol versus lactulose (RR $0.19,95 \%$ CI 0.08 to $0.44 ; 190$ participants; 3 trials; $\mathrm{I}^{2}=0 \%$; NNTB 4). We did not observe beneficial effects in the remaining three trials with extractable data viz. sodium benzoate versus non-absorbable disaccharides (RR 1.22, 95\% CI 0.51 to 2.93 ; 74 participants; 1 trial); ornithine phenylacetate versus placebo (RR 2.71, 95\% CI 0.12 to 62.70 ; 38 participants; 1 trial); or AST-120 versus lactulose (RR 1.05, 95\% CI 0.59 to 1.85 ; 41 participants; 1 trial).

\section{Serious adverse events}

Ten trials, involving 790 participants, reported a total of 130 serious adverse events (Analysis 1.3). Our analyses found no beneficial or harmful effects of sodium benzoate versus non-absorbable disaccharides (RR 1.08, 95\% CI 0.44 to 2.68 ; 101 participants; 2 trials), glycerol phenylbutyrate versus placebo (RR 1.63, 95\% CI 0.85 to 3.13 ; 178 participants; 1 trial), ornithine phenylacetate versus placebo (RR $0.92,95 \%$ CI 0.62 to 1.36 ; 264 participants; 2 trials; $\mathrm{I}^{2}=0 \%$ ), or polyethylene glycol versus lactulose (RR $0.57,95 \%$ CI 0.18 to $1.82 ; 190$ participants; 3 trials; $\mathrm{I}^{2}=$ $0 \%)$. There were no events in the trial evaluating sodium benzoate versus placebo or in the trial evaluating AST-120 versus lactulose.

\section{Secondary outcomes}

\section{Non-serious adverse events}

Eight trials, involving 782 participants, reported a total of 374 non-serious adverse events (Analysis 1.4). Our analyses found no beneficial or harmful effects of sodium benzoate versus non-absorbable disaccharides (RR 1.13, 95\% CI 0.96 to 1.32 ; 182 participants; 2 trials; $\mathrm{I}^{2}=0 \%$ ), glycerol phenylbutyrate versus placebo (RR $1.04,95 \%$ CI 0.88 to 1.21 ; 178 participants; 1 trial), ornithine phenylacetate versus placebo (RR $1.08,95 \%$ CI 0.78 to 1.51; 269 participants; 2 trials; $\mathrm{I}^{2}=11 \%$ ), or polyethylene glycol versus non-absorbable disaccharides (RR $0.71,95 \%$ CI 0.43 to 1.18; 137 participants; 2 trials). There were no events in the trial evaluating sodium benzoate versus placebo.

\section{Health-related quality of life}

One included trial with 48 participants (Pockros 2009), reported data on quality of life extracted from the sub-scores of the Hepatic Encephalopathy Scoring Algorithm (HESA: Table 2). Use of both AST-120 and lactulose resulted in improvement in anxiety and in memory for recent events; use of AST-120 was associated, in addition, with improvements in complex computations.
No other trials reported quality-of-life outcomes.

\section{Blood ammonia}

Nine trials, involving 733 participants, reported data on blood ammonia concentrations measured variously in venous and arterial blood (Table 3), and at various time points in the trial (Analysis 1.5). Our analyses showed a beneficial effect on blood ammonia concentration in trials of sodium benzoate versus placebo (MD $-32.00 \mu \mathrm{g} / \mathrm{dL}, 95 \% \mathrm{CI}-46.85$ to $-17.15 ; 16$ participants; 1 trial), glycerol phenylbutyrate versus placebo (MD $-12.00 \mu \mathrm{mol} /$ L*week, 95\% CI -23.37 to -0.63 ; 178 participants; 1 trial), ornithine phenylacetate versus placebo (MD $-27.10 \mu \mathrm{mol} / \mathrm{L}, 95 \%$ CI -48.55 to $-5.65 ; 231$ participants; 1 trial), and AST-120 versus placebo $(\mathrm{MD}-22.00 \mu \mathrm{g} / \mathrm{dL}, 95 \% \mathrm{CI}-26.75$ to -17.25 ; 98 participants; 1 trial). However, there were no beneficial effects on blood ammonia concentration in the trials of sodium benzoate versus non-absorbable disaccharides (MD $9.80 \mu \mathrm{g} / \mathrm{dL}, 95 \% \mathrm{CI}$ -0.48 to 20.08 ; 58 participants; 1 trial; and MD $-14.94 \mu \mathrm{g} / \mathrm{dL}$, 95\% CI -71.32 to $41.44 ; 27$ participants; 1 trial), AST-120 versus lactulose (MD 5.20 units not specified, $95 \%$ CI -2.75 to 13.15 ; 35 participants; 1 trial), or polyethylene glycol versus lactulose (MD $-29.28 \mu \mathrm{mol} / \mathrm{L}, 95 \% \mathrm{CI}-95.96$ to 37.39 ; 90 participants; 2 trials).

\section{'Summary of findings' tables}

For all outcomes, we downgraded the certainty of the evidence by three levels to 'very low' as eight trials were at high risk of bias (one level) and the number of trials, participants, and events in each meta-analysis was small (two levels). See Summary of findings for the main comparison.

\section{ISCUSSION}

\section{Summary of main results}

This systematic review included qualitative and quantitative data from 11 randomised clinical trials, involving 943 participants, treated with one of five drugs of interest. Although all five drugs specifically target ammonia, the ways in which they do so differ considerably. In consequence, we evaluated each separately and did not undertake any overall group analyses. In the primary analyses, we found evidence that glycerol phenylbutyrate had a beneficial effect on hepatic encephalopathy when compared to placebo (one trial) as did polyethylene glycol when compared to lactulose (three trials). We found no beneficial or harmful effects on hepatic encephalopathy in the other seven trials. None of these pharmacotherapies had a beneficial or harmful effect on the risk of mortality or the development of adverse events. The majority of

Pharmacotherapies that specifically target ammonia for the prevention and treatment of hepatic encephalopathy in adults with cirrhosis 26 
these agents effectively lowered circulating ammonia concentrations when compared to placebo but not when compared to the non-absorbable disaccharides.

The certainty of the evidence was very low. This was because there were only three trials at low risk of bias and the number of trials, participants, and events in each analysis was small. Hence, no conclusions can be made with certainty regarding the clinical benefits and harms of these five pharmacotherapies.

\section{Overall completeness and applicability of evidence}

We included 11 randomised clinical trials with 943 participants with cirrhosis and a history or current evidence of hepatic encephalopathy. The trials were generally small, involving an average of 86 (range 18 to 231) people. Only five of the 11 trials conducted a sample size calculation for assessment of statistical power (Naderian 2017; Rahimi 2014; Rockey 2014; Shehata 2018; Ventura-Cots 2016). Of these, only two trials met the required sample size after withdrawal or loss of participants (Rahimi 2014; Shehata 2018). Thus, several of the trials are likely to be underpowered to detect a difference in the effectiveness and safety of the interventions. In addition, we classified eight of the 11 included trials at high risk of bias for all outcomes.

We evaluated five pharmacotherapies in this review. In most instances there was only one trial per comparison. Thus, three trials assessed sodium benzoate; one in a comparison with placebo (Gonzalez 1994), and two in comparison with non-absorbable disaccharides but with different agents (Sushma 1992; Uribe 1990). One trial assessed glycerol phenylbutyrate versus placebo (Rockey 2014). Two trials assessed ornithine phenylacetate against placebo (STOP-HE 2017; Ventura-Cots 2016). Two trials assessed AST120 , one in comparison with placebo (Bajaj 2013), and one in comparison with lactulose (Pockros 2009). Finally, three trials compared polyethylene glycol with lactulose (Naderian 2017; Rahimi 2014; Shehata 2018).

Overall, the included trials compared four of the five pharmacotherapies to placebo (Bajaj 2013; Gonzalez 1994; Rockey 2014; STOP-HE 2017; Ventura-Cots 2016); none of the trials undertook placebo-controlled trials of polyethylene glycol; this would be extremely difficult to do except in an open, likely unblinded, fashion. The trials compared three of the five pharmacotherapies to non-absorbable disaccharides (Naderian 2017; Pockros 2009; Rahimi 2014; Shehata 2018; Sushma 1992; Uribe 1990), the exceptions being glycerol phenylbutyrate and ornithine phenylacetate. None of the trials compared any of the five pharmacotherapies to other active agents, such as rifaximin or branched chain amino acids.

Four of the 11 trials were only published in abstract form and hence did not report all outcomes (Bajaj 2013; Gonzalez 1994; Pockros 2009; STOP-HE 2017). Although further information was obtainable from some trials, many authors did not, or could not, provide us with the additional information we needed for our analyses. Data were also missing from some of the trials published as full papers; again some of these were retrievable from the trial authors but some were not. Thus, we could extract mortality data from all 11 trials but six of them reported no events. This limits the usefulness of these analyses, although we included three of the latter six trials in meta-analyses (Naderian 2017; Uribe 1990; Ventura-Cots 2016). We were able to retrieve data on hepatic encephalopathy from seven trials only, while data on serious adverse events were available from 10 trials, but with the same issue that we could not estimate the data in the four trials reporting no events. Differences in the way in which the trials utilized the drugs could confound the results. For example, in two of the three trials comparing polyethylene glycol to lactulose, participants were allowed to receive a single dose of lactulose prior to randomisation and after 24 hours of treatment regardless of their group allocation (Rahimi 2014), or were not given lactulose at all (Shehata 2018). However, the third trial gave lactulose to the participants allocated to polyethylene glycol in the same amount enterally or rectally as in the control group (Naderian 2017). Thus, two trials assessed polyethylene glycol as an alternative to lactulose (Rahimi 2014; Shehata 2018), whereas the other assessed it as an adjuvant (Naderian 2017).

The majority of trials used co-interventions alongside the study drug and, in the main, participants randomised to experimental or control groups had equal access to them. However, in the large, placebo-controlled trial of ornithine phenylacetate (STOP-HE 2017), 58\% of participants were taking rifaximin, 5.2\% were taking L-ornithine L-aspartate, and an unspecified proportion were taking lactulose, but no information was provided on the numbers of participants in the experimental and control groups involved. In addition, there were differences in the route of drug administration both between and within trials; for example, some trials administered study or control drugs or both by either enema or orally. Between trials, doses of the study or control substance or both also varied, which might have altered the effect size, particularly if the therapeutic effect is dose-dependent.

All participants included in our review had cirrhosis and a history of or current clinical evidence of hepatic encephalopathy. The majority of the included trials involved participants with an acute episode of hepatic encephalopathy (Gonzalez 1994; Naderian 2017; Rahimi 2014; Shehata 2018; STOP-HE 2017; Sushma 1992). Two trials involved participants with stable chronic hepatic encephalopathy (Pockros 2009; Uribe 1990), while one study involved participants with minimal and Grade 1 hepatic encephalopathy (Bajaj 2013). One study evaluated the primary prevention of hepatic encephalopathy following an upper gastrointestinal bleed (Ventura-Cots 2016), while one further trial evaluated the secondary prevention of hepatic encephalopathy in participants who had had at least two previous episodes of hepatic encephalopathy Grade 2 or greater in the previous six months (Rockey 2014). Thus, the included trials evaluated both the pre-

Pharmacotherapies that specifically target ammonia for the prevention and treatment of hepatic encephalopathy in adults with cirrhosis 27 
vention of hepatic encephalopathy and treatment of the various manifestations of the syndrome. However, no systematic evaluation of the use of the five pharmacotherapies across the spectrum of hepatic encephalopathy is possible based on the trials available to date. It would, therefore, be difficult to predict where these drugs might best fit into clinical practice.

Hepatic encephalopathy may also develop in people with noncirrhotic portal hypertension and in people with acute liver failure but these people are encountered much less frequently than people with cirrhosis in clinical practice; these populations were not represented in the included trials. However, there is no reason why our results could not be extrapolated to people with hepatic encephalopathy associated with non-cirrhotic portal hypertension (e.g. portal vein block). The results may, on the other hand, not be directly applicable to people with fulminant hepatic failure.

Hepatic encephalopathy can often be precipitated by stressors such as infection, gastrointestinal bleeding, alcohol misuse or electrolyte disturbances. Therefore, it is important to be able to identify and treat these precipitating factors (AASLD/EASL 2014; Vilstrup 2014). The trials assessed in this review did not provide detailed information on possible precipitating events and the effects of the interventions designed to ameliorate them, nor did they evaluate the effects, if any, of the addition of pharmacotherapies that specifically target ammonia. It is, therefore, unclear whether these pharmacotherapies provide additional benefit in situations where hepatic encephalopathy is precipitated by a treatable event.

Hepatic encephalopathy imposes a significant burden on healthcare systems, and resource utilization associated with its management is increasing (Stepanova 2012). None of the randomised clinical trials included in this review conducted a detailed assessment of the costs associated with hospitalisation and treatment with pharmacotherapies that target ammonia. One study found that the cost of lactulose was 30 times the cost of sodium benzoate, although there is a possibility that this has changed, as the study was conducted over 15 years ago (Sushma 1992). Another study found that polyethylene glycol significantly reduced the length of hospital admission versus lactulose (Shehata 2018).

Whilst ammonia levels significantly decreased during use of most of the study drugs, the degree of hepatic encephalopathy, on the whole, did not significantly improve. This may reflect the fact that, while ammonia is known to play an important role in the pathogenesis of the syndrome, simply reducing circulating ammonia level may not be sufficient to reverse the complex cascade of events that contribute to the pathophysiology of this condition.

\section{Quality of the evidence}

The main reason for downgrading the certainty of the evidence in this review were incomplete outcome data (attrition bias), and the small number of trials giving rise to uncertainty.

We included randomised clinical trials published as full papers or abstracts and attempted to obtain additional information on essential aspects of bias control from the authors of these works. We combined the individual bias domains into an overall assessment ( hbg.cochrane.org/information-authors). We identified potential biases in all but three of the included trials (Bajaj 2013; Uribe 1990; Ventura-Cots 2016). We defined mortality, but not serious adverse events, as an outcome that is robust to performance and detection biases (Savović 2012a). This decision can be questioned, as lack of blinding is not likely to influence the assessment of serious adverse events such as variceal bleeding, hepatorenal syndrome, and liver failure. We classified all of the included trials but three (Bajaj 2013; Uribe 1990; Ventura-Cots 2016), as being at high risk in the overall assessments of mortality and non-mortality outcomes. Based on the assessment of incomplete outcome data (attrition bias), and due to the small number of trials giving rise to uncertainty, we classified the certainty of the evidence as very low for the assessment of all our outcomes.

\section{Potential biases in the review process}

We undertook the review based on current recommendations for bias control ( hbg.cochrane.org/information-authors; Higgins 2017). We attempted to minimize possible selection bias (Page 2014), by using a comprehensive search strategy. We combined searches in electronic databases with hand searches of the biographies of identified trials, and the conference proceedings and abstract books from relevant national and international society meetings. We consider it unlikely that we failed to identify any published trials.

Two of the included trials, involving 216 participants, evaluated the prevention of hepatic encephalopathy while nine trials, involving 727 participants evaluated its treatment. We combined these trials in the analyses of the primary outcomes because they involved different agents and this may have introduced an element of bias.

\section{Agreements and disagreements with other studies or reviews}

This review is the first and largest identified systematic review of pharmacotherapies that specifically target ammonia for the prevention and treatment of hepatic encephalopathy in people with cirrhosis. It includes 11 randomised clinical trials involving five different specific pharmacotherapies and 943 participants. There are no other systematic reviews and meta-analyses evaluating these drugs with which to compare the findings of the present review. A number of general reviews of the management of hepatic encephalopathy have been published (Ahuja 2014; Bass 2007; Butterworth 2000; Jawaro 2016; Toris 2011), some of which look specifically at the drugs included in this review (Acharya 2018; De Las Heras 2017; Hadjihambi 2018; Jover-Cobos 2013; Kornerup 2018; Matoori 2015; Misel 2013; Rahimi 2016; Sturgeon 2014).

Pharmacotherapies that specifically target ammonia for the prevention and treatment of hepatic encephalopathy in adults with cirrhosis 28 
The EASL/AASLD Practice Guidelines state that further clinical reports are awaited on ornithine phenylacetate and that more trials are needed on glyceryl phenylbutyrate which, if they confirmed the original results, 'might lead to clinical recommendations' (AASLD/EASL 2014; Vilstrup 2014).

\section{A U THORS' CONCLUSIONS}

\section{Implications for practice}

This review includes 11 randomised clinical trials evaluating the use of five pharmacotherapies that specifically target ammonia for the prevention and treatment of hepatic encephalopathy in adults with cirrhosis. The analyses found that these drugs have the potential to reduce blood ammonia concentrations, when compared to placebo, but the evidence was of low certainty. However, there is insufficient evidence to determine the effects of these pharmacotherapies on clinical outcomes and serious adverse events. Thus, further research is needed before these drugs can be fully evaluated and their place in clinical practice defined.

\section{Implications for research}

We used the EPICOT format (Brown 2006a), to define the implications for research.

Evidence (what is the current state of the evidence?). We included 11 trials involving 943 participants. We found evidence that sodium benzoate, glycerol phenylbutyrate, ornithine phenylacetate, and AST-120 effectively lower blood ammonia concentrations when compared to placebo and that polyethylene glycol lowered blood ammonia concentrations when compared to lactulose. However, there was little evidence that this ammonialowering effect translated into clinical benefit except that glycerol phenylbutyrate had a beneficial effect on hepatic encephalopathy when compared to placebo, and polyethylene glycol had a beneficial effect on hepatic encephalopathy when compared to lactulose. However, the certainty of the evidence was very low, and hence, we are very uncertain about these findings. Further high-quality randomised clinical trials are needed.

Participants (what is the population of interest?). We focused on people with cirrhosis and hepatic encephalopathy or people with cirrhosis who were at risk of developing hepatic encephalopathy. Because of the small number of randomised clinical trials available, we were not able to undertake subgroup analyses to determine differences in outcomes between trials looking at the prevention or treatment of hepatic encephalopathy, or determine if there were differences in outcomes by the degree of hepatic encephalopathy. Future trials should be designed to look for these potential differences. The effects of these drugs should also be assessed in people with hepatic encephalopathy associated with acute liver failure or with non-cirrhotic portal hypertension.
Interventions (what are the interventions of interest?): the interventions assessed are sodium benzoate, glycerol phenylbutyrate, ornithine phenylacetate, AST-120 (spherical carbon adsorbent), and polyethylene glycol. Although they all specifically target ammonia, they differ by mode of action, formulation, and route of administration. In some cases, the evidence for beneficial and harmful effects was based on only one trial and at most three. All the interventions considered in this review should be evaluated in further high-quality, randomised clinical trials.

Comparisons (what are the comparisons of interest?). The comparisons assessed in the trials in this review were a variety of placebo preparations and the non-absorbable disaccharides lactulose and lactitol. Future trials should include comparisons against placebo and no intervention, where considered feasible, and also against other agents thought to benefit people with hepatic encephalopathy, including non-absorbable disaccharides and non-absorbable antibiotics. Future trials should also evaluate the effect of co-interventions.

Outcomes (what are the outcomes of interest?). The primary outcomes included in this review - mortality, hepatic encephalopathy, and serious adverse events - should be included in any future trials. Health-related quality of life is also an important outcome, particularly in any future trials involving participants with minimal or chronic persistent hepatic encephalopathy. As these agents specifically target ammonia, blood ammonia concentrations will need to be monitored; the best outcome measure in relation to blood ammonia is the percentage change in concentration over trial baseline.

Time stamp (date of literature search): 5 March 2019

\section{ACKNOWLEDGEMENTS}

We thank Sarah Louise Klingenberg, Cochrane Hepato-Biliary's Information Specialist, for her help with the strategies for the electronic searches.

This review did not receive funding support.

Cochrane Review Group funding acknowledgement: the Danish State is the largest single funder of Cochrane Hepato-Biliary through its investment in the Copenhagen Trial Unit, Centre for Clinical Intervention Research, Rigshospitalet, Copenhagen University Hospital, Denmark.

Disclaimer: the views and opinions expressed in this review are those of the authors and do not necessarily reflect those of the Danish State or the Copenhagen Trial Unit.

Peer reviewers of the protocol: Bruce F Scharschmidt, USA; Fernando Gomes Romeiro, Brazil; Baresh S Sharma, India; Peter Yepsen, Denmark 
Contact editor: Goran Bjelacovic, Serbia

Sign-off editor: Christian Gluud, Denmark

Peer reviewers of the review: Piero Amodio, Italy

Contact editor: Goran Poropat, Croatia

Sign-off editor: Agostino Colli, Italy

\section{R E F E R E N C E S}

\section{References to studies included in this review}

Bajaj 2013 \{published data only (unpublished sought but not used)\} Bajaj JS, Sheikh MY, Chojkier M, Balart L, Sherker AH, Vemuru R, et al. AST-120 (spherical carbon adsorbent) in covert hepatic encephalopathy: results of the Astute trial. Journal of Hepatology 2013;58(Suppl 1):S84. DOI: 10.1016/S0168-8278(13)60192-0

* Bajaj JS, Sheikh MY, Chojkier M, Balart LA, Sherker AH, Vemuru RP, et al. Su1685 AST-120 (spherical carbon adsorbent) in covert hepatic encephalopathy: results of the Astute trial. Gastroenterology 2013;144(5 (Suppl 1)):S997.

Gonzalez 1994 \{published data only (unpublished sought but not used)\}

Gonzalez A, Neri M, Campollo O, Amacio O. Treatment of acute portal systemic encephalopathy (PSE) grades III and IV with sodium benzoate and lactose. Hepatology (Baltimore, Md.) 1994;19(4 Suppl):67I

Naderian 2017 \{published and unpublished data\} Naderian M, Heshmatollah A, Saeedi M, Sohrabpour A. Polyethylene glycol and lactulose alone in the treatment of hepatic encephalopathy in patients with cirrhosis: a noninferiority randomised control trial. Middle East Journal of DIgestive Diseases 2017;9(1):12-9. PUBMED: 28316761]

Pockros 2009 \{published data only (unpublished sought but not used)\} Pockros P, Hassanein T, Vierling J, Heuman D, Hillebrand D, Chojkier M. Phase 2, multicenter, randomised study of AST-120 (spherical carbon adsorbent) vs. lactulose in the treatment of low-grade hepatic encephalopathy (HE). Journal of Hepatology 2009; Vol. 50, issue Suppl 1:S43. $\mathrm{CN}-00715816$

Rahimi 2014 \{published data only\}

* Rahimi R, Singal A, Cuthbert J, Rockey D. Lactulose vs polyethylene glycol 3350-electrolyte solution for treatment of overt hepatic encephalopathy: the HELP randomised clinical trial. Journal of the American Medical Association Internal Medicine 2014;174(11):1727-33. PUBMED: 25243839]

Rahimi RS, Singal AG, Cuthbert JA, Rockey DC. A randomised trial of polyethylene glycol 3350-electrolyte solution (PEG) and lactulose for patients hospitalized with acute hepatic encephalopathy. Hepatology (Baltimore, Md.) 2012;56(Suppl):915A-6A.
Rockey 2014 \{published data only (unpublished sought but not used)\} Jurek M, Mokhtarani M, Vierling J, Coakley D, Ganju J, Rowell R, et al. Variation in liver biochemistries in patients with decompensated cirrhosis: implications for assessing drug-induced liver injury in clinical trials. Pharmaceutical Medicine 2016;30(2):95-101.

* Rockey DC, Vierling JM, Mantry P, Ghabril M, Brown RS Jr, Alexeeva O, et al. Randomized, double-blind, controlled study of glycerol phenylbutyrate in hepatic encephalopathy. Hepatology (Baltimore, Md.) 2014;59(3): 1073-83. PUBMED: 23847109]

Shehata 2018 \{published data only\} Shehata HH, Elfert AA, Abdin AA, Soliman SM, Elkhouly RA, Hawah NI, et al. Randomized controlled trial of polyethylene glycol versus lactulose for the treatment of overt hepatic encephalopathy. European Journal of Gastroenterology \& Hepatology 2018;30(12):1476-81. DOI: 10.1097/MEG.0000000000001267

STOP-HE 2017 \{published and unpublished data\} Rahimi RS, Safadi R, Thabut D, Bajaj JS, Bhamidimarri KR, Pyrsopoulos NT, et al. STOP-HE: a randomised, double-blind, placebo-controlled study of OCR-002 in patients with hepatic encephalopathy. Hepatology (Baltimore, Md.) 2017;66(Suppl 1):276A.

Safadi R, Rahimi RS, DiLiberti CE, Wang L, Pyrsopoulos NT, Pothoff AP, et al. OCR-002 (ornithine phenylacetate) is a potent ammonia scavenger as demonstrated in phase $2 \mathrm{~b}$ STOP-HE study. Hepatology (Baltimore, Md.) 2017;66 (Suppl 1):126A.

Thabut D, Stadlbauer V, Bhamidimarri KR, Pothoff A, Bukofzer S, on behalf of the STOP-HE study group. Geographic differences for patients enrolled in STOPHE: a randomised, phase 2 study of OCR-002 for hepatic encephalopathy. Hepatology (Baltimore, Md.) 2017;66 (Suppl 1):274A.

Sushma 1992 \{published data only (unpublished sought but not used)\} Sushma S, Dasarathy S, Tandon RK, Jain S, Gupta S, Bhist MS. Sodium benzoate in the treatment of acute hepatic encephalopathy: a double-blind randomised trial. Hepatology (Baltimore, Md.) 1992;16(1):138-44. PUBMED: 1618465$]$

Uribe 1990 \{published data only\} Uribe M, Bosques F, Marín E, Cervera E, Gil S, Poo JL, et al. Sodium benzoate in portalsystemic encephalopathy

Pharmacotherapies that specifically target ammonia for the prevention and treatment of hepatic encephalopathy in adults with cirrhosis 
induced blood ammonia normalization and clinical improvement. Interim report of a double blind multicenter trial [Derivacion metabolica del amonio plasmatico con benzoato de sodio, como metodo de tratamiento en pacientes con cirrosis y encefalopatia portosistemica. Informe interino de un estudio multicentrico, doble ciego]. Revista de Investigación Clínica 1990;42(Suppl):149-54. PUBMED: 19256155]

\section{Ventura-Cots 2016 \{published and unpublished data\}}

Ventura-Cots M, Arranz JA, Simón-Talero M, Torrens M, Blanco A, Riudor E, et al. Safety of ornithine phenylacetate in cirrhotic decompensated patients: an open-label, dose-escalating, single-cohort study. Journal of Clinical Gastroenterology 2013;47(10):881-7. PUBMED: 23751856]

* Ventura-Cots M, Concepción M, Arranz JA, SimónTalero M, Torrens M, Blanco-Grau A, et al. Impact of ornithine phenylacetate (OCR-002) in lowering plasma ammonia after upper gastrointestinal bleeding in cirrhotic patients. Therapeutic Advances in Gastroenterology 2016;9 (6):823-35. PUBMED: 27803737]

\section{References to studies excluded from this review}

\section{Campollo 1992 \{published data only\}}

Campollo O, Gil S, Olvera G, Poo JL, Uribe M. Efficacy and safety of sodium benzoate for the long-term treatment of chronic hyperammonemic hepatic encephalopathy. Hepatology (Baltimore, Md.) 1992;16(Suppl 1):248A.

Ghabril 2013 \{published data only\}

Ghabril M, Zupanets I, Vierling J, Mantry P, Rockey D, Wolf D, et al. Glycerol phenylbutyrate in patients with cirrhosis and episodic hepatic encephalopathy: a pilot study of safety and effect on venous ammonia concentration. Clinical Pharmacology in Drug Development 2013;2(3): 278-84. PUBMED: 27121790]

Mendenhall 1986 \{published data only\} Mendenhall CL, Rouster S, Marshall L, Weesner R. A new therapy for portal systemic encephalopathy. American Journal of Gastroenterology 1986;81(7):540-3. PUBMED: 3717115]

Panella 1993 \{published data only\} Panella C, Guglielmi FW, Mastronuzzi T, Contento F, Siciliano N, Francavilla A. Oral Na-benzoate in the treatment of chronic hepatic encephalopathy. Italian Journal of Gastroenterology 1993;25:228.

Panella C, Guglielmi FW, Mastronuzzi T, Contento F, Siciliano N, Francavilla A. Oral sodium benzoate in the treatment of chronic hepatic encephalopathy. Gut 1993;34 (Suppl 3):S43.

Weiss 2018 \{published data only\} Tripon S, Mallet M, Lodey M, Guiller E, Rudler M, Mouri $S$, et al. Sodium phenylbutyrate administration to avoid neurological worsening in cirrhotic patients with hepatic encephalopathy admitted in ICU. Journal of Hepatology 2016;64(2 Suppl):S288.

* Weiss N, Tripon S, Lodey M, Guiller E, Junot H, Monneret D, et al. Treating hepatic encephalopathy in cirrhotic patients admitted to ICU with sodium phenylbutyrate: a preliminary study. Fundamental \& Clinical Pharmacology 2018;32(2):206-8.

\section{References to ongoing studies}

\section{NCT00558038 \{published data only\}}

NCT00558038. Safety and efficacy of AST-120 compared to lactulose in patients with hepatic encephalopathy (AST015). clinicaltrials.gov/ct2/show/NCT00558038 (first posted 14 November 2007).

\section{NCT03448770 \{unpublished data only\}}

NCT03448770. To compare efficacy and safety of lactulose versus polyethylene glycol for treatment of overt hepatic encephalopathy in cirrhotics: a randomised controlled trial. clinicaltrials.gov/ct2/show/nct03448770 (first posted 28 February 2018).

\section{Additional references}

\section{AASLD/EASL 2014}

American Association for the Study of Liver Diseases, European Association for the Study of the Liver. Hepatic encephalopathy in chronic liver disease: 2014 practice guideline by the European Association for the Study of the Liver and the American Association for the Study of Liver Diseases. Journal of Hepatology 2014;61(3):642-59.

\section{Acharya 2018}

Acharya C, Bajaj J. Current management of hepatic encephalopathy. American Journal of Gastroenterology 2018; 113(11):1600-12.

\section{Ahuja 2014}

Ahuja N, Ally W, Caldwell S. Direct acting inhibitors of ammoniagenesis: a role in post-TIPS encephalopathy?. Annals of Hepatology 2014;13(2):179-86.

\section{Allampati 2016}

Allampati S, Duarte-Rojo A, Thacker L, Patidar K, White M, Klair J, et al. Diagnosis of minimal hepatic encephalopathy using strop EncephalApp: a multicentre US-based, norm-based study. American Journal of Gastroenterology 2016;111(1):78-86. [PUBMED: 26644276]

\section{Bajaj 2008}

Bajaj JS, Hafeezullah M, Franco J, Varma RR, Hoffmann RG, Knox JF, et al. Inhibitory control test for the diagnosis of minimal hepatic encephalopathy. Gastroenterology 2008; 135(5):1591-600. [PUBMED: 18723018]

\section{Bajaj 2009}

Bajaj JS, Wade JB, Sanyal AJ. Spectrum of neurocognitive impairment in cirrhosis: implications for the assessment of hepatic encephalopathy. Hepatology (Baltimore, Md.) 2009; 50(6):2014-21. DOI: 10.1002/hep.23216; PUBMED: 19787808

Pharmacotherapies that specifically target ammonia for the prevention and treatment of hepatic encephalopathy in adults with cirrhosis 3 I 
Bajaj 2010

Bajaj JS, Schubert CM, Heuman DM, Wade JB, Gibson DP, Topaz A, et al. Persistence of cognitive impairment after resolution of overt hepatic encephalopathy. Gastroenterology 2010;138(7):2332-40. [PUBMED: 20178797]

Bajaj 2011a

Bajaj JS, Cordoba J, Mullen KD, Amodio P, Shawcross DL, Butterworth RF, et al. Review article: the design of clinical trials in hepatic encephalopathy - an International Society for Hepatic Encephalopathy and Nitrogen Metabolism (ISHEN) consensus statement. Alimentary Pharmacology \& Therapeutics 2011;33(7):739-47. [PUBMED: 21306407]

Bajaj 2011b

Bajaj JS, Wade JB, Gibson DP, Heuman DM, Thacker LR, Sterling RK, et al. The multi-dimensional burden of cirrhosis and hepatic encephalopathy on patients and caregivers. American Journal of Gastroenterology 2011;106 (9):1646-53. [PUBMED: 21556040]

Bass 2007

Bass N. Review article: the current pharmacological therapies for hepatic encephalopathy. Alimentary Pharmacology \& Therapeutics 2007;25(S1):23-31.

Berry 2014

Berry SA, Lichter-Konecki U, Diaz GA, McCandless SE, Rhead W, Smith W, et al. Glycerol phenylbutyrate treatment in children with urea cycle disorders: pooled analysis of short and long-term ammonia control and outcomes. Molecular Genetics and Metabolism 2014;112(1): 17-24. [PUBMED: 24630270]

\section{Blanco Vela 2011}

Blanco Vela CI, Bosques Padilla FJ. Determination of ammonia concentrations in cirrhosis patients - still confusing after all these years?. Annals of Hepatology 2011; 10(Suppl 2):S60-5. [PUBMED: 22228884]

\section{Bosoi 2011}

Bosoi CR, Parent-Robitaille C, Anderson K, Tremblay M, Rose CF. AST-120 (spherical carbon adsorbent) lowers ammonia levels and attenuates brain edema in bile ductligated rats. Hepatology (Baltimore, Md.) 2011;53(6): 1995-2002. [PUBMED: 21384402]

\section{Brown 2006a}

Brown P, Brunnhuber K, Chalkidou K, Chalmers I, Clarke M, Fenton M, et al. How to formulate research recommendations. BMJ (Clinical Research Ed.) 2006;333 (7572):804-6. [PUBMED: 17038740]

\section{Bustamante 1999}

Bustamante J, Rimola A, Ventura PJ, Navasa M, CireraI I, Reggiardo V, et al. Prognostic significance of hepatic encephalopathy in patients with cirrhosis. Journal of Hepatology 1999;30(5):890-5. [PUBMED: 10365817]

\section{Butterworth 2000}

Butterworth R. Complications of cirrhosis III. Hepatic encephalopathy. Journal of Hepatology 2000;32(Suppl 1): $171-80$.
Butterworth 2013

Butterworth RF. The liver-brain axis in liver failure: neuroinflammation and encephalopathy. Nature Reviews. Gastroenterology \& Hepatology 2013;10(9):522-8. [PUBMED: 23817325]

\section{Cadranel 2001}

Cadranel JF, Lebiez E, Di Martino V, Bernard B, El Koury $\mathrm{S}$, Tourbah A, et al. Focal neurological signs in hepatic encephalopathy in cirrhotic patients: an underestimated entity?. American Journal of Gastroenterology 2001;96(2): 515-8. [PUBMED: 11232699]

\section{Chu 1997}

Chu NS, Yang SS, Liaw YF. Evoked potentials in liver diseases. Journal of Gastroenterology and Hepatology 1997;12 (Suppl):S288-93. [PUBMED: 9407349]

\section{Conn 1977}

Conn HO, Leevy CM, Vlahcevic ZR, Rodgers JB, Maddrey WC, Seeff L, et al. Comparison of lactulose and neomycin in the treatment of chronic portal-systemic encephalopathy. A double blind controlled trial. Gastroenterology 1977;72(4 Pt 1):573-83. [PUBMED: 14049]

\section{De Jongh 1992}

De Jongh FE, Janssen HL, De Man RA, Hop WC, Schalm SW, Van Blankenstein M. Survival and prognostic indicators in hepatitis B surface antigen-positive cirrhosis of the liver. Gastroenterology 1992;103(5):1630-5. [PUBMED: 1426884]

\section{De Las Heras 2017}

De Las Heras J, Aldámiz-Echevarría L, Martínez-Chantar ML, Delgado T. An update on the use of benzoate, phenylacetate and phenylbutyrate ammonia scavengers for interrogating and modifying liver nitrogen metabolism and its implications in urea cycle disorders and liver disease. Expert Opinion on Drug Metabolism \& Toxicology 2017;13 (4):439-48.

\section{Deeks 2017}

Deeks JJ, Higgins JP, Altman DG (editors) on behalf of the Cochrane Statistical Methods Group. Chapter 9: Analysing data and undertaking meta-analyses. In: Higgins JPT, Churchill R, Chandler J, Cumpston MS (editors), Cochrane Handbook for Systematic Reviews of Interventions version 5.2.0 (updated June 2017), Cochrane, 2017. Available from www.training.cochrane.org/handbook.

\section{Dhiman 1995}

Dhiman RK, Saraswat VA, Verma M, Naik SR. Figure connection test: a universal test for assessment of mental state. Journal of Gastroenterology and Hepatology 1995;10 (1):14-23. [PUBMED: 7620102]

\section{D'Amico 1986}

D’Amico G, Morabito A, Pagliaro L, Marubini E. Survival and prognostic indicators in compensated and decompensated cirrhosis. Digestive Diseases and Sciences 1986;31(5):468-75. [PUBMED: 3009109]

\section{D’Amico 2006}

D'Amico G, Garcia-Tsao G, Pagliaro L. Natural history and prognostic indicators of survival in cirrhosis: a systematic

Pharmacotherapies that specifically target ammonia for the prevention and treatment of hepatic encephalopathy in adults with cirrhosis 32 
review of 118 studies. Journal of Hepatology 2006;44: 217-31.

\section{Efrati 2000}

Efrati C, Masini A, Merli M, Valeriano V, Riggio O. Effect of sodium benzoate on blood ammonia response to oral glutamine challenge in cirrhotic patients: a note of caution. American Journal of Gastroenterology 2000;95(12):3574-8. [PUBMED: 11151894$]$

Egger 1997

Egger M, Davey Smith G, Schneider M, Minder C. Bias in meta analysis detected by a simple, graphical test. BMJ (Clinical Research Ed.) 1997;315(7109):629-34.

Ferenci 2002

Ferenci P, Lockwood A, Mullen K, Tarter R, Weissenborn K, Blei AT. Hepatic encephalopathy--definition, nomenclature, diagnosis, and quantification: final report of the working party at the 11th World Congresses of Gastroenterology, Vienna, 1998. Hepatology (Baltimore, Md.) 2002;35(3): 716-21. [PUBMED: 11870389]

\section{Gluud 2016}

Gluud LL, Vilstrup H, Morgan MY. Non-absorbable disaccharides versus placebo/no intervention and lactulose versus lactitol for the prevention and treatment of hepatic encephalopathy in people with cirrhosis. Cochrane Database Systematic Review 2016;5:CD003044. DOI: 10.1002/ 14651858.CD003044.pub4; PUBMED: 27153247

\section{Goh 2018}

Goh ET, Stokes CS, Sidhu SS, Vilstrup H, Gluud LL, Morgan MY. L-ornithine L-aspartate for prevention and treatment of hepatic encephalopathy in people with cirrhosis. Cochrane Database of Systematic Reviews 2018, Issue 5. DOI: 10.1002/14651858.CD012410.pub2

\section{GradePro 2015 [Computer program]}

McMaster University (developed by Evidence Prime). GRADEpro. Version accessed 16 August 2016. Hamilton (ON): McMaster University (developed by Evidence Prime), 2015.

\section{Groeneweg 1998}

Groeneweg M, Quero JC, De Bruijn I, Hartmann IJ, Essink-bot ML, Hop WC, et al. Subclinical hepatic encephalopathy impairs daily functioning. Hepatology (Baltimore, Md.) 1998;28(1):45-9. [PUBMED: 9657095]

\section{Guérit 2009}

Guérit JM, Amantini A, Fischer C, Kaplan PW, Mecarelli O, Schnitzler A, et al. Neurophysiological investigations of hepatic encephalopathy: ISHEN practice guidelines. Liver International 2009;29(6):789-96. [PUBMED: 19638107]

\section{Hadjihambi 2018}

Hadjihambi A, Arias N, Sheikh M, Jalan R. Hepatic encephalopathy: a critical current review. Hepatology International 2018;12(Suppl 1):135-47.

\section{Harbord 2006}

Harbord RM, Egger M, Sterne JA. A modified test for small-study effects in meta-analyses of controlled trials with binary endpoints. Statistics in Medicine 2006;25(20): 3443-57. [PUBMED: 16345038]

\section{Hassanein 2008}

Hassanein TI, Hilsabeck RC, Perry W. Introduction to the Hepatic Encephalopathy Scoring Algorithm (HESA). Digestive Diseases and Sciences 2008;53(2):529-38. DOI: 10.1007/s10620-007-9895-0; PUBMED: 17710551

\section{Haussinger 2000}

Haussinger D, Kircheis G, Fischer R, Schliess F, vom Dahl $S$. Hepatic encephalopathy in chronic liver disease: a clinical manifestation of astrocyte swelling and low-grade cerebral edema?. Journal of Hepatology 2000;32(6):1035-8. [PUBMED: 10898326]

\section{Higgins 2008}

Higgins JP, White IR, Wood AM. Imputation methods for missing outcome data in meta-analysis of clinical trials. Clinical Trials 2008;5(3):225-39.

\section{Higgins 2011}

Higgins JP, Green S, editor(s). Cochrane Handbook for Systematic Reviews of Interventions Version 5.1.0 (updated March 2011). The Cochrane Collaboration, 2011. Available from handbook.cochrane.org.

\section{Higgins 2017}

Higgins JP, Altman DG, Sterne JA. Chapter 8: Assessing risk of bias in included studies. Higgins JPT, Churchill R, Chandler J, Cumpston MS (editors), Cochrane Handbook for Systematic Reviews of Interventions version 5.2.0 (updated June 2017), Cochrane, 2017 Available from: www.training.cochrane.org/handbook.

\section{ICH-GCP 1997}

International Conference on Harmonisation Expert Working Group. International conference on harmonisation of technical requirements for registration of pharmaceuticals for human use. ICH harmonised tripartite guideline. Guideline for good clinical practice CFR \& ICH Guidelines. Vol. 1, Philadelphia (PA): Barnett International/PAREXEL, 1997.

\section{Jackson 2016}

Jackson CD, Gram M, Halliday E, Olesen SS, Sandberg TH, Drewes AM, et al. New spectral thresholds improve the utility of the electroencephalogram for the diagnosis of hepatic encephalopathy. Clinical Neurophysiology 2016; 127(8):2933-41. DOI: 10.1016/j.clinph.2016.03.027; PUBMED: 27236607

\section{Jalan 2007}

Jalan R, Wright G, Davies NA, Hodges SJ. L-Ornithine phenylacetate (OP): a novel treatment for hyperammonemia and hepatic encephalopathy. Medical Hypotheses 2007;69 (5):1064-9. [PUBMED: 17467190]

\section{Jawaro 2016}

Jawaro T, Yang A, Dixit D, Bridgeman M. Management of hepatic encephalopathy. Annals of Pharmacology 2016;50 (7):569-77.

\section{Jepsen 2010}

Jepsen P, Ott P, Andersen PK, Sørensen HT, Vilstrup H. The clinical course of alcoholic liver cirrhosis: a Danish population-based cohort study. Hepatology (Baltimore, Md.) 2010;51(5):1675-82. DOI: 10.1002/hep.23500; PUBMED: 20186844

Pharmacotherapies that specifically target ammonia for the prevention and treatment of hepatic encephalopathy in adults with cirrhosis 


\section{Jover-Cobos 2013}

Jover-Cobos M, Noiret L, Sharifi Y, Jalan R. Ornithine phenylacetate revisited. Metabolic Brain Disease 2013;28(2): 327-31. [PUBMED: 23456516]

Kircheis 2002

Kircheis G, Wettstein M, Timmermann L, Schnitzler A, Haussinger D. Critical flicker frequency for quantification of low-grade hepatic encephalopathy. Hepatology (Baltimore, Md.) 2002;35(2):357-66. [PUBMED: 11826409]

\section{Kircheis 2009}

Kircheis G, Knoche A, Hilger N, Manhart F, Schnitzler A, Schulze H, et al. Hepatic encephalopathy and fitness to drive. Gastroenterology 2009;137(5):1706-15. [PUBMED: $19686744]$

\section{Kornerup 2018}

Kornerup L, Gluud L, Vilstrup H, Dam G. Update on the therapeutic management of hepatic encephalopathy. Current Gastroenterology Reports 2018;20(5):20-1.

\section{Lauridsen 2011}

Lauridsen MM, Jepsen P, Vilstrup H. Critical flicker frequency and continuous reaction times for the diagnosis of minimal hepatic encephalopathy: a comparative study of 154 patients with liver disease. Metabolic Brain Disease 2011;26(2):135-9. [PUBMED: 21484318]

Lee 2010

Lee B, Rhead W, Diaz GA, Scharschmidt BF, Mian A, Shchelochkov O, et al. Phase 2 comparison of a novel ammonia scavenging agent with sodium phenylbutyrate in patients with urea cycle disorders: safety, pharmacokinetics and ammonia control. Molecular Genetics and Metabolism 2010;100(3):221-8. [PUBMED: 20382058]

\section{Lockwood 2004}

Lockwood AH. Blood ammonia levels and hepatic encephalopathy. Metabolic Brain Disease 2004;19(3-4): 345-9. [PUBMED: 15554426]

\section{Mardini 2008}

Mardini H, Saxby BK, Record CO. Computerized psychometric testing in minimal encephalopathy and modulation by nitrogen challenge and liver transplant. Gastroenterology 2008;135(5):1582-90. DOI: 10.1053/ j.gastro.2008.06.043; PUBMED: 18647604

Matoori 2015

Matoori S, Leroux JC. Recent advances in the treatment of hyperammonemia. Advanced Drug Delivery Reviews 2015; 90(1):55-68.

McGuire 2010

McGuire BM, Zupanets IA, Lowe ME, Xiao X, Syplyviy VA, Monteleone J, et al. Pharmacology and safety of glycerol phenylbutyrate in healthy adults and adults with cirrhosis. Hepatology (Baltimore, Md.) 2010;51(6): 2077-85. [PUBMED: 20512995]

\section{MECIR 2018}

Higgins JP, Lasserson T, Chandler J, Tovey D, Churchill R. Methodological expectations of Cochrane intervention reviews - Version 1.07. community.cochrane.org/mecirmanual 2018 (accessed 5 March 2019).

\section{Misel 2013}

Misel ML, Gish RG, Patton H, Mendler M. Sodium benzoate for treatment of hepatic encephalopathy. Gastroenterology \& Hepatology 2013;9(4):219-27. [PUBMED: 24711766]

\section{Montagnese 2004}

Montagnese S, Amodio P, Morgan MY. Methods for diagnosing hepatic encephalopathy in patients with cirrhosis: a multidimensional approach. Metabolic Brain Disease 2004;19(3-4):281-312. [PUBMED: 15554423]

\section{Montagnese 2014}

Montagnese S, Balistreri E, Schiff S, De Rui M, Angeli P, Zanus G, et al. Covert hepatic encephalopathy: agreement and predictive validity of different indices. World Journal of Gastroenterology 2014;20(42):15756-62. DOI: 10.3748/ wjg.v20.i42.15756; PMCID: PMC4229541; PUBMED: 25400460

\section{Morgan 2018}

Morgan MY. Hepatic encephalopathy. In: Dooley JS, Lok ASF, Garcia-Tsao G, Pinzani M editor(s). Sherlock's Diseases of the Liver and Biliary System. 13th Edition. London: Wiley-Blackwell, 2018:Chapter 10: pp 151-80. [ASIN: 1119237548; ISBN-13: 978-1119237549]

\section{O’Carroll 1991}

O'Carroll RE, Hayes PC, Ebmeier KP, Dougall N, Murray C, Best JJ, et al. Regional cerebral blood flow and cognitive function in patients with chronic liver disease. Lancet 1991; 337(8752):1250-3. [PUBMED: 1674063]

\section{Olesen 2016}

Olesen SS, Gram M, Jackson CD, Halliday E, Sandberg $\mathrm{TH}$, Drewes AM, et al. Electroencephalogram variability in patients with cirrhosis associates with the presence and severity of hepatic encephalopathy. Journal of Hepatology 2016;65(3):517-23. DOI: 10.1016/j.jhep.2016.05.004; PUBMED: 27184531

Ortiz 2007

Ortiz M, Córdoba J, Doval E, Jacas C, Pujadas F, Esteban $\mathrm{R}$, et al. Development of a clinical hepatic encephalopathy staging scale. Alimentary Pharmacology \& Therapeutics 2007; 26(6):859-67. DOI: 10.1111/j.1365-2036.2007.03394.x; PUBMED: 17767470

\section{Page 2014}

Page MJ, McKenzie JE, Kirkham J, Dwan K, Kramer $S$, Green S, et al. Bias due to selective inclusion and reporting of outcomes and analyses in systematic reviews of randomised trials of healthcare interventions. Cochrane Database of Systematic Reviews 2014, Issue 10. DOI: 10.1002/14651858.MR000035.pub2; MROOOO35

\section{Pantham 2017}

Pantham G, Post A, Venkat D, Einstadter D, Mullen KD A new look at precipitants of overt hepatic encephalopathy in cirrhosis. Digestive Diseases and Sciences 2017;62(8): 2166-73. DOI: 10.1007/s10620-017-4630-y; PUBMED: 28560484

Pharmacotherapies that specifically target ammonia for the prevention and treatment of hepatic encephalopathy in adults with cirrhosis 
Parsons-Smith 1957

Parsons-Smith BG, Summerskill WH, Dawson AM, Sherlock $S$. The electroencephalograph in liver disease. Lancet 1957;270(7001):867-71. [PUBMED: 13482229]

\section{Poodad 2007}

Poodad FF. Review article: the burden of hepatic encephalopathy. Alimentary Pharmacology \& Therapeutics 2007;25(Suppl 1):3-9.

\section{Rahimi 2016}

Rahimi RS, Rockey DC. Hepatic encephalopathy: pharmacological therapies targeting ammonia. Seminars in Liver Disease 2016;36(1):48-55. [PUBMED: 26870932]

\section{Randolph 1998}

Randolph C. The Repeatable Battery for the Assessment of Neuropsychological Status (RBANS). San Antonio: The Psychological Corporation, 1998.

\section{Randolph 2009}

Randolph C, Hilsabeck R, Kato A, Kharbanda P, Li YY, Mapelli D, et al. Neuropsychological assessment of hepatic encephalopathy: ISHEN practice guidelines. Liver International 2009;29(5):629-35. [PUBMED: 19302444]

Review Manager 2014 [Computer program]

Nordic Cochrane Centre, The Cochrane Collaboration. Review Manager 5 (RevMan 5). Version 5.3. Copenhagen: Nordic Cochrane Centre, The Cochrane Collaboration, 2014.

\section{Roman 2011}

Roman E, Córdoba J, Torrens M, Torras X, Villanueva C, Vargas V, et al. Minimal hepatic encephalopathy is associated with falls. American Journal of Gastroenterology 2011;106(3):476-82.

\section{Rose 2012}

Rose CF. Ammonia-lowering strategies for the treatment of hepatic encephalopathy. Clinical Pharmacology and Therapeutics 2012;92(3):321-31. [PUBMED: 22871998]

\section{Royle 2003}

Royle P, Milne R. Literature searching for randomised controlled trials used in Cochrane Reviews: rapid versus exhaustive searches. International Journal of Technology Assessment in Health Care 2003;19(1):591-603.

\section{Saunders 1981}

Saunders JB, Walters JR, Davies AP, Paton A. A 20-year prospective study of cirrhosis. BMJ (Clinical Research Ed.) 1981;282(6260):263-6. [PUBMED: 6779978]

\section{Savović 2012a}

Savović J, Jones H, Altman D, Harris R, Juni P, Pildal J, et al. Influence of reported study design characteristics on intervention effect estimates from randomised controlled trials: combined analysis of meta-epidemiological studies. Health Technology Assessment 2012;16(35):1-82. [PUBMED: 22989478]

Savovic 2012b

Savović J, Jones HE, Altman DG, Harris RJ, Juni P, Pildal $\mathrm{J}$, et al. Influence of reported study design characteristics on intervention effect estimates from randomised, controlled trials. Annals of Internal Medicine 2012;157(6):429-38.

[PUBMED: 22945832]

Schomerus 1981

Schomerus H, Hamster W, Blunck H, Reinhard U, Mayer K, Dölle W. Latent portasystemic encephalopathy. I. Nature of cerebral functional defects and their effect on fitness to drive. Digestive Diseases and Sciences 1981;26(7):522-30. [PUBMED: 7249898]

\section{Schomerus 1998}

Schomerus H, Hamster W. Neuropsychological aspects of portal-systemic encephalopathy. Metabolic Brain Disease 1998;13(4):361-77. [PUBMED: 10206827]

\section{Schünemann 2013}

Schünemann H, Broż ek J, Guyatt G, Oxman A, editor (s). Handbook for grading the quality of evidence and the strength of recommendations using the GRADE approach. gdt.gradepro.org/app/handbook/handbook.html 2013 (accessed 24 January 2019).

\section{Sharma 2010}

Sharma P, Sharma BC, Sarin SK. Predictors of non response to lactulose in patients with cirrhosis and hepatic encephalopathy. European Journal of Gastroenterology \& Hepatology 2010;22(5):526-31. [PUBMED: 20009938]

\section{Sotil 2009}

Sotil EU, Gottstein J, Ayala E, Randolph C, Blei AT. Impact of preoperative overt hepatic encephalopathy on neurocognitive function after liver transplantation. Liver Transplantation 2009;15(2): 184-92.

Stata 2015 [Computer program] Stata Corp. Stata: Release 14. Texas, USA: Stata Corp, 2015.

\section{Stepanova 2012}

Stepanova M, Mishra A, Venkatesan C, Younossi ZM. Inhospital mortality and economic burden associated with hepatic encephalopathy in the United States from 2005 to 2009. Clinical Gastroenterology and Hepatology 2012;10(9): 1034-41.

\section{Stewart 2007}

Stewart CA, Malinchoc M, Kim WR, Kamath PS. Hepatic encephalopathy as a predictor of survival in patients with end-stage liver disease. Liver Transplantation 2007;13(10): 1366-71.

\section{Sturgeon 2014}

Sturgeon J, Shawcross D. Recent insights into the pathogenesis of hepatic encephalopathy and treatments. Expert Review of Gastroenterology \& Hepatology 2014;8(1) 83-100.

\section{Taylor-Robinson 1994}

Taylor-Robinson SD, Sargentoni J, Marcus CD, Morgan MY, Bryant DJ. Regional variations in cerebral proton spectroscopy in patients with chronic hepatic encephalopathy. Metabolic Brain Disease 1994;9(4):347-59. [PUBMED: 7898401]

Pharmacotherapies that specifically target ammonia for the prevention and treatment of hepatic encephalopathy in adults with cirrhosis 35 


\section{Teasdale 1974}

Teasdale G, Jennett B. Assessment of coma and impaired consciousness. A practical scale. Lancet 1974;304(7872): 81-4. [PUBMED: 4136544]

Toris 2011

Toris G, Bikis C, Tsourouflis G, Theocharis S. Hepatic encephalopathy: an updated approach from pathogenesis to treatment. Medical Science Monitor 2011;17(2):RA53-63. [PUBMED: 21278704]

\section{Victor 1965}

Victor M, Adams RD, Cole M. The acquired (nonWilsonian) type of chronic hepatocerebral degeneration. Medicine 1965;44(5):345-96. [PUBMED: 5318075]

\section{Vilstrup 2014}

Vilstrup H, Amodio P, Bajaj J, Cordoba J, Ferenci P, Mullen $\mathrm{KD}$, et al. Hepatic encephalopathy in chronic liver disease: 2014 Practice Guideline by the American Association for the Study of Liver Diseases and the European Association for the Study of the Liver. Hepatology (Baltimore, $M d$.) 2014;60(2):715-35. [PUBMED: 25042402]

\section{Weissenborn 1998}

Weissenborn K. Diagnosis of encephalopathy. Digestion 1998;59(Suppl 2):22-4.

\section{Weissenborn 2001}

Weissenborn K, Ennen JC, Schomerus H, Ruckert N Hecker H. Neuropsychological characterization of hepatic encephalopathy. Journal of Hepatology 2001;34(5):768-73. [PUBMED: 11434627]

\section{Wetterslev 2008}

Wetterslev J, Thorlund K, Brok J, Gluud C. Trial Sequential Analysis may establish when firm evidence is reached in cumulative meta-analysis. Journal of Clinical Epidemiology 2008;61(1):64-75.

\section{Wright 2011}

Wright G, Noiret L, Olde Damink SW, Jalan R. Interorgan ammonia metabolism in liver failure: the basis of current and future therapies. Liver International 2011;31(2): 163-75. DOI: 10.1111/j.1478-3231.2010.02302.x; PUBMED: 20673233

Zacharias 2017

Zacharias HD, Jackson CD, Morgan MY, Olesen SS . Alimentary Pharmacology, Therapeutics. Stepwise diagnosis in covert hepatic encephalopathy - critical flicker frequency and MELD-score as a first-step approach. Replication and pitfalls. Alimentary Pharmacology \& Therapeutics 2017;45(1):187-9. DOI: 10.1111/apt.13830; PUBMED: 27910151

\section{Zipprich 2012}

Zipprich A, Garcia-Tsao G, Rogowski S, Fleig WE, Seufferlein T, Dollinger MM. Prognostic indicators of survival in patients with compensated and decompensated cirrhosis. Liver International 2012;32(9):1407-14. [PUBMED: 22679906]

\section{References to other published versions of this review}

\section{Zacharias 2016}

Zacharias HD, Zacharias AP, Oliveira Ferreira A, Morgan MY, Gluud LL. Ammonia scavenging agents for people with cirrhosis and hepatic encephalopathy. Cochrane Database of Systematic Reviews 2016, Issue 8. DOI: 10.1002/ 14651858.CD012334

* Indicates the major publication for the study 


\section{CHARACTERISTICS OFSTUDIES}

\section{Characteristics of included studies [author-defined order]}

\section{Gonzalez 1994}

Methods

Sodium benzoate: single-centre, double-blind, placebo-controlled, randomised clinical trial

Participants

Included participants: cirrhosis with acute Grade 3 or 4 hepatic encephalopathy ( $\mathrm{n}$ $=18) ; 2$ participants were excluded shortly after inclusion because of gastrointestinal bleeding

Age: not reported

Proportion of men: not reported

Aetiology of the liver disease: not reported

MELD score: not reported

\begin{tabular}{|c|c|}
\hline Interventions & $\begin{array}{l}\text { Intervention comparison: sodium benzoate vs placebo } \\
\text { Sodium benzoate: } 7.2 \mathrm{~g} / 24 \mathrm{~h} \text { administered orally or via nasogastric tube }(\mathrm{n}=7) \\
\text { Placebo: (not detailed) administered orally or via nasogastric tube }(\mathrm{n}=9) \\
\text { Duration of treatment: } 7 \text { days } \\
\text { Co-intervention: participants in both groups received lactose enemata }(200 \mathrm{~g} / \mathrm{L}) \text { thrice- } \\
\text { daily }\end{array}$ \\
\hline Outcomes & $\begin{array}{l}\text { Neurocognitive assessment: } \\
\text { Modified PSE Index comprising: } \\
\text { - mental status (West Haven Criteria) } \\
\text { - asterixis } \\
\text { - Number Connection Test A } \\
\text { - venous blood ammonia } \\
\text { Others: } \\
\text { - time to awakening }\end{array}$ \\
\hline Inclusion period & Not reported \\
\hline Country of origin & Mexico \\
\hline Outcomes included in meta-analyses & $\begin{array}{l}\text { - Mortality } \\
\text { - Adverse events } \\
\text { - Venous blood ammonia }\end{array}$ \\
\hline Notes & $\begin{array}{l}\text { Publication status: abstract } \\
\text { - The authors reported that the characteristics of the treatment and control groups } \\
\text { were comparable } \\
\text { - The trial describes the effects of the interventions on hepatic encephalopathy } \\
\text { based on change over the trial period in mental status (West Haven Criteria) and the } \\
\text { PSE Index. } \\
\text { - The authors give the impression that none of the included participants died, } \\
\text { although this was no explicitly conveyed. } \\
\text { Funding: }\end{array}$ \\
\hline
\end{tabular}

Pharmacotherapies that specifically target ammonia for the prevention and treatment of hepatic encephalopathy in adults with cirrhosis 


\section{Gonzalez 1994 (Continued)}

- No information provided

\section{Risk of bias}

\begin{tabular}{|c|c|c|}
\hline Bias & Authors' judgement & Support for judgement \\
\hline $\begin{array}{l}\text { Random sequence generation (selection } \\
\text { bias) }\end{array}$ & Unclear risk & Not reported \\
\hline Allocation concealment (selection bias) & Unclear risk & Not reported \\
\hline $\begin{array}{l}\text { Blinding of participants and personnel } \\
\text { (performance bias) } \\
\text { All outcomes }\end{array}$ & Low risk & $\begin{array}{l}\text { Blinding of participants and personnel us- } \\
\text { ing a placebo }\end{array}$ \\
\hline $\begin{array}{l}\text { Blinding of outcome assessment (detection } \\
\text { bias) } \\
\text { Non-mortality outcomes }\end{array}$ & Low risk & $\begin{array}{l}\text { Blinding of outcome assessment using a } \\
\text { placebo }\end{array}$ \\
\hline $\begin{array}{l}\text { Incomplete outcome data (attrition bias) } \\
\text { All outcomes }\end{array}$ & High risk & $\begin{array}{l}\text { Two participants were excluded due to } \\
\text { gastrointestinal bleeding. The allocation } \\
\text { group of these participants was not re- } \\
\text { ported }\end{array}$ \\
\hline Selective reporting (reporting bias) & Low risk & $\begin{array}{l}\text { The trial reported clinically relevant out- } \\
\text { comes. We did not have access to the trial } \\
\text { protocol }\end{array}$ \\
\hline Other bias & Low risk & None identified \\
\hline $\begin{array}{l}\text { Overall assessment } \\
\text { Non-mortality outcomes }\end{array}$ & High risk & \\
\hline $\begin{array}{l}\text { Overall assessment } \\
\text { Mortality outcomes }\end{array}$ & High risk & \\
\hline
\end{tabular}

Sushma 1992

\section{Methods}

Participants
Sodium benzoate: single-centre, double-blind, randomised clinical trial

Included participants: overt hepatic encephalopathy, Grade 2-4, associated with cirrhosis or creation of a surgical portal-systemic anastomosis with evidence of fibrosis ( $\mathrm{n}$ $=74)$

Age $($ mean $\pm \mathrm{SD})$ :

- sodium benzoate group $35.6 \pm 18.4$ years

- lactulose group $37.9 \pm 12.8$ years.

Proportion of men:

- sodium benzoate group $79 \%$ 
- lactulose group $72 \%$.

Aetiology of liver disease (sodium benzoate: lactulose group):

- post-hepatitis 66\%: $75 \%$

- alcohol 26\%: 22\%

MELD score: not reported

Interventions

Outcomes
Intervention comparison: sodium benzoate vs lactulose

Sodium benzoate: $5 \mathrm{~g} / 30 \mathrm{~mL}$ tap water, given orally or via nasogastric tube twice daily $(\mathrm{n}=38)$; standard dose $10 \mathrm{~g} /$ day for $7.9 \pm 6.4$ days

Lactulose: $30 \mathrm{~mL} / 8 \mathrm{~h}$ administered orally or by nasogastric tube; dose adjusted to achieve 3 semi-soft stools daily $(\mathrm{n}=36)$; mean dose $66.8 \pm 24.8 \mathrm{~mL} /$ day for $8.8 \pm 7.1$ days

Duration of treatment: until complete recovery - maximum follow-up 42 days

Co-intervention: standard treatment was continued in both groups and included twicedaily bowel washes with tap water, maintenance of fluid and electrolyte levels, restriction of oral intake of proteins to $20 \mathrm{~g} /$ day in participants in whom oral intake was possible; antibiotics were prescribed to treat infections in 7 participants receiving sodium benzoate and in 1 participant receiving lactulose

\begin{tabular}{|c|c|}
\hline & $\begin{array}{l}\text { PSE Sum and Index comprising: } \\
\text { - mental status (West Haven Criteria) } \\
\text { - asterixis } \\
\text { - Number Connection Test A } \\
\text { - arterial blood ammonia } \\
\text { - electroencephalography } \\
\text { Additional psychometric tests including: } \\
\text { - 5-pointed star construction } \\
\text { - serial-7 subtraction } \\
\text { - backward counting tests } \\
\text { Visual, auditory and somatosensory evoked potentials } \\
\text { Others: } \\
\text { - time elapsed before response }\end{array}$ \\
\hline Inclusion period & January 1990-June 1991 \\
\hline Country of origin & India \\
\hline Outcomes included in meta-analyses & $\begin{array}{l}\text { - Mortality } \\
\text { - Hepatic encephalopathy } \\
\text { - Serious adverse events } \\
\text { - Non-serious adverse events } \\
\text { - Blood ammonia }\end{array}$ \\
\hline Notes & $\begin{array}{l}\text { Publication status: full paper } \\
\text { - Separate results were not provided for the } 2 \text { participants who developed hepatic } \\
\text { encephalopathy following portal-systemic shunt surgery with underlying hepatic } \\
\text { fibrosis. They are included in the overall analyses. } \\
\text { - Therapeutic success was defined as a sustained improvement of one grade in } \\
\text { mental status in less than } 48 \mathrm{~h} \text { or improvement of more than two grades in mental }\end{array}$ \\
\hline
\end{tabular}

Pharmacotherapies that specifically target ammonia for the prevention and treatment of hepatic encephalopathy in adults with cirrhosis 
status.

- Complete response was defined as recovery to normal mental status with no evidence of asterixis.

- Partial response was defined as improvement in mental status by at least two grades without normalization.

- Therapeutic failure was defined as:

$\circ$ no change in mental state after $48 \mathrm{~h}$ of therapy;

- sustained deterioration of 1 grade in mental state during $48 \mathrm{~h}$ of therapy;

$\circ$ deterioration of 2 grades in mental state; and

o death in coma despite treatment.

- Participants who failed treatment on sodium benzoate were unblinded, and received lactulose; participants who failed treated with lactulose continued with the same treatment.

- The trial authors were contacted for more information regarding random sequence generation, serious and non-serious adverse events; quality-of-life measures and liver-related mortality. No response was received.

Funding:

- No information provided

\section{Risk of bias}

\begin{tabular}{l|l|l}
\hline Bias & Authors' judgement & Support for judgement \\
\hline $\begin{array}{l}\text { Random sequence generation (selection } \\
\text { bias) }\end{array}$ & Unclear risk & Information not provided \\
\hline $\begin{array}{l}\text { Allocation concealment (selection bias) } \\
\text { Blinding of participants and personnel } \\
\text { (performance bias) } \\
\begin{array}{l}\text { All outcomes } \\
\text { Low risk }\end{array}\end{array}$ & Sealed envelopes \\
\hline
\end{tabular}

Blinding of outcome assessment (detection Low risk bias)

Non-mortality outcomes

Incomplete outcome data (attrition bias) High risk All outcomes

Selective reporting (reporting bias)

Low risk

Other bias
The assessment of response was conducted by a blinded trial author
Participants who did not complete some of the tests were not included in the analyses. However, it is unclear whether all participants were included in the assessment of the primary outcomes

The trial reported clinically relevant outcomes in full. The original trial protocol was not available

None identified 
Overall assessment

High risk

Non-mortality outcomes

Overall assessment

High risk

Mortality outcomes

Uribe 1990

\begin{tabular}{|c|c|}
\hline Methods & Sodium benzoate: multicentre, double-blind, randomised clinical trial \\
\hline Participants & $\begin{array}{l}\text { Included participants: cirrhosis with chronic Grade I or } 2 \text { hepatic encephalopathy (n } \\
=27 \text { ) } \\
\text { Age (mean } \pm \text { SD): } \\
\text { - sodium benzoate group } 58 \pm 8 \text { years } \\
\text { - lactitol group } 58 \pm 11 \text { years } \\
\text { Proportion of men: } \\
\text { - sodium benzoate group } 41.7 \% \\
\text { - lactitol group } 53.3 \% \\
\text { Aetiology of liver disease: } \\
\text { - alcohol: } 55.6 \% \\
\text { - 'postnecrotic': } 40.7 \% \\
\text { - cryptogenic: } 3.7 \% \\
\text { MELD score: not reported }\end{array}$ \\
\hline
\end{tabular}

Interventions

Intervention comparison: sodium benzoate vs lactitol both given orally as a syrup

Sodium benzoate: mean $5.6 \mathrm{~g} /$ day $(\mathrm{n}=12)$

Lactitol: mean $29.1 \mathrm{~g} /$ day $(\mathrm{n}=15)$

Duration of treatment: 2 weeks

Co-intervention: all participants received lactitol, titrated to produce 2-3 soft stools/ day, for 1 week prior to randomisation

Outcomes
Neurocognitive assessment:
PSE Sum and Index comprising:
- mental status (West Haven Criteria)
- asterixis
- Number Connection Test A
- blood ammonia
- electroencephalography

Inclusion period Not reported

Country of origin $\quad$ Mexico

Outcomes included in meta-analyses

- Mortality

- Hepatic encephalopathy

- Serious adverse events

- Non-serious adverse events

- Blood ammonia

Pharmacotherapies that specifically target ammonia for the prevention and treatment of hepatic encephalopathy in adults with cirrhosis 


\begin{tabular}{ll}
\hline Notes & $\begin{array}{l}\text { Publication status: } \\
- \text { the trial was published as a full paper in Spanish but an English translation was } \\
\text { available. } \\
\text { We contacted the trial authors who provided additional data and information regarding } \\
\text { randomisation and funding } \\
\text { Funding: } \\
\text { Supported by Fundacion Clinica Medica Sur and Fundacion Mexicana Para La } \\
\text { Salud }\end{array}$ \\
\hline
\end{tabular}

\section{Risk of bias}

\section{Bias}

Authors' judgement

Support for judgement

Random sequence generation (selection Low risk bias)

\begin{tabular}{|c|c|c|}
\hline Allocation concealment (selection bias) & Low risk & Central allocation \\
\hline $\begin{array}{l}\text { Blinding of participants and personnel } \\
\text { (performance bias) } \\
\text { All outcomes }\end{array}$ & Low risk & $\begin{array}{l}\text { Participants, and personnel measuring par- } \\
\text { ticipants' mental state, were blinded to their } \\
\text { allocation group }\end{array}$ \\
\hline $\begin{array}{l}\text { Blinding of outcome assessment (detection } \\
\text { bias) } \\
\text { Non-mortality outcomes }\end{array}$ & Low risk & $\begin{array}{l}\text { Personnel measuring participants' mental } \\
\text { state were blinded to their allocation group }\end{array}$ \\
\hline $\begin{array}{l}\text { Incomplete outcome data (attrition bias) } \\
\text { All outcomes }\end{array}$ & Low risk & $\begin{array}{l}\text { No missing outcome data and all partici- } \\
\text { pants were included in the analyses }\end{array}$ \\
\hline Selective reporting (reporting bias) & Low risk & No reporting bias identified \\
\hline Other bias & Low risk & None identified \\
\hline $\begin{array}{l}\text { Overall assessment } \\
\text { Non-mortality outcomes }\end{array}$ & Low risk & \\
\hline $\begin{array}{l}\text { Overall assessment } \\
\text { Mortality outcomes }\end{array}$ & Low risk & \\
\hline
\end{tabular}

Rockey 2014

Methods

Glycerol phenylbutyrate: multicentre, double-blind, placebo-controlled, randomised clinical trial

Participants

Included participants: cirrhosis with 2 episodes of hepatic encephalopathy at West Haven Grade 2 or higher in the previous 6 months, 1 of which was within 3 months of randomisation ( $\mathrm{n}=178)$; $91 \%$ in the glycerol phenylbutyrate group and $92 \%$ in the placebo group had no evidence of hepatic encephalopathy at trial entry but the majority 
were on treatment with lactulose or rifaximin or both

Age (mean $\pm \mathrm{SD})$ :

- glycerol phenylbutyrate group $53.8 \pm 8.9$ years

- placebo group $55.4 \pm 8.8$ years

Proportion of men:

- glycerol phenylbutyrate group 50\%

- placebo group $67 \%$

Aetiology of liver disease: not reported

MELD score (mean \pm SD):

- glycerol phenylbutyrate group $12.6 \pm 3.7$

- placebo group $12.3 \pm 3.8$

Interventions

Intervention comparison: oral glycerol phenylbutyrate vs placebo

Glycerol phenylbutyrate: $6 \mathrm{~mL}$ twice daily $(\mathrm{n}=90)$

Placebo: identically presented but not specified $(\mathrm{n}=88)$

Duration of treatment: 16 weeks

Co-intervention:

Lactulose use at baseline $(\mathrm{mL} /$ day)

- glycerol phenylbutyrate $\mathrm{n}=72$; median $45(5-266) \mathrm{mL} / \mathrm{day}$

- placebo $\mathrm{n}=65$; median $45(15-160) \mathrm{mL} /$ day

Rifaximin use at baseline (mg/day); participants in the USA were eligible if they had experienced at least 1 of their 2 qualifying episodes of hepatic encephalopathy after $\geq 1$ month rifaximin treatment

- glycerol phenylbutyrate $\mathrm{n}=30$; median 1100 (550-1200) mg/day

- placebo $\mathrm{n}=29$; median 1100 (400-1650) mg/day

- mental status (West Haven Criteria)

- asterixis grade

- venous blood ammonia

Others:

- time to first episode of hepatic encephalopathy

- total number of episodes of hepatic encephalopathy

Outcomes included in meta-analyses

- Mortality

- Hepatic encephalopathy

- Serious adverse events

- Non-serious adverse events

- Venous blood ammonia

- Primary endpoint: the proportion of participants experiencing an episode of hepatic encephalopathy, defined as either the development of West Haven Grade $\geq 2$ change or an increase $\geq 1$ in both the West Haven and asterixis grade, if West Haven Grade 0 at baseline 
- Secondary endpoints: included time to the first episode of hepatic encephalopathy; total episodes of hepatic encephalopathy

- Assessment by caregiver based on the CHESS used as a safety check

- More participants randomised to glycerol phenylbutyrate than placebo where Childs Class C (21 versus 8, respectively)

- Precipitating factors were most commonly listed as unknown or other, followed by dehydration, infection, constipation, excess dietary protein, and use of sedatives

- The treatment effect of glycerol phenylbutyrate was more pronounced in the 119 participants who were not taking rifaximin at entry compared to the 59 who were. However, there was no difference in primary or secondary outcomes between treatment arms in the 59 participants who were taking rifaximin at entry.

- The authors of the trial were contacted for more information regarding the aetiology of participants' cirrhosis; and data relating to quality-of-life and the Number Connection Test results. No reply was received.

Funding:

- Trial sponsored by Hyperion Therapeutics, Inc

\section{Risk of bias}

\begin{tabular}{llll} 
Bias & Authors' judgement & Support for judgement \\
\hline $\begin{array}{l}\text { Random sequence generation (selection } \\
\text { bias) }\end{array}$ & Low risk & $\begin{array}{l}\text { Computer-generated } \\
\text { schedule }\end{array}$ & randomisation \\
\hline Allocation concealment (selection bias) & Low risk & Central allocation \\
\hline
\end{tabular}

Blinding of participants and personnel Low risk (performance bias)

All outcomes

All trial personnel, participants and caregivers were blinded to treatment group assignment

Blinding of outcome assessment (detection Low risk bias)

Non-mortality outcomes

The primary efficacy measure was adjudicated by the blinded investigators during the study and analysed after unblinding

Incomplete outcome data (attrition bias) Unclear risk All outcomes

No missing outcome data. However, more participants randomised to glycerol phenylbutyrate exited the study before completion than participants receiving placebo

Selective reporting (reporting bias) Low risk

All clinically relevant outcomes were reported.

\begin{tabular}{lll}
\hline Other bias & Low risk & None \\
\hline
\end{tabular}

Overall assessment

High risk

Non-mortality outcomes

Pharmacotherapies that specifically target ammonia for the prevention and treatment of hepatic encephalopathy in adults with cirrhosis 

mum of 12 h of 'standard care' $(\mathrm{n}=231)$

Age: not reported

Proportion of men: USA 59\%; elsewhere 72\%

Aetiology of liver disease: not reported

MELD score (mean): USA 20; elsewhere 18

- clinical improvement in hepatic encephalopathy symptoms assessed with HESA; no details provided

- venous blood ammonia

- median time to improvement

- time to normal plasma ammonia levels

- reduction in plasma ammonia levels

- correlation of ammonia levels with clinical improvement

- Venous blood ammonia

- No extractable data are available in the abstracts for the primary end-points.

- Differences, some of them significant, were observed between participants 
STOP-HE 2017 (Continued)

enrolled in the USA $(n=130)$ and elsewhere $(n=101)$ in baseline characteristics, the severity of the underlying liver disease, the precipitant factors and use of additional anti-encephalopathy treatments

Funding:

- Trial sponsored by Ocera Therapeutics Inc

Risk of bias

\begin{tabular}{|c|c|c|}
\hline Bias & Authors' judgement & Support for judgement \\
\hline $\begin{array}{l}\text { Random sequence generation (selection } \\
\text { bias) }\end{array}$ & Low risk & $\begin{array}{l}\text { Computer-generated randomisation } \\
\text { schedule }\end{array}$ \\
\hline Allocation concealment (selection bias) & Low risk & Central allocation \\
\hline $\begin{array}{l}\text { Blinding of participants and personnel } \\
\text { (performance bias) } \\
\text { All outcomes }\end{array}$ & Low risk & $\begin{array}{l}\text { Participants, care providers, investigators } \\
\text { and outcomes assessors were blinded }\end{array}$ \\
\hline $\begin{array}{l}\text { Blinding of outcome assessment (detection } \\
\text { bias) } \\
\text { Non-mortality outcomes }\end{array}$ & Low risk & $\begin{array}{l}\text { Participants, care providers, investigators } \\
\text { and outcomes assessors were blinded }\end{array}$ \\
\hline $\begin{array}{l}\text { Incomplete outcome data (attrition bias) } \\
\text { All outcomes }\end{array}$ & Low risk & $\begin{array}{l}\text { No missing outcome data. All participants } \\
\text { were included in the analyses }\end{array}$ \\
\hline Selective reporting (reporting bias) & High risk & $\begin{array}{l}\text { The primary end-point in the registered } \\
\text { trial protocol is 'change from baseline in } \\
\text { hepatic encephalopathy stage'. However, in } \\
\text { the published abstracts the primary end- } \\
\text { point reported is 'the time to meaningful } \\
\text { clinical improvement in hepatic encephalopa- } \\
\text { thy symptoms assessed using the Hepatic En- } \\
\text { cephalopathy Staging Tool together with a } \\
\text { number of other time-related variables. }\end{array}$ \\
\hline Other bias & High risk & $\begin{array}{l}\text { Differences were reported for a number of } \\
\text { variables in participants recruited in the } \\
\text { USA and those recruited elsewhere in the } \\
\text { world, which is an additional source of bias }\end{array}$ \\
\hline $\begin{array}{l}\text { Overall assessment } \\
\text { Non-mortality outcomes }\end{array}$ & High risk & \\
\hline $\begin{array}{l}\text { Overall assessment } \\
\text { Mortality outcomes }\end{array}$ & High risk & \\
\hline
\end{tabular}




\section{Methods}

Participants
Ornithine phenylacetate (OCR-002): two-centre, double-blind, placebo-controlled, randomised clinical trial

Included participants: cirrhosis, enrolled within $24 \mathrm{~h}$ of an upper gastrointestinal bleed $(\mathrm{n}=38)$. Three people in each group had hepatic encephalopathy at the time of randomisation

Age $($ mean $\pm \mathrm{SD})$ :

- ornithine phenylacetate group $55 \pm 10$ years

- placebo group $56 \pm 11$ years

Proportion of men:

- ornithine phenylacetate group $70 \%$

- placebo group $66 \%$

Aetiology of liver disease (ornithine phenylacetate: placebo group):

- alcohol 70\%: $44.4 \%$

- hepatitis $\mathrm{C}$ virus 5\%: $33.3 \%$

- hepatitis $\mathrm{C}$ virus and alcohol $10 \%: 5.6 \%$

- others 15\%: $16.7 \%$

MELD score (mean \pm SD):

- ornithine phenylacetate group $11.6 \pm 4.4$

- placebo group $12.2 \pm 3.9$
Intervention comparison: ornithine phenylacetate vs placebo

Ornithine phenylacetate: $10 \mathrm{~g} /$ day by continuous IV infusion at a rate of $0.416 \mathrm{~g} / \mathrm{h}$ (n $=20$ )

Placebo: identically presented glucose-saline solution by continuous IV infusion $(\mathrm{n}=$ 18)

Duration of treatment: 5 days

Co-intervention: all participants received standard care which included:

- IV ceftriaxone $1 \mathrm{~g} /$ day

- lactulose initially given as an enema 12 hourly; then orally, adjusted to produce 2

- 3 bowel movements/day

\section{Outcomes}

\section{Neurocognitive assessment:}

- hepatic encephalopathy, measured using the West Haven Criteria, and CHESS

- venous blood ammonia at $24 \mathrm{~h}$ (primary measure), and at any time-point (secondary outcome)

\section{Others:}

- pharmacokinetic profiles of the drug and its metabolites

- safety and tolerability of the drug

- bacterial infections during treatment

Outcomes included in meta-analyses

- Mortality

- Hepatic encephalopathy

- Serious adverse events

- Non-serious adverse events 


Publication status: full paper
- This trial was designed primarily to assess the efficacy of ornithine phenylacetate
as an ammonia-lowering agent versus placebo in people with cirrhosis after an upper
gastrointestinal bleed. The primary outcome was the decrease in venous plasma
ammonia at $24 \mathrm{~h}$.
- The trial authors were contacted for more information regarding changes in
participants' blood ammonia concentrations during the time course of the study but
these data were not retrievable.
Funding:
- Trial sponsored by Ocera Therapeutics Inc

Risk of bias

\begin{tabular}{|c|c|c|}
\hline Bias & Authors' judgement & Support for judgement \\
\hline $\begin{array}{l}\text { Random sequence generation (selection } \\
\text { bias) }\end{array}$ & Low risk & Computer-generated randomisation \\
\hline Allocation concealment (selection bias) & Low risk & $\begin{array}{l}\text { Correspondence with the trial authors con- } \\
\text { firmed the use of sealed envelopes }\end{array}$ \\
\hline $\begin{array}{l}\text { Blinding of participants and personnel } \\
\text { (performance bias) } \\
\text { All outcomes }\end{array}$ & Low risk & $\begin{array}{l}\text { Participants and investigators were blinded. } \\
\text { The pharmacy department prepared the in- } \\
\text { fusion solutions independently }\end{array}$ \\
\hline $\begin{array}{l}\text { Blinding of outcome assessment (detection } \\
\text { bias) } \\
\text { Non-mortality outcomes }\end{array}$ & Low risk & $\begin{array}{l}\text { Data were independently monitored by a } \\
\text { separate institution. A data-blind review } \\
\text { was conducted before locking the trial } \\
\text { database }\end{array}$ \\
\hline $\begin{array}{l}\text { Incomplete outcome data (attrition bias) } \\
\text { All outcomes }\end{array}$ & Low risk & $\begin{array}{l}\text { Correspondence with the trial authors con- } \\
\text { firmed use of ITT analyses }\end{array}$ \\
\hline Selective reporting (reporting bias) & Low risk & All pre-defined outcomes were reported. \\
\hline Other bias & Low risk & None identified \\
\hline $\begin{array}{l}\text { Overall assessment } \\
\text { Non-mortality outcomes }\end{array}$ & Low risk & \\
\hline $\begin{array}{l}\text { Overall assessment } \\
\text { Mortality outcomes }\end{array}$ & Low risk & \\
\hline
\end{tabular}


Methods
AST-120 (spherical carbon absorbant): multicentre, double-blind, placebo-controlled, dose-ranging, randomised clinical trial

Included participants: compensated cirrhosis (MELD score < 25) and covert hepatic encephalopathy (minimal and Grade 1) $(\mathrm{n}=148)$

Age (mean): 55 years

Proportion of men: not reported

Aetiology of liver disease:

- alcohol: not reported

- hepatitis C virus: $53 \%$

MELD score (mean): 10
Interventions
Intervention comparison: oral AST-120 vs placebo

AST-120: $6 \mathrm{~g} /$ day $(\mathrm{n}=50), 12 \mathrm{~g} /$ day $(\mathrm{n}=50)$

Placebo: no details provided $(\mathrm{n}=48)$

Duration of treatment: 8 weeks

Co-intervention: none reported

\begin{tabular}{|c|c|}
\hline Outcomes & $\begin{array}{l}\text { Neurocognitive assessment: } \\
\text { - West Haven Criteria } \\
\text { - RBANS } \\
\text { - PHES battery } \\
\text { - clinical global assessment of hepatic encephalopathy } \\
\text { - venous blood ammonia }\end{array}$ \\
\hline Inclusion period & March 2009-June 2010 \\
\hline Country of origin & USA \\
\hline Outcomes included in meta-analyses & $\begin{array}{l}\text { - Mortality } \\
\text { - Venous blood ammonia }\end{array}$ \\
\hline Notes & $\begin{array}{l}\text { Publication status: abstract; unpublished information about trial methods (randomi- } \\
\text { sation) received from the trial authors } \\
\text { - The primary endpoint was neurocognitive improvement, defined as a change in } \\
\text { global RBANS at } 8 \text {-weeks compared to baseline. } \\
\text { - The trial report does not describe the number of participants with an overall } \\
\text { improvement in neurocognitive status. We were therefore unable to include the trial in } \\
\text { our meta-analysis of this outcome. } \\
\text { - The trial report does not describe whether adverse events were classified as serious } \\
\text { or non-serious. We were therefore unable to include the trial in our meta-analysis of } \\
\text { this outcome. } \\
\text { - The authors have stated that the results were confounded by the study design, } \\
\text { which allowed for an improvement in neurocognitive measures before drug } \\
\text { randomisation. } \\
\text { - We included data from the group receiving the highest dose of AST-120 in the } \\
\text { analysis of blood ammonia changes. } \\
\text { Funding: } \\
\text { - Trial sponsored by Ocera Therapeutic Inc }\end{array}$ \\
\hline
\end{tabular}

Pharmacotherapies that specifically target ammonia for the prevention and treatment of hepatic encephalopathy in adults with cirrhosis 
Bajaj 2013 (Continued)

\section{Risk of bias}

\begin{tabular}{l|ll}
\hline Bias & Authors' judgement & Support for judgement \\
\hline $\begin{array}{l}\text { Random sequence generation (selection } \\
\text { bias) }\end{array}$ & Low risk & Computer-generated randomisation \\
\hline Allocation concealment (selection bias) & Low risk & Central allocation \\
\hline
\end{tabular}

Blinding of participants and personnel Low risk (performance bias)

Blinding of participants and personnel using placebo

All outcomes

Blinding of outcome assessment (detection Low risk bias)

Non-mortality outcomes

Blinding of outcome assessment using placebo

Incomplete outcome data (attrition bias) Low risk

All outcomes

All participants were accounted for and included in the analyses

Selective reporting (reporting bias) Low risk

Clinically relevant outcomes were reported. Outcomes in the published abstract correspond with the published protocol

\begin{tabular}{|c|c|}
\hline Other bias & Low risk \\
\hline
\end{tabular}

Overall assessment

Low risk

Non-mortality outcomes

Overall assessment

Low risk

Mortality outcomes

Pockros 2009

Methods

Participants
AST-120 (spherical carbon absorbant): multicentre, open-label, clinical trial

Included participants: cirrhosis (MELD score $\leq 15)$ and hepatic encephalopathy Grades 1 or 2 using West Haven Criteria $(n=47)$

Age: not reported

Proportion of men: not reported

Aetiology of liver disease: not reported

MELD score: not reported

Interventions

Intervention comparison: oral AST-120 vs lactulose

AST-120: $2 \mathrm{~g} 4$ times/day $(\mathrm{n}=24)$

Lactulose: no details reported $(\mathrm{n}=23)$

Duration of treatment: 4 weeks

Co-intervention: some participants were taking lactulose on admission: this was stopped

Pharmacotherapies that specifically target ammonia for the prevention and treatment of hepatic encephalopathy in adults with cirrhosis $\mathbf{5 0}$

(Review)

Copyright (c) 2019 The Cochrane Collaboration. Published by John Wiley \& Sons, Ltd. 
Pockros 2009 (Continued)

in the participants randomised to AST-120

\begin{tabular}{|c|c|}
\hline Outcomes & $\begin{array}{l}\text { Neurocognitive assessment: } \\
\text { - mental status (West Haven Criteria) } \\
\text { - HESA } \\
\text { - venous blood ammonia }\end{array}$ \\
\hline Inclusion period & September 2007 - June 2009 \\
\hline Country of origin & USA \\
\hline Outcomes included in meta-analyses & $\begin{array}{l}\text { - Mortality } \\
\text { - Hepatic encephalopathy } \\
\text { - Venous blood ammonia }\end{array}$ \\
\hline Notes & $\begin{array}{l}\text { Publication status: abstract } \\
\text { - Participants were classified using West Haven Criteria as Grade } 1 \text { or } 2 \text { hepatic } \\
\text { encephalopathy but, based on the HESA score, were predominantly Grade } 0 \text {. } \\
\text { - The trial report describes non-serious adverse events including diarrhoea and } \\
\text { flatulence, but does not provide the number or proportion of participants affected. } \\
\text { - The trial authors provided further information regarding random sequence } \\
\text { generation. } \\
\text { Funding: } \\
\text { - Trial sponsored by Ocera Therapeutic Inc }\end{array}$ \\
\hline
\end{tabular}

Risk of bias

\begin{tabular}{l|l|l}
\hline Bias & Authors' judgement & Support for judgement \\
\hline $\begin{array}{l}\text { Random sequence generation (selection } \\
\text { bias) }\end{array}$ & Low risk & Computer-generated random numbers \\
\hline $\begin{array}{l}\text { Allocation concealment (selection bias) } \\
\text { Blinding of participants and personnel } \\
\text { (performance bias) } \\
\text { All outcomes }\end{array}$ & Low risk & Central allocation \\
\hline $\begin{array}{l}\text { Blinding of outcome assessment (detection } \\
\text { bias) } \\
\text { Non-mortality outcomes }\end{array}$ & High risk & Open-label trial without blinding \\
\hline $\begin{array}{l}\text { Incomplete outcome data (attrition bias) } \\
\text { All outcomes }\end{array}$ & High risk & Open-label trial without blinding \\
\hline
\end{tabular}

Pharmacotherapies that specifically target ammonia for the prevention and treatment of hepatic encephalopathy in adults with cirrhosis 
Pockros 2009 (Continued)

\begin{tabular}{l|l|l}
\hline Selective reporting (reporting bias) & Low risk & $\begin{array}{l}\text { The outcomes reported in the published } \\
\text { abstract correspond to the outcomes listed } \\
\text { in the trial protocol }\end{array}$ \\
\hline $\begin{array}{l}\text { Other bias } \\
\begin{array}{l}\text { Overall assessment } \\
\text { Non-mortality outcomes }\end{array}\end{array}$ & Low risk & None identified \\
\hline $\begin{array}{l}\text { Overall assessment } \\
\text { Mortality outcomes }\end{array}$ & High risk & \\
\hline
\end{tabular}

Naderian 2017

\begin{tabular}{|c|c|}
\hline Methods & PEG: single-centre, double-blind, randomised clinical trial \\
\hline Participants & $\begin{array}{l}\text { Included participants: cirrhosis with an acute episode of overt hepatic encephalopathy } \\
\text { (n = } 40 \text { ) } \\
\text { Age (mean } \pm \text { SD): } \\
\text { - PEG group } 53.6 \pm 11.6 \text { years } \\
\text { - lactulose group } 59.6 \pm 9.2 \text { years } \\
\text { Proportion of men: } \\
\text { - PEG group } 76 \% \\
\text { - lactulose group } 58 \% \\
\text { Aetiology of liver disease (PEG: lactulose group): } \\
\text { - alcohol } 4.8 \%: 5.3 \% \\
\text { - cryptogenic } 23.8 \%: 31.6 \% \\
\text { - hepatitis B } 28.6 \%: 31.6 \% \\
\text { - hepatitis C } 23.8 \%: 21.1 \% \\
\text { - non-alcoholic steatohepatitis } 4.8 \%: 5.3 \% \\
\text { - portal thrombosis } 9.5 \%: 0 \% \\
\text { - primary sclerosing cholangitis } 4.8 \%: 0 \% \\
\text { MELD score (median } \pm \text { interquartile range): } \\
\text { - PEG group } 17.5 \pm 15 \\
\text { - lactulose group } 17.5 \pm 6\end{array}$ \\
\hline
\end{tabular}

Interventions

Intervention comparison: $\mathrm{PEG}$ plus lactulose vs lactulose

PEG: 280 g PEG in $4 \mathrm{~L}$ water as a single dose over 30-120 min. In addition lactulose was administered in the same amount enterally or rectally as in the control group ( $\mathrm{n}=$ 21)

Lactulose: $20-30$ g lactulose administered orally or via nasogastric tube (at least 3 doses in $24 \mathrm{~h})$ or $200 \mathrm{~g}$ administered via rectal tube $(\mathrm{n}=19)$

Duration of treatment: $24 \mathrm{~h}$

Co-intervention: none reported

Outcomes

Neurocognitive assessment:

- HESA

- blood ammonia

Pharmacotherapies that specifically target ammonia for the prevention and treatment of hepatic encephalopathy in adults with cirrhosis 
Naderian 2017 (Continued)

\section{Others}

- length of hospitalisation

\begin{tabular}{l|l}
\hline Inclusion period & September 2015 - January 2016 \\
\hline Country of origin & Iran \\
\hline Outcomes included in meta-analyses & $\begin{array}{l}\text { — Mortality } \\
\text { - Hepatic encephalopathy } \\
\text { - Adverse events } \\
\text { - Blood ammonia }\end{array}$ \\
\hline Notes & $\begin{array}{l}\text { Publication status: full paper } \\
\text { — The primary end-point was improvement in at least 1 grade on the HESA at } 24 \mathrm{~h} \\
\text { - The trial authors were contacted for more details regarding blinding of } \\
\text { participants and personnel - the required information was provided. } \\
\text { Funding: } \\
\text { — No funding from industry }\end{array}$ \\
\hline
\end{tabular}

Risk of bias

\begin{tabular}{|c|c|c|}
\hline Bias & Authors' judgement & Support for judgement \\
\hline $\begin{array}{l}\text { Random sequence generation (selection } \\
\text { bias) }\end{array}$ & Low risk & $\begin{array}{l}\text { Computer-generated, block randomisa- } \\
\text { tion (block size } 6 \text { participants) }\end{array}$ \\
\hline Allocation concealment (selection bias) & Low risk & $\begin{array}{l}\text { One team member was responsible for pre- } \\
\text { scribing the trial drugs, while assessment } \\
\text { of HESA scores at presentation and at } 24 \\
\mathrm{~h} \text { were done by another team member } \\
\text { blinded to the allocation }\end{array}$ \\
\hline $\begin{array}{l}\text { Blinding of participants and personnel } \\
\text { (performance bias) } \\
\text { All outcomes }\end{array}$ & Low risk & $\begin{array}{l}\text { Participants were blinded. The statistica } \\
\text { analysis was undertaken by a blinded ana- } \\
\text { lyst }\end{array}$ \\
\hline $\begin{array}{l}\text { Blinding of outcome assessment (detection } \\
\text { bias) } \\
\text { Non-mortality outcomes }\end{array}$ & Low risk & $\begin{array}{l}\text { Outcome assessors were independent from } \\
\text { the people who prescribed the study drugs }\end{array}$ \\
\hline $\begin{array}{l}\text { Incomplete outcome data (attrition bias) } \\
\text { All outcomes }\end{array}$ & High risk & $\begin{array}{l}\text { Four of the original } 48 \text { eligible participant } \\
\text { refused consent, while a further } 4 \text { ( } 1 \text { allo- } \\
\text { cated to PEG; } 3 \text { allocated to lactulose) were } \\
\text { excluded from the analyses because they } \\
\text { had received sedative drugs }\end{array}$ \\
\hline Selective reporting (reporting bias) & Low risk & Clinically relevant outcomes are reported. \\
\hline Other bias & Low risk & None identified \\
\hline
\end{tabular}

Pharmacotherapies that specifically target ammonia for the prevention and treatment of hepatic encephalopathy in adults with cirrhosis

(Review)

Copyright @ 2019 The Cochrane Collaboration. Published by John Wiley \& Sons, Ltd. 
Naderian 2017 (Continued)

Overall assessment

High risk

Non-mortality outcomes

Overall assessment High risk

Mortality outcomes

Rahimi 2014

Methods

Participants
PEG: single-centre, open-label, randomised clinical trial. The HELP study

Included participants: cirrhosis and any grade of overt hepatic encephalopathy $(\mathrm{n}=50)$ Age $($ mean $\pm S D)$ :

- PEG group $56 \pm 7$ years

- lactulose group $56 \pm 11$ years

Proportion of men:

- PEG group $64 \%$

- lactulose group $60 \%$

Aetiology of liver disease (PEG, lactulose group):

- alcohol 40\%, 36\%

- cryptogenic $24 \%, 24 \%$

- hepatitis C $32 \%, 36 \%$

- hepatitis B $4 \%, 4 \%$

MELD score (mean $\pm \mathrm{SD})$ :

- PEG group $17 \pm 6$

- lactulose group $17 \pm 5$
Intervention comparison: $\mathrm{PEG}$ vs lactulose

PEG: 3350-electrolyte solution; $4 \mathrm{~L}$ given as a single dose over $4 \mathrm{~h}(\mathrm{n}=25)$

Lactulose: $20-30 \mathrm{~g}$ lactulose administered orally or via nasogastric tube (at least 3 doses in $24 \mathrm{~h})$ or $200 \mathrm{~g}$ administered via rectal tube $(\mathrm{n}=25)$

Duration of treatment: $24 \mathrm{~h}$

Co-intervention: participants were allowed to receive a single dose of lactulose prior to randomisation, and after $24 \mathrm{~h}$ of treatment regardless of their group allocation

\begin{tabular}{l|l}
\hline Outcomes & Neuropsychiatric assessment: \\
& - HESA \\
& blood ammonia at baseline and $24 \mathrm{~h}$ \\
Others: & \\
- & time to resolution of hepatic encephalopathy \\
& overall length of hospitalisation
\end{tabular}

Inclusion period January 2011-June 2012

Country of origin USA

Outcomes included in meta-analyses

- Mortality

- Hepatic encephalopathy

- Serious adverse events 


\begin{tabular}{l}
$\begin{array}{l}\text { - Non-serious events } \\
\text { - Blood ammonia }\end{array}$ \\
\hline Notes \\
$\begin{array}{l}\text { Publication status: full paper } \\
\text { - Baseline blood urea nitrogen concentrations were significantly higher in the } \\
\text { participants randomised to the PEG group. } \\
\text { - One participant in the PEG group received a lactulose enema due to inability to } \\
\text { site the nasogastric tube. One additional participant in the PEG group was discharged } \\
\text { before the study was complete, and one refused to continue. } \\
\text { - The primary end point was an improvement of } 1 \text { or more HESA grade at } 24 \text { h, } \\
\text { Funding: } \\
\text { - No conflicts of interest identified. Funding was received from national grants; } \\
\text { these had no influencing role in the study. }\end{array}$ \\
\hline
\end{tabular}

Risk of bias

\begin{tabular}{|c|c|c|}
\hline Bias & Authors' judgement & Support for judgement \\
\hline $\begin{array}{l}\text { Random sequence generation (selection } \\
\text { bias) }\end{array}$ & Low risk & $\begin{array}{l}\text { Computer-generated number and treat- } \\
\text { ment assignment }\end{array}$ \\
\hline Allocation concealment (selection bias) & Low risk & $\begin{array}{l}\text { Participants' allocation was concealed in } \\
\text { opaque sealed envelopes. In some partic- } \\
\text { ipants one investigator obtained consent, } \\
\text { randomised the participants and ensured } \\
\text { that the appropriate study medication was } \\
\text { administered while the follow-up was un- } \\
\text { dertaken by another investigator }\end{array}$ \\
\hline
\end{tabular}

Blinding of participants and personnel High risk (performance bias)

All outcomes

Blinding of outcome assessment (detection Low risk bias)

Non-mortality outcomes

Incomplete outcome data (attrition bias) High risk All outcomes
Open-label trial

A separate, blinded investigator conducted the assessment of neuropsychological status after randomisation

All analyses were conducted as ITT. Two participants did not achieve the full 24-h follow-up and so data are missing for the assessment of neuropsychological status. One participant in the PEG group did not receive the allocated treatment and so was treated with a lactulose enema. Two participants in the PEG group did not have follow-up HESA scores; of these one became alert and oriented and refused assessment while the other improved to point of discharge home in less than $24 \mathrm{~h}$. Conse- 
Rahimi 2014

(Continued)

\begin{tabular}{l|l|l} 
& & $\begin{array}{l}\text { quently, these two participants were not in- } \\
\text { cluded in either the initial or 24-h analysis }\end{array}$ \\
\hline Selective reporting (reporting bias) & Low risk & $\begin{array}{l}\text { All pre-defined outcomes were reported. } \\
\text { However, non-serious adverse events were } \\
\text { not extractable }\end{array}$ \\
\hline Other bias & High risk & $\begin{array}{l}\text { The blood urea nitrogen level was sig- } \\
\text { nificantly higher in the participants ran- } \\
\text { domised to PEG }\end{array}$ \\
\hline
\end{tabular}

Overall assessment

High risk

Non-mortality outcomes

Overall assessment

High risk

Mortality outcomes

Shehata 2018

Methods

Participants
PEG: single-centre, open label, randomised clinical trial

Included participants: people admitted with cirrhosis and an acute episode of overt hepatic encephalopathy $(\mathrm{n}=100)$

Age $($ mean $\pm \mathrm{SD})$ :

- PEG group $56.4 \pm 8.6$ years

- lactulose group $54.5 \pm 11.8$ years

Proportion of men:

- PEG group $44 \%$

- lactulose group $60 \%$

Aetiology of liver disease: all participants had hepatitis C-related cirrhosis

Interventions

PEG: single dose (3 sachets if participant $<75 \mathrm{~kg}$ or 4 sachets if participant $>75 \mathrm{~kg}$ ) administered orally over 3-4 h or via a nasogastric tube at a rate of $20-30 \mathrm{~mL} / \mathrm{min}$. Each sachet contained $64 \mathrm{~g}$ PEG dissolved in $1 \mathrm{~L}$ tap water

Lactulose: $20-30 \mathrm{~mL}$ lactulose orally or via nasogastric tube, given as 3 doses over $24 \mathrm{~h}$. $200 \mathrm{~mL}$ lactulose and plain water also given as a retention enema every $4 \mathrm{~h}$

Outcomes

Primary: at least 1 scale improvement in the HESA score after $24 \mathrm{~h}$

Secondary: length of hospital stay, adverse events

May-December 2017

Inclusion period

Egypt

- Mortality

- Hepatic encephalopathy

- Adverse events 


\begin{tabular}{|c|c|c|}
\hline Notes & \multicolumn{2}{|c|}{$\begin{array}{l}\text { Publication status: full paper } \\
\text { - The registered trial number cited in the published paper is incorrect; the corrected } \\
\text { number, later provided by the trial authors, is NCT03100513. The study was } \\
\text { completed } 18 \text { months earlier than anticipated, although it is still registered as } \\
\text { 'recruiting'. } \\
\text { Funding: } \\
\text { - No funding from industry }\end{array}$} \\
\hline \multicolumn{3}{|l|}{ Risk of bias } \\
\hline Bias & Authors' judgement & Support for judgement \\
\hline $\begin{array}{l}\text { Random sequence generation (selection } \\
\text { bias) }\end{array}$ & Low risk & $\begin{array}{l}\text { Computer-generated block randomisation } \\
\text { (block size } 10 \text { participants) }\end{array}$ \\
\hline Allocation concealment (selection bias) & Low risk & $\begin{array}{l}\text { Participant allocation was in opaque, sealed } \\
\text { envelopes }\end{array}$ \\
\hline $\begin{array}{l}\text { Blinding of participants and personnel } \\
\text { (performance bias) } \\
\text { All outcomes }\end{array}$ & High risk & $\begin{array}{l}\text { Investigators were blinded to the random } \\
\text { code sequence. Participants and person- } \\
\text { nel administering the treatments were not } \\
\text { blinded }\end{array}$ \\
\hline $\begin{array}{l}\text { Blinding of outcome assessment (detection } \\
\text { bias) } \\
\text { Non-mortality outcomes }\end{array}$ & Low risk & $\begin{array}{l}\text { Participants were identified only by code } \\
\text { numbers }\end{array}$ \\
\hline $\begin{array}{l}\text { Incomplete outcome data (attrition bias) } \\
\text { All outcomes }\end{array}$ & Low risk & $\begin{array}{l}\text { All randomised participants were included } \\
\text { in the analyses. Those lost to follow-up } \\
\text { were evaluated using ITT analyses except } \\
\text { for adverse events }\end{array}$ \\
\hline Selective reporting (reporting bias) & Low risk & $\begin{array}{l}\text { All clinically relevant predefined outcomes } \\
\text { were reported. Changes in blood ammonia } \\
\text { levels were not reported }\end{array}$ \\
\hline Other bias & Low risk & None identified \\
\hline $\begin{array}{l}\text { Overall assessment } \\
\text { Non-mortality outcomes }\end{array}$ & High risk & \\
\hline $\begin{array}{l}\text { Overall assessment } \\
\text { Mortality outcomes }\end{array}$ & High risk & \\
\hline
\end{tabular}

CHESS: Clinical Hepatic Encephalopathy Staging Scale; HESA: Hepatic Encephalopathy Scoring Algorithm; ITT: intention-to-treat; IV: intravenous; MELD: Model for End-stage Liver Disease; PEG: polyethylene glycol; PHES: Psychometric Hepatic Encephalopa- 
thy Score; PSE: Portal-Systemic Encephalopathy; RBANS: Repeatable Battery for the Assessment of Neuropsychological Status; SD: standard deviation

\section{Characteristics of excluded studies [author-defined order]}

\begin{tabular}{ll}
\hline Study & Reason for exclusion \\
\hline Campollo 1992 & $\begin{array}{l}\text { Sodium benzoate: } 18 \text { participants with cirrhosis and chronic persistent hepatic encephalopathy were treated for } \\
6 \text { months with oral sodium benzoate in a mean dose of } 6.4 \text { g/day given as an } 8 \% \text { solution } \\
\text { We excluded this study as it was observational. }\end{array}$ \\
\hline Mendenhall 1986 & $\begin{array}{l}\text { Sodium benzoate: double-blind, cross-over, randomised clinical trial, undertaken in } 8 \text { participants with overt } \\
\text { hepatic encephalopathy allocated to oral sodium benzoate or sodium phenylacetate } \\
\text { We excluded this trial because it compared sodium benzoate with another ammonia-lowering agent }\end{array}$ \\
\hline Panella 1993 & $\begin{array}{l}\text { Sodium benzoate: double-blind, cross-over, randomised clinical trial undertaken in } 7 \text { participants with cirrhosis } \\
\text { and stable Grade } 1-2 \text { hepatic encephalopathy randomised to sodium benzoate or placebo as an adjuvant to } \\
\text { treatment with branched chain amino acids; participants were crossed over to the alternative arm after } 7 \text { days. } \\
\text { Lactulose and the antibiotic Colimicin were added to standard treatment but it is unclear whether this was } \\
\text { provided equally in both groups. Participants receiving adjuvant sodium benzoate showed a significant reduction } \\
\text { in blood ammonia levels compared to the group receiving placebo and a trend to a greater reduction in Number } \\
\text { Connection Test times and the PSE Index } \\
\text { We excluded this trial as it was not a direct comparison of the drug of interest against either placebo or another } \\
\text { active agent }\end{array}$ \\
\hline
\end{tabular}

Ghabril 2013 Glycerol phenylbutyrate: open-label, phase IIa study designed to evaluate the safety, tolerability and effect on blood ammonia concentrations of 2 doses of glycerol phenylbutyrate in 15 participants with cirrhosis and a history of at at least 2 previous episodes of overt hepatic encephalopathy

We excluded this trial as it was observational.

Weiss 2018 Sodium phenylbutyrate: 18 participants with cirrhosis, overt hepatic encephalopathy and hyperammonaemia admitted to an ICU were given sodium phenylbutyrate $200 \mathrm{mg} / \mathrm{kg} /$ day orally or via a nasogastric tube until blood ammonia levels returned to normal on 2 consecutive occasions or until neurological status improved. Other treatments such as lactulose or rifaximin, were maintained if prescribed before inclusion. The results in this group were compared with those in an historical control group (matched for age, sex, MELD score, and severity of hepatic encephalopathy using West Haven Criteria), managed in the same unit, using the same guidelines We excluded this trial as it was observational.

ICU: intensive care unit; MELD: Model for End-stage Liver Disease; PSE: Portal-Systemic Encephalopathy (see Table 2) 


\section{Characteristics of ongoing studies [ordered by study ID]}

\section{NCT00558038}

\begin{tabular}{|c|c|}
\hline Trial name or title & $\begin{array}{l}\text { AST-120 } \\
\text { Randomized trial comparing the efficacy of AST-120 versus lactulose for treatment of mild hepatic en- } \\
\text { cephalopathy }\end{array}$ \\
\hline Methods & Open-label, randomised clinical trial \\
\hline Participants & End-stage liver disease with a MELD score $<16$ and Grade $1-2$ hepatic encephalopathy $(\mathrm{n}=40)$ \\
\hline Interventions & $\begin{array}{l}\text { AST-120: } 2 \mathrm{~g} \text { sachets } 4 \text { times/day } \\
\text { Lactulose: as previously prescribed or started at } 30 \mathrm{~mL} \text { twice and titrated to produce } 2-3 \mathrm{soft} \text { stools/day }\end{array}$ \\
\hline Outcomes & $\begin{array}{l}\text { Primary: change in West Haven grade over } 4 \text { weeks } \\
\text { Secondary: change in the HESA, ammonia levels, serum bile acid and amino acid profiles, itching (visual } \\
\text { analogue scale), asterixis, clinical laboratory tests, clinical examination }\end{array}$ \\
\hline Starting date & September 2007 \\
\hline Contact information & Paul Pockros, Scripps Clinic \\
\hline Country of origin & USA \\
\hline Notes & Phase 2 study; completed on 30 May 2014 \\
\hline
\end{tabular}

\section{NCT03448770}

Trial name or title

PEG:

To compare efficacy and safety of lactulose versus polyethylene glycol for treatment of overt hepatic encephalopathy in cirrhotics; a randomised controlled trial

\begin{tabular}{|c|c|}
\hline Methods & Open-label, randomised clinical trial \\
\hline Participants & Cirrhosis and hepatic encephalopathy of Grade 2 and above $(n=110)$ \\
\hline Interventions & $\begin{array}{l}\text { PEG: } 17 \mathrm{~g} \text { administered orally or via nasogastric tube } 3-4 \text { times/day } \\
\text { Lactulose: } 20-30 \mathrm{~g} \text { lactulose administered orally or via nasogastric tube (at least } 3 \text { doses in } 24 \mathrm{~h} \text { ) or } 200 \mathrm{~g} \\
\text { administered via rectal tube }\end{array}$ \\
\hline Outcomes & $\begin{array}{l}\text { Primary: complete reversal of hepatic encephalopathy (Grade } 0 \text { ) } \\
\text { Secondary: improvement in hepatic encephalopathy by } 2 \text { grades; length of ICU stay; presence of EED } \\
\text { changes; adverse events }\end{array}$ \\
\hline Starting date & 1 August 2017 \\
\hline Contact information & Dr Abhinav Verma, abhinav.3183@gmail.com \\
\hline
\end{tabular}




\section{NCT03448770 (Continued)}

\section{Country of origin India}

Notes

The estimated final data collection date for the primary outcome measure and for study completion was 31 July 2018

EEG: electroencephalogram;HESA: Hepatic Encephalopathy Scoring Algorithm; ICU: intensive care unit; MELD: Model for Endstage Liver Disease; PEG: Polyethylene glycol; 
DATA AND ANALYSES

Comparison 1. Pharmacotherapies that specifically target ammonia versus placebo, lactulose, or lactitol

\begin{tabular}{|c|c|c|c|c|}
\hline Outcome or subgroup title & $\begin{array}{l}\text { No. of } \\
\text { studies }\end{array}$ & $\begin{array}{c}\text { No. of } \\
\text { participants }\end{array}$ & Statistical method & Effect size \\
\hline 1 Mortality & 11 & & Risk Ratio (IV, Random, 95\% CI) & Subtotals only \\
\hline $\begin{array}{l}\text { 1.1 Sodium benzoate versus } \\
\text { placebo }\end{array}$ & 1 & 16 & Risk Ratio (IV, Random, 95\% CI) & $0.0[0.0,0.0]$ \\
\hline $\begin{array}{l}\text { 1.2 Sodium benzoate versus } \\
\text { lactulose/lactitol }\end{array}$ & 2 & 101 & Risk Ratio (IV, Random, 95\% CI) & $1.26[0.49,3.28]$ \\
\hline $\begin{array}{l}1.3 \text { Glycerol phenylbutyrate } \\
\text { versus placebo }\end{array}$ & 1 & 178 & Risk Ratio (IV, Random, 95\% CI) & $0.65[0.11,3.81]$ \\
\hline $\begin{array}{l}1.4 \text { Ornithine phenylacetate } \\
\text { versus placebo }\end{array}$ & 2 & 269 & Risk Ratio (IV, Random, 95\% CI) & $0.73[0.35,1.51]$ \\
\hline 1.5 AST-120 versus placebo & 1 & 148 & Risk Ratio (IV, Random, 95\% CI) & $0.0[0.0,0.0]$ \\
\hline 1.6 AST-120 versus lactulose & 1 & 41 & Risk Ratio (IV, Random, 95\% CI) & $1.05[0.59,1.85]$ \\
\hline $\begin{array}{l}1.7 \text { Polyethylene glycol versus } \\
\text { lactulose }\end{array}$ & 3 & 190 & Risk Ratio (IV, Random, 95\% CI) & $0.5[0.09,2.64]$ \\
\hline 2 Hepatic encephalopathy & 7 & & Risk Ratio (IV, Random, 95\% CI) & Subtotals only \\
\hline $\begin{array}{l}\text { 2.1 Sodium benzoate versus } \\
\text { lactulose/lactitol }\end{array}$ & 1 & 74 & Risk Ratio (IV, Random, 95\% CI) & $1.22[0.51,2.93]$ \\
\hline $\begin{array}{l}2.2 \text { Glycerol phenylbutyrate } \\
\text { versus placebo }\end{array}$ & 1 & 178 & Risk Ratio (IV, Random, 95\% CI) & $0.57[0.36,0.90]$ \\
\hline $\begin{array}{l}2.3 \text { Ornithine phenylacetate } \\
\text { versus placebo }\end{array}$ & 1 & 38 & Risk Ratio (IV, Random, 95\% CI) & $2.71[0.12,62.70]$ \\
\hline 2.4 AST-120 versus lactulose & 1 & 41 & Risk Ratio (IV, Random, 95\% CI) & $1.05[0.59,1.85]$ \\
\hline $\begin{array}{l}2.5 \text { Polyethylene glycol versus } \\
\text { lactulose }\end{array}$ & 3 & 190 & Risk Ratio (IV, Random, 95\% CI) & $0.19[0.08,0.44]$ \\
\hline 3 Serious adverse events & 10 & & Risk Ratio (IV, Random, 95\% CI) & Subtotals only \\
\hline $\begin{array}{l}3.1 \text { Sodium benzoate versus } \\
\text { placebo }\end{array}$ & 1 & 16 & Risk Ratio (IV, Random, 95\% CI) & $0.0[0.0,0.0]$ \\
\hline $\begin{array}{l}3.2 \text { Sodium benzoate versus } \\
\text { lactulose/lactitol }\end{array}$ & 2 & 101 & Risk Ratio (IV, Random, 95\% CI) & $1.08[0.44,2.68]$ \\
\hline $\begin{array}{l}3.3 \text { Glycerol phenylbutyrate } \\
\text { versus placebo }\end{array}$ & 1 & 178 & Risk Ratio (IV, Random, 95\% CI) & $1.63[0.85,3.13]$ \\
\hline $\begin{array}{l}3.4 \text { Ornithine phenylacetate } \\
\text { versus placebo }\end{array}$ & 2 & 264 & Risk Ratio (IV, Random, 95\% CI) & $0.92[0.62,1.36]$ \\
\hline 3.5 AST-120 versus lactulose & 1 & 41 & Risk Ratio (IV, Random, 95\% CI) & $0.0[0.0,0.0]$ \\
\hline $\begin{array}{l}\text { 3.6 Polyethylene glycol versus } \\
\text { lactulose }\end{array}$ & 3 & 190 & Risk Ratio (IV, Random, 95\% CI) & $0.57[0.18,1.82]$ \\
\hline 4 Non-serious adverse events & 8 & & Risk Ratio (IV, Random, 95\% CI) & Subtotals only \\
\hline $\begin{array}{l}\text { 4.1 Sodium benzoate versus } \\
\text { placebo }\end{array}$ & 1 & 16 & Risk Ratio (IV, Random, 95\% CI) & $0.0[0.0,0.0]$ \\
\hline $\begin{array}{l}4.2 \text { Sodium benzoate versus } \\
\text { lactulose/lactitol }\end{array}$ & 2 & 182 & Risk Ratio (IV, Random, 95\% CI) & $1.13[0.96,1.32]$ \\
\hline $\begin{array}{l}4.3 \text { Glycerol phenylbutyrate } \\
\text { versus placebo }\end{array}$ & 1 & 178 & Risk Ratio (IV, Random, 95\% CI) & $1.04[0.88,1.21]$ \\
\hline
\end{tabular}

Pharmacotherapies that specifically target ammonia for the prevention and treatment of hepatic encephalopathy in adults with cirrhosis 61 (Review)

Copyright $\odot 2019$ The Cochrane Collaboration. Published by John Wiley \& Sons, Ltd. 


\begin{tabular}{|c|c|c|c|c|}
\hline $\begin{array}{l}4.4 \text { Ornithine phenylacetate } \\
\text { versus placebo }\end{array}$ & 2 & 269 & Risk Ratio (IV, Random, 95\% CI) & $1.08[0.78,1.51]$ \\
\hline $\begin{array}{l}4.5 \text { Polyethylene glycol versus } \\
\text { lactulose }\end{array}$ & 2 & 137 & Risk Ratio (IV, Random, 95\% CI) & $0.71[0.43,1.18]$ \\
\hline Ammonia & 9 & & Mean Difference (IV, Random, 95\% CI) & Subtotals only \\
\hline $\begin{array}{l}5.1 \text { Sodium benzoate versus } \\
\text { placebo }\end{array}$ & 1 & 16 & Mean Difference (IV, Random, 95\% CI) & $\begin{array}{l}-32.0[-46.85,-17 . \\
15]\end{array}$ \\
\hline $\begin{array}{l}5.2 \text { Sodium benzoate versus } \\
\text { lactulose/lactitol }\end{array}$ & 2 & 85 & Mean Difference (IV, Random, 95\% CI) & $9.00[-1.10,19.11]$ \\
\hline $\begin{array}{l}5.3 \text { Glycerol phenylbutyrate } \\
\text { versus placebo }\end{array}$ & 1 & 178 & Mean Difference (IV, Random, 95\% CI) & $-12.0[-23.37,-0.63]$ \\
\hline $\begin{array}{l}5.4 \text { Ornithine phenylacetate } \\
\text { versus placebo }\end{array}$ & 1 & 231 & Mean Difference (IV, Random, 95\% CI) & $\begin{array}{l}-27.10[-48.55,-5 . \\
65]\end{array}$ \\
\hline 5.5 AST-120 versus placebo & 1 & 98 & Mean Difference (IV, Random, 95\% CI) & $\begin{array}{l}-22.0[-26.75,-17 . \\
25]\end{array}$ \\
\hline 5.6 AST-120 versus lactulose & 1 & 35 & Mean Difference (IV, Random, 95\% CI) & $5.2[-2.75,13.15]$ \\
\hline $\begin{array}{l}5.7 \text { Polyethylene glycol versus } \\
\text { lactulose }\end{array}$ & 2 & 90 & Mean Difference (IV, Random, 95\% CI) & $\begin{array}{l}-29.28[-95.96,37 . \\
39]\end{array}$ \\
\hline
\end{tabular}

\section{Analysis I.I. Comparison I Pharmacotherapies that specifically target ammonia versus placebo, lactulose, or lactitol, Outcome I Mortality.}

Review: Pharmacotherapies that specifically target ammonia for the prevention and treatment of hepatic encephalopathy in adults with cirrhosis

Comparison: I Pharmacotherapies that specifically target ammonia versus placebo, lactulose, or lactitol

Outcome: | Mortality

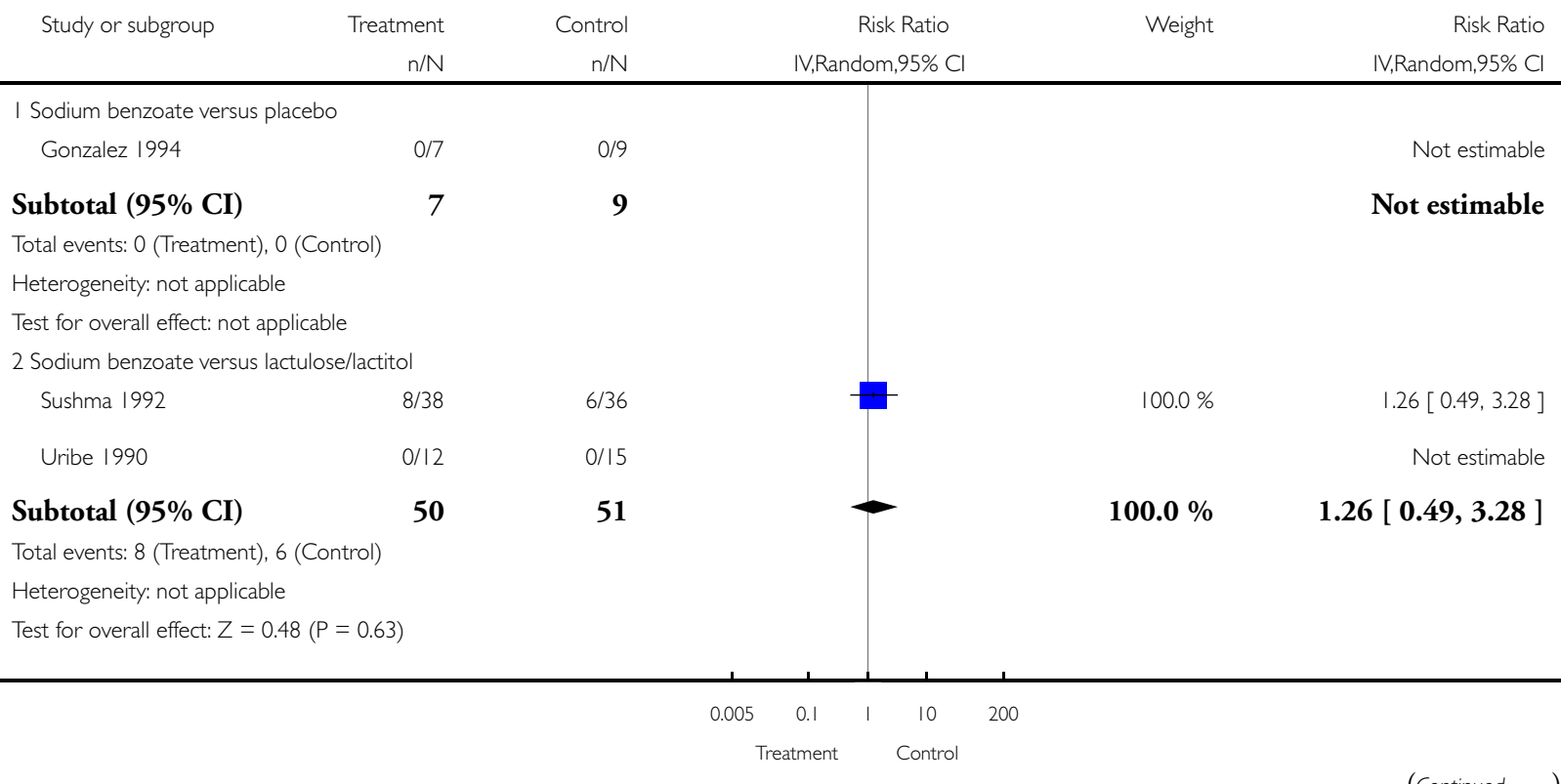

Pharmacotherapies that specifically target ammonia for the prevention and treatment of hepatic encephalopathy in adults with cirrhosis 


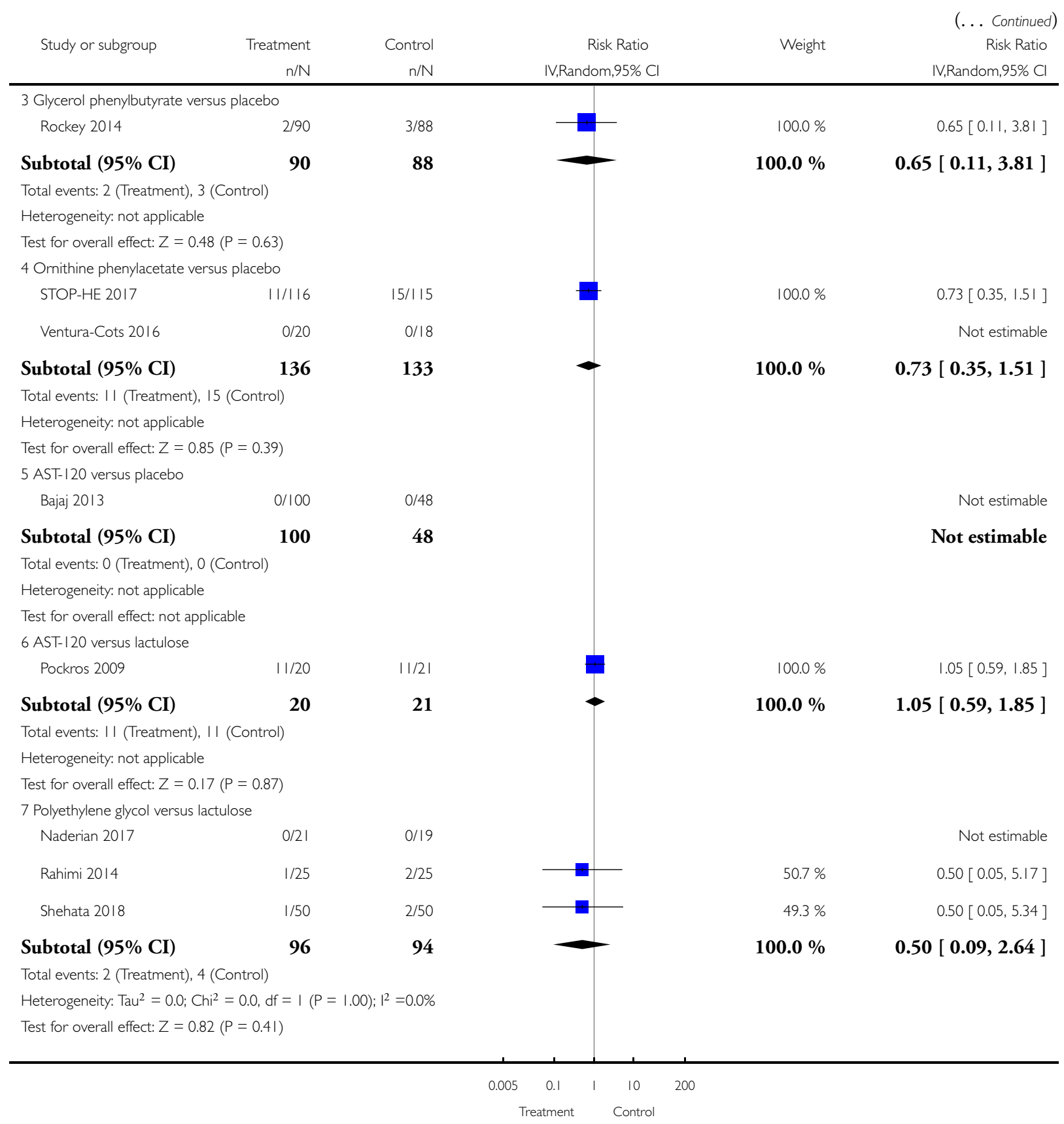


Analysis I.2. Comparison I Pharmacotherapies that specifically target ammonia versus placebo, lactulose, or lactitol, Outcome 2 Hepatic encephalopathy.

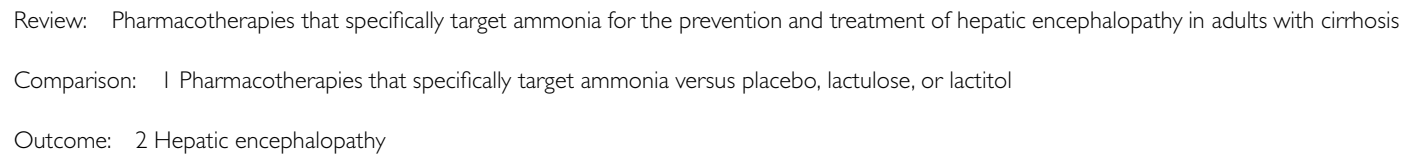


Analysis I.3. Comparison I Pharmacotherapies that specifically target ammonia versus placebo, lactulose, or lactitol, Outcome 3 Serious adverse events.

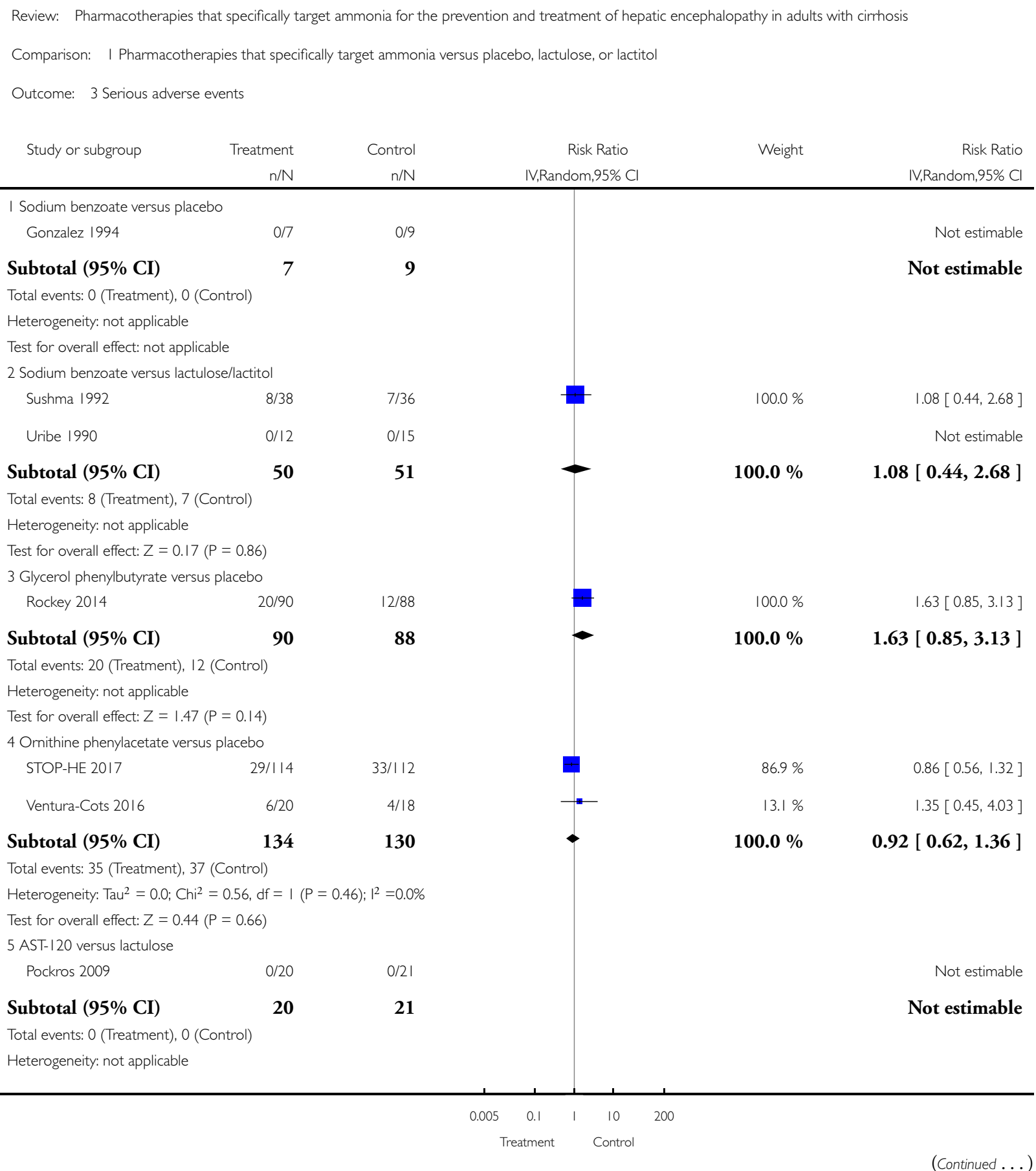




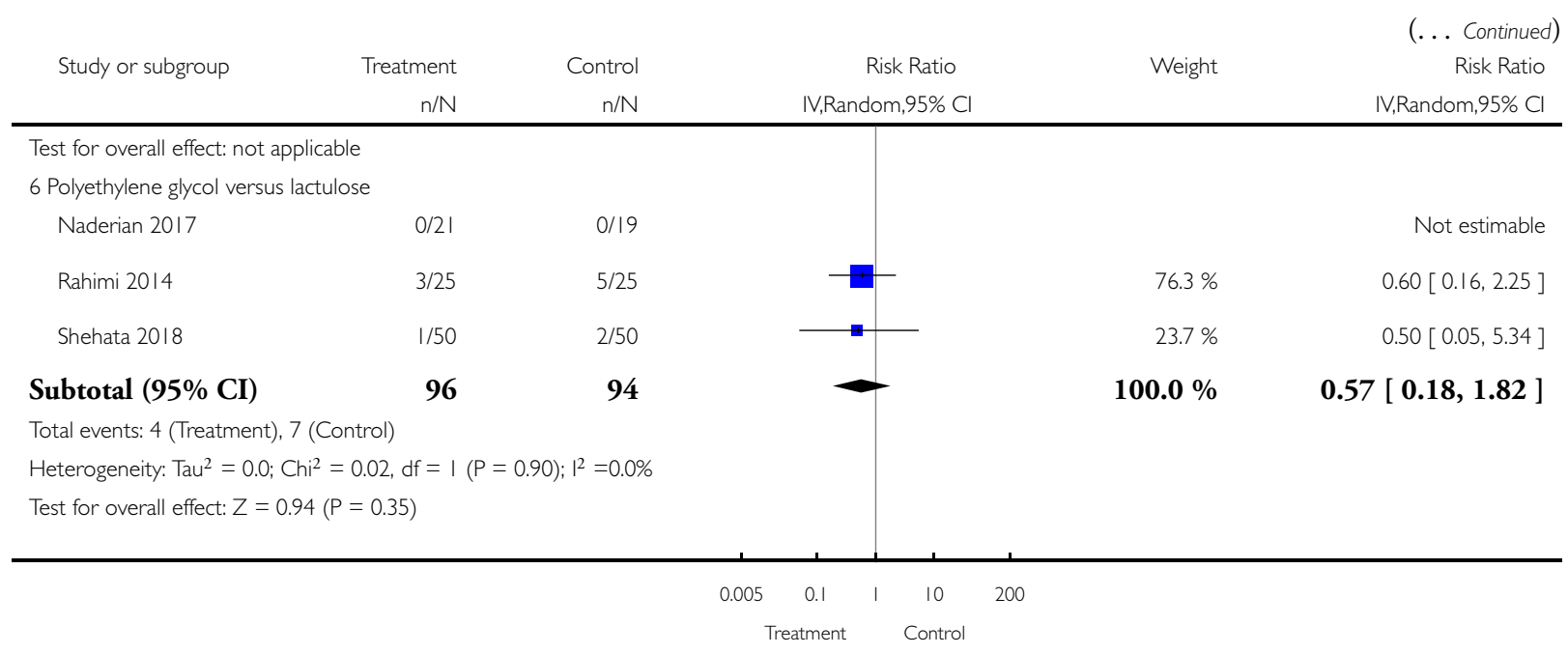

Analysis I.4. Comparison I Pharmacotherapies that specifically target ammonia versus placebo, lactulose, or lactitol, Outcome 4 Non-serious adverse events.

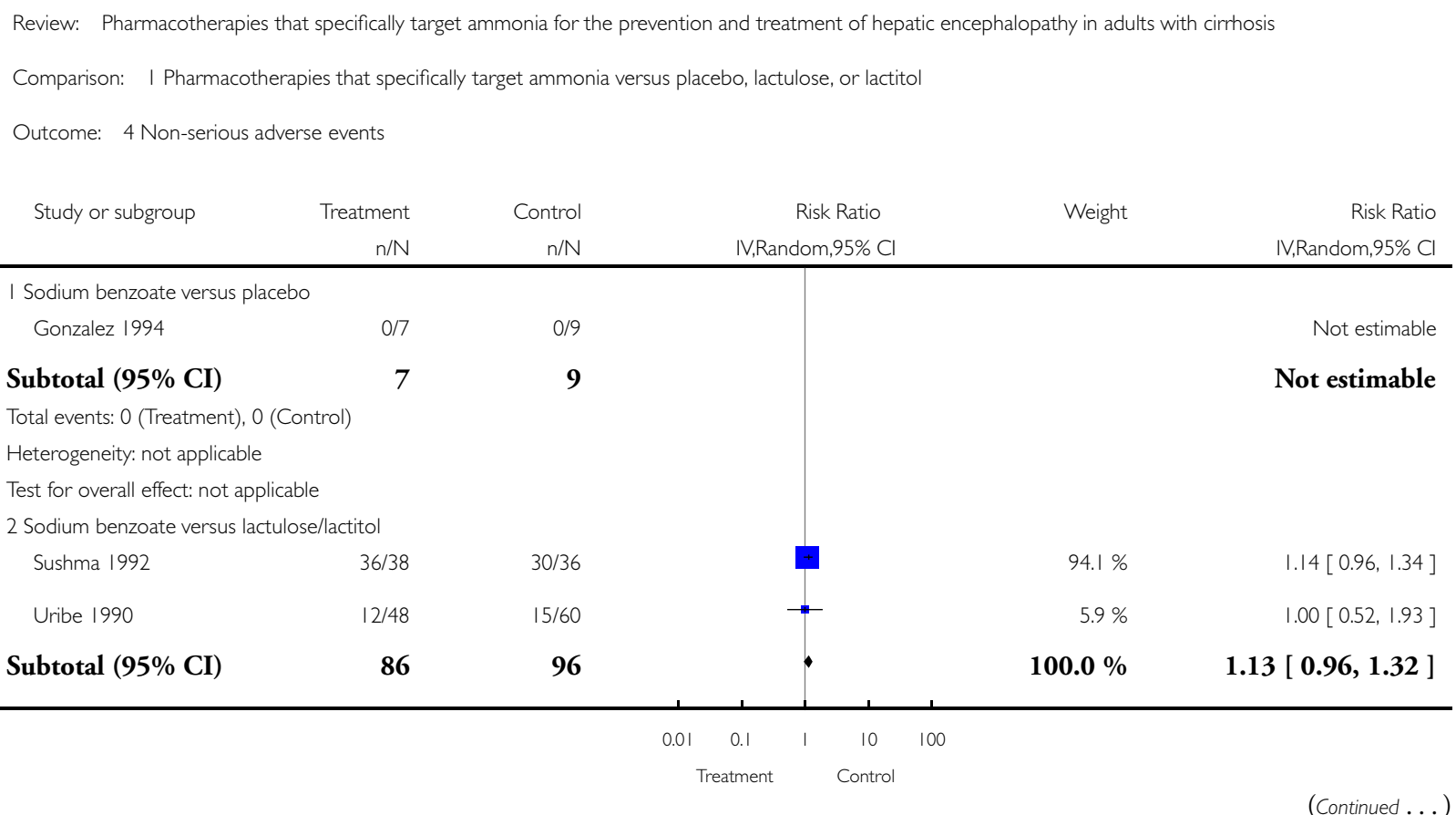

Pharmacotherapies that specifically target ammonia for the prevention and treatment of hepatic encephalopathy in adults with cirrhosis 


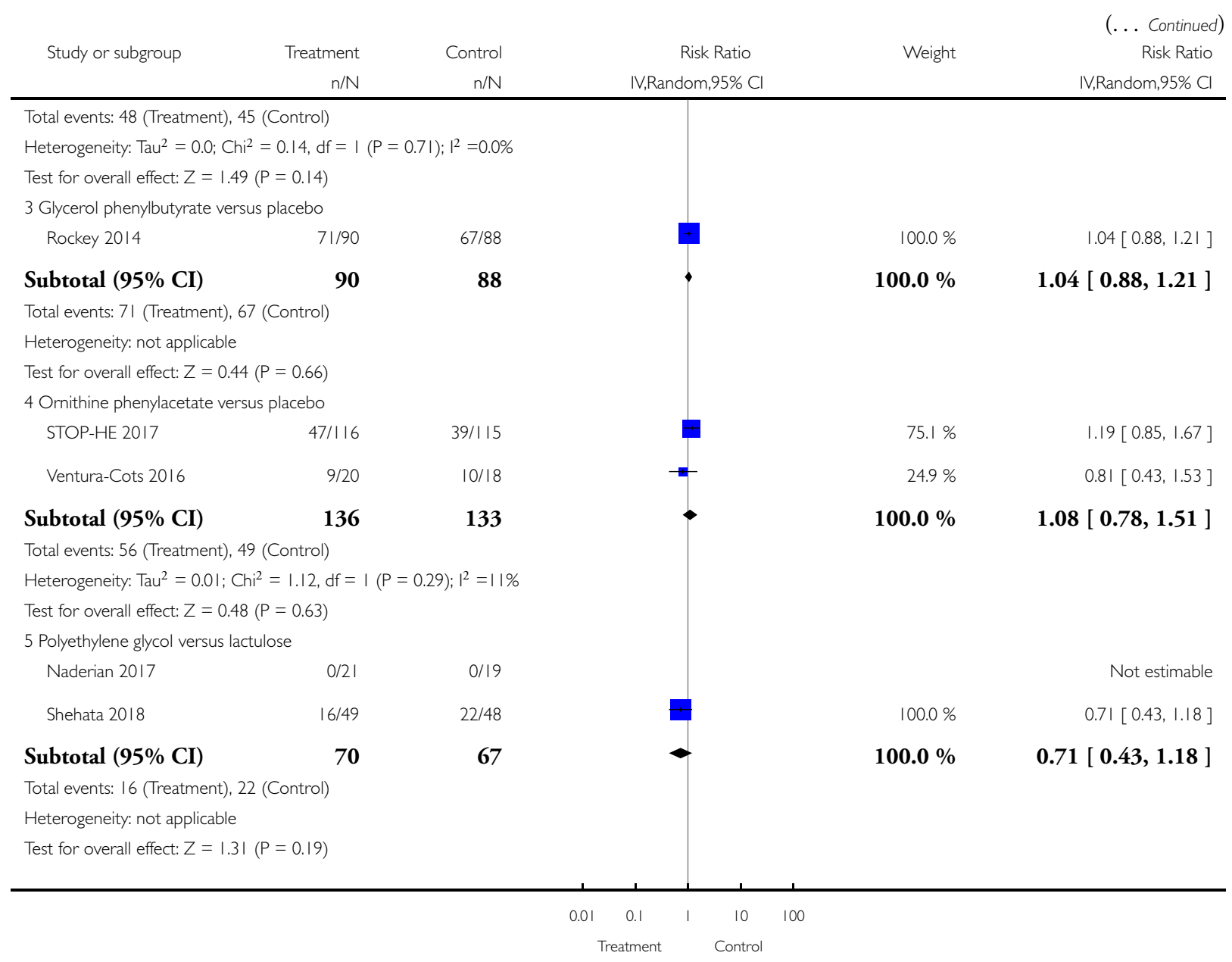


Analysis I.5. Comparison I Pharmacotherapies that specifically target ammonia versus placebo, lactulose, or lactitol, Outcome 5 Ammonia.

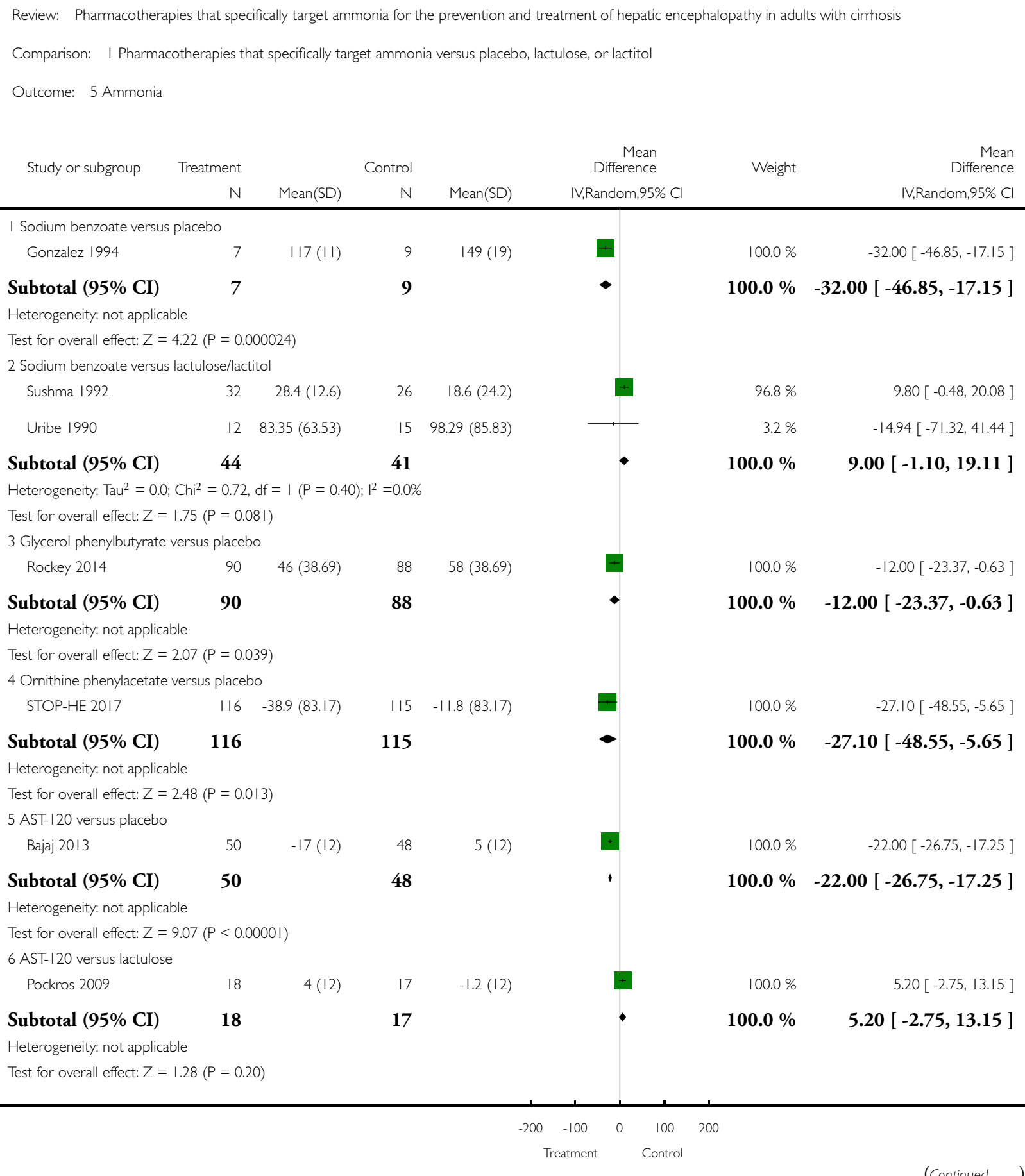

(Continued ... )

Pharmacotherapies that specifically target ammonia for the prevention and treatment of hepatic encephalopathy in adults with cirrhosis 


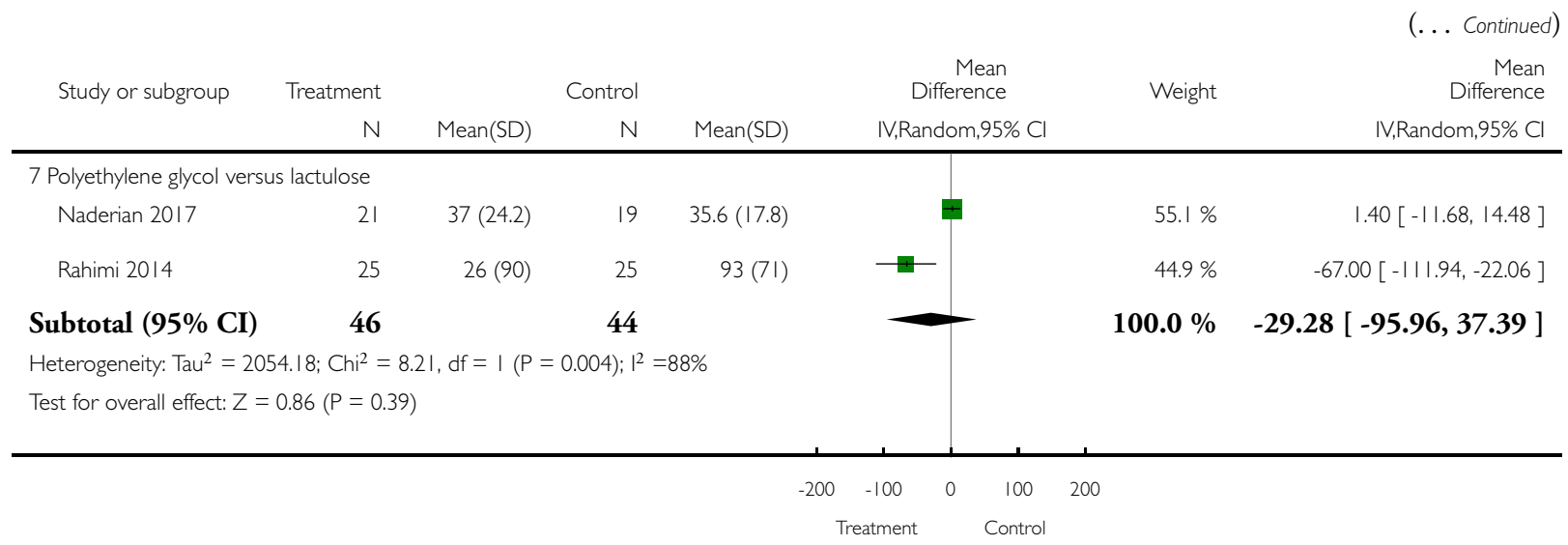

\section{ADDITIONALTABLES}

Table 1. Pharmacotherapeutic agents that specifically target ammonia

\begin{tabular}{|c|c|c|c|}
\hline Agent & Appearance & Doses used & Mechanisms of action \\
\hline Sodium benzoate ${ }^{a}$ & Crystalline powder & $\begin{array}{l}\text { Given orally in solution: stan- } \\
\text { dard dose } 10 \mathrm{~g} \text { daily in divided } \\
\text { doses }\end{array}$ & $\begin{array}{l}\text { Conjugates with glycine to } \\
\text { form hippurate, which is then } \\
\text { excreted via the kidneys }\end{array}$ \\
\hline Sodium phenylbutyrate ${ }^{a}$ & Crystalline powder & $\begin{array}{l}\text { Administered orally or via naso- } \\
\text { gastric tube; } 200 \mathrm{mg} / \mathrm{kg} / \text { day }\end{array}$ & $\begin{array}{l}\text { Conjugates with glutamine } \\
\text { to form phenylacetylglutamine } \\
\text { (PAG) in the liver and kidneys, } \\
\text { which is then eliminated in the } \\
\text { urine. As glutamine is incorpo- } \\
\text { rated into PAG, more is synthe- } \\
\text { sized by amidation of glutamic } \\
\text { acid by ammonia through glu- } \\
\text { tamine synthetase }\end{array}$ \\
\hline Glycerol phenylbutyrate & Liquid & $\begin{array}{l}\text { Administered orally, } 6 \mathrm{~mL} \text { twice } \\
\text { daily for } 16 \text { weeks }\end{array}$ & $\begin{array}{l}\text { Prodrug of sodium phenylbu- } \\
\text { tyrate. Conjugates with glu- } \\
\text { tamine to form phenylacetyl- } \\
\text { glutamine (PAG) in the liver } \\
\text { and kidneys, which is then } \\
\text { eliminated in the urine. As } \\
\text { glutamine is incorporated into } \\
\text { PAG, more is synthesized by } \\
\text { amidation of glutamic acid by } \\
\text { ammonia through glutamine } \\
\text { synthetase }\end{array}$ \\
\hline
\end{tabular}


Table 1. Pharmacotherapeutic agents that specifically target ammonia (Continued)

\begin{tabular}{|c|c|c|c|}
\hline Sodium phenylacetate & Crystalline powder & $\begin{array}{l}\text { Sodium phenylacetate is usu- } \\
\text { ally used in combination with } \\
\text { sodium benzoate as adjunctive } \\
\text { therapy for the treatment of } \\
\text { acute hyperammonaemia and } \\
\text { associated encephalopathy in } \\
\text { people with urea cycle enzyme } \\
\text { deficiencies. It is supplied as } \\
\text { a solution containing } 100 \mathrm{mg} / \\
\mathrm{mL} \text { of sodium phenylacetate } \\
\text { and } 100 \mathrm{mg} / \mathrm{mL} \text { of sodium ben- } \\
\text { zoate }(\mathrm{Ammonul} 10 \% / 10 \%) \text {. It } \\
\text { is administered as an IV infu- } \\
\text { sion } 5.5 \mathrm{~g} / \mathrm{m}^{2} / \mathrm{day}\end{array}$ & $\begin{array}{l}\text { Conjugates with glutamine } \\
\text { to form phenylacetylglutamine } \\
\text { (PAG) in the liver and kidneys, } \\
\text { which is then eliminated in the } \\
\text { urine. As glutamine is incorpo- } \\
\text { rated into PAG, more is synthe- } \\
\text { sized by amidation of glutamic } \\
\text { acid by ammonia through glu- } \\
\text { tamine synthetase }\end{array}$ \\
\hline $\begin{array}{l}\text { Ornithine phenylacetate } \\
\text { (OCR-002) }\end{array}$ & Crystalline salt & $\begin{array}{l}\text { Administered as IV infusion } 10 \\
\mathrm{~g} / 24 \mathrm{~h}(0.42 \mathrm{~g} / \mathrm{h})\end{array}$ & $\begin{array}{l}\text { Reduces ammonia through } 2 \\
\text { pathways: } \\
\text { - L-ornithine acts as a } \\
\text { substrate for the synthesis of } \\
\text { glutamine from ammonia in } \\
\text { skeletal muscle; and, } \\
\text { - phenylacetate and } \\
\text { glutamine combines to form } \\
\text { phenylacetylglutamine, which } \\
\text { is excreted in the urine. }\end{array}$ \\
\hline $\begin{array}{l}\text { AST-120 (spherical carbon mi- } \\
\text { crosphere adsorbent) }\end{array}$ & Powder & $\begin{array}{l}\text { Orally administered powder } \\
\text { (sachets), } 2 \mathrm{~g} \text { three times daily }\end{array}$ & $\begin{array}{l}\text { Differs structurally from ac- } \\
\text { tivated charcoal and exhibits } \\
\text { superior adsorptive capacity } \\
\text { for certain organic compounds } \\
\text { typically those with a low } \\
\text { molecular weight }<10 \mathrm{kDa} \text {. It } \\
\text { binds ammonia in the lumen of } \\
\text { the lower gastrointestinal tract } \\
\text { and facilitates its excretion }\end{array}$ \\
\hline Polyethylene glycol (PEG) & $\begin{array}{l}\text { Solution of } 280 \mathrm{~g} \text { of PEG in } 4 \\
\text { L of water }\end{array}$ & $\begin{array}{l}\text { Administered orally or via a na- } \\
\text { sogastric tube in a single } 4 \mathrm{~L} \\
\text { dose over } 20-30 \mathrm{~min}\end{array}$ & $\begin{array}{l}\text { A cathartic which causes rapid } \\
\text { clearance of ammonia-synthe- } \\
\text { sising gut bacteria from the gut } \\
\text { lumen }\end{array}$ \\
\hline
\end{tabular}

${ }^{a}$ Includes relatively high amounts of sodium. 
Table 2. Composite neurocognitive assessment tools

\begin{tabular}{|c|c|c|c|}
\hline Assessment tool & Description & Advantages & Disadvantages \\
\hline $\begin{array}{l}\text { Portal-Systemic En- } \\
\text { cephalopathy Sum and Index } \\
\text { (PSE Sum/PSE Index) } \\
\text { (Conn 1977) }\end{array}$ & $\begin{array}{l}\text { Provides an index of the sever- } \\
\text { ity of hepatic encephalopathy } \\
\text { derived by adding scores for } \\
\text { the degree of abnormality, ex- } \\
\text { pressed on a } 0 \text { to } 4+\text { scale, for: } \\
\text { - Mental status assessed } \\
\text { using West Haven Criteria } \\
\text { - Asterixis } \\
\text { - Number Connection Test } \\
\text { A time } \\
\text { - Blood ammonia } \\
\text { concentration } \\
\text { - EEG mean cycle } \\
\text { frequency } \\
\text { Each component is arbitrar- } \\
\text { ily weighted in proportion to } \\
\text { its importance; mental state is } \\
\text { weighted by a factor of } 3 \text {, while } \\
\text { the other variables are assigned } \\
\text { a factor of } 1 \\
\text { The PSE Sum is the total of the } \\
\text { weighted scores; its maximum } \\
\text { possible value is } 28 \\
\text { The PSE Index is the ratio of } \\
\text { the estimated PSE Sum to the } \\
\text { maximum possible } \\
\text { Approximate time required: } \\
\text { dependent on the time taken to } \\
\text { obtain the results of the blood } \\
\text { ammonia and the EEG }\end{array}$ & $\begin{array}{l}\text { - Comprehensive } \\
\text { - Use of the PSE Index } \\
\text { takes account of the eventuality } \\
\text { that information on one or } \\
\text { more of the components of the } \\
\text { PSE Sum may not be available } \\
\text { at every time point }\end{array}$ & $\begin{array}{l}\text { - Time-consuming } \\
\text { - EEG is often not readily } \\
\text { available }\end{array}$ \\
\hline $\begin{array}{l}\text { Psychometric Hepatic En- } \\
\text { cephalopathy Score } \\
\text { (PHES) } \\
\text { (Weissenborn 2001) }\end{array}$ & $\begin{array}{l}\text { Format: a battery of five pencil } \\
\text { and paper tests } \\
\text { Aproximate time required: } 20 \\
\text { minutes } \\
\text { Domains tested: } \\
\text { - psychomotor speed } \\
\text { - precision } \\
\text { - visual perception } \\
\text { - visuo-spatial orientation } \\
\text { - visual construction } \\
\text { - concentration } \\
\text { - attention } \\
\text { - memory }\end{array}$ & $\begin{array}{l}\text { - Validated in several } \\
\text { populations internationally } \\
\text { - High diagnostic } \\
\text { sensitivity and specificity } \\
\text { - Multiple versions } \\
\text { available to allow for repeated } \\
\text { testing } \\
\text { - Specifically designed to } \\
\text { detect subtle cognitive changes } \\
\text { in people with minimal } \\
\text { hepatic encephalopathy }\end{array}$ & $\begin{array}{l}\text { - Poor test of memory } \\
\text { - Difficult to interpret and } \\
\text { to score } \\
\text { - Relies on fine motor skills } \\
\text { - Unpopular in countries } \\
\text { such as the USA due to lack of } \\
\text { normative data and availability }\end{array}$ \\
\hline
\end{tabular}

Pharmacotherapies that specifically target ammonia for the prevention and treatment of hepatic encephalopathy in adults with cirrhosis 
Table 2. Composite neurocognitive assessment tools (Continued)

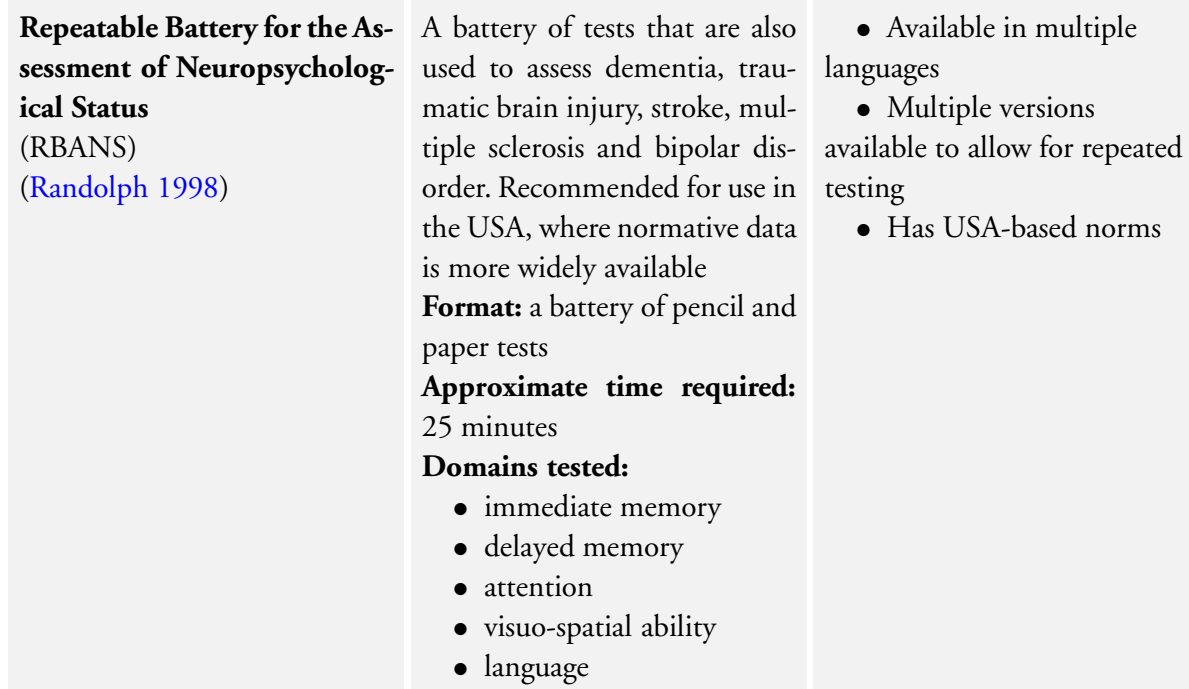
matic brain injury, stroke, multiple sclerosis and bipolar disorder. Recommended for use in the USA, where normative data is more widely available

Format: a battery of pencil and paper tests

Approximate time required:

- Available in multiple languages

- Multiple versions available to allow for repeated testing

- Has USA-based norms

25 minutes

Domains tested:

- immediate memory

- delayed memory

- attention

- visuo-spatial ability

- language

- Two domains are not affected in minimal hepatic encephalopathy

- Difficult to interpret and to score

- Relies on fine motor skills

- Scarce data on sensitivity and specificity in hepatic encephalopathy

\section{Hepatic Scoring Algorithm (HESA)} Encephalopath

(Hassanein 2008)
An algorithm originally developed to assess the utility of extracorporeal albumin dialysis in the treatment of people with severe hepatic encephalopathy Format: a combination of clinical indicators and results from neurophysiological tests

Approximate time required: 15 minutes

Domains tested:

- orientation

- mental control

- visuo-spatial memory

- verbal memory

- depression/anxiety

- computation

- attention

- constructional ability
- Uses well-defined criteria

- Simple and objective

- Time-efficient

- Able to identify low grades of hepatic encephalopathy more precisely

- Thorough, so useful to grade hepatic encephalopathy
- Requires training of personnel to use

- A long, labour-intensive test, so not widely used in clinical practice
Clinical Hepatic En- A scale from 0-9, designed to cephalopathy Staging Scale (CHESS)

(Ortiz 2007) reduce interobserver variability Format: a set of nine questions that the observer must answer Approximate time required: 10 minutes

Domains tested:

- orientation

- attention

- language

- consciousness
- Reflects the spectral nature of hepatic encephalopathy

- Shows good consistency and reproducibility
- Not widely used apart from in clinical trials

- Needs further validation

Pharmacotherapies that specifically target ammonia for the prevention and treatment of hepatic encephalopathy in adults with cirrhosis 


\begin{tabular}{|c|c|c|c|}
\hline $\begin{array}{l}\text { Cognitive Drug Research } \\
\text { (CDR) } \\
\text { (Mardini 2008) }\end{array}$ & $\begin{array}{l}\text { Developed in the UK specifi- } \\
\text { cally for people with minimal } \\
\text { hepatic encephalopathy } \\
\text { Format: computerized test con- } \\
\text { sisting of a set of increasingly } \\
\text { complex tasks based on yes/no } \\
\text { responses. Seven tests with } 50 \\
\text { parallel forms of each task } \\
\text { Approximate time required: } \\
\text { up to } 30 \text { minutes } \\
\text { Domains } \\
\text { attention power and continuity, } \\
\text { speed and quality of working } \\
\text { and episodic memory }\end{array}$ & $\begin{array}{l}\text { - Large normative data } \\
\text { pool in the United Kingdom } \\
\text { - Good correlation with } \\
\text { the PHES test } \\
\text { - High sensitivity and } \\
\text { specificity } \\
\text { - Multiple versions } \\
\text { available to allow for repeated } \\
\text { testing }\end{array}$ & $\begin{array}{l}\text { - Time-consuming } \\
\text { - Trail run needed before } \\
\text { formal testing } \\
\text { - Requires validation in } \\
\text { other countries } \\
\text { - Few data available for its } \\
\text { use in people with cirrhosis }\end{array}$ \\
\hline
\end{tabular}

EEG: electroencephalogram

Table 3. Measurement of ammonia concentrations in the included trials

\begin{tabular}{|c|c|c|c|}
\hline Trial & Type of blood sample & Unit measure & Time period for measurement differences \\
\hline Gonzalez 1994 & Venous & $\mu \mathrm{g} / \mathrm{dL}$ & Baseline, 72 hours and 7 days \\
\hline Sushma 1992 & Arterial & $\mu \mathrm{g} / \mathrm{dL}$ & Baseline, 72 hours and at recovery \\
\hline Uribe 1990 & Not specified & $\mu \mathrm{g} / \mathrm{dL}$ & Baseline and 2 weeks \\
\hline Rockey 2014 & Venous & $\mu \mathrm{mol} / \mathrm{L}^{*}$ week & $\begin{array}{l}\text { Measure based on the time normalised area under the time-con- } \\
\text { centration curve (TN-AUC }{ }_{\text {week }} \text { ) }\end{array}$ \\
\hline STOP-HE 2017 & Venous & $\mu \mathrm{mol} / \mathrm{L}$ & Mean reduction in ammonia concentrations \\
\hline Ventura-Cots 2016 & Venous & $\mu \mathrm{mol} / \mathrm{L}^{*} 120 \mathrm{hr}$ & $\begin{array}{l}\text { Measurement based on the time-normalized area under the curve } \\
\left.\text { time concentration curve (TN-AUC }{ }_{0-120 h}\right)\end{array}$ \\
\hline Bajaj 2013 & Venous & $\mu \mathrm{g} / \mathrm{dL}$ & Baseline and 8 weeks \\
\hline Pockros 2009 & Venous & Not specified & Baseline and 4 weeks \\
\hline Naderian 2017 & Not specified & $\mu \mathrm{mol} / \mathrm{L}$ & Reported as the mean difference from baseline to 24 hours \\
\hline Rahimi 2014 & Not specified & $\mu \mathrm{mol} / \mathrm{L}$ & Reported as the mean difference from 6 to 24 hours \\
\hline
\end{tabular}




\section{A P P E N D I CES}

\section{Appendix I. Search strategy}

\begin{tabular}{|c|c|c|}
\hline Database & Time span & Search terms \\
\hline $\begin{array}{l}\text { Cochrane Hepato-Biliary Controlled Trials } \\
\text { Register }\end{array}$ & March 2019 & $\begin{array}{l}\text { ((sodium and (benzoate or phenylacetate or phenylbutyrate)) or } \\
\text { glycerol phenylbutyrate or ornithine phenylacetate or spherical } \\
\text { carbon absorbant or activated charcoal or ammonul or buphenyl } \\
\text { or ravicti or AST-120 or polyethylene* glycol or PEG or (am- } \\
\text { moni* and scaveng*)) AND ((encephalopath* or HE) and cir- } \\
\text { rho*) }\end{array}$ \\
\hline
\end{tabular}

Cochrane Central Register of Controlled 2019, Issue 3 Trials (CENTRAL) in the Cochrane Library
\#1 MeSH descriptor: [Phenylbutyrates] explode all trees \#2 MeSH descriptor: [Phenylacetates] explode all trees \#3 MeSH descriptor: [Sodium Benzoate] explode all trees \#4 MeSH descriptor: [Charcoal] explode all trees \#5 ((sodium and (benzoate or phenylacetate or phenylbutyrate) ) or glycerol phenylbutyrate or ornithine phenylacetate or spherical carbon absorbant or activated charcoal or ammonul or buphenyl or ravicti or AST-120 or polyethylene* glycol or PEG or (ammoni* and scaveng*))

\#6 \#1 or \#2 or \#3 or \#4 or \#5

\#7 MeSH descriptor: [Hepatic Encephalopathy] explode all trees \#8 MeSH descriptor: [Fibrosis] explode all trees \#9 \#7 and \#8

\#10 ((encephalopath* or HE) and cirrho*)

\#11 \#9 or \#10

$\# 12$ \#6 and \#11

MEDLINE Ovid

1946 to March 2019

1. exp Phenylbutyrates/ or exp Phenylacetates/ or exp Sodium Benzoate/

2. exp Charcoal/

3. ((sodium and (benzoate or phenylacetate or phenylbutyrate)) or glycerol phenylbutyrate or ornithine phenylacetate or spherical carbon absorbant or activated charcoal or ammonul or buphenyl or ravicti or AST-120 or polyethylene* glycol or PEG or $\left(\right.$ ammoni* $^{*}$ and scaveng*)).mp. [mp=title, abstract, original title, name of substance word, subject heading word, keyword heading word, protocol supplementary concept word, rare disease supplementary concept word, unique identifier]

4. 1 or 2 or 3

5. exp Hepatic Encephalopathy/

6. $\exp$ Fibrosis/

7. 5 and 6

8. ((encephalopath* or HE) and cirrho*).mp. [mp=title, abstract, original title, name of substance word, subject heading word, keyword heading word, protocol supplementary concept word, rare disease supplementary concept word, unique identifier] 
9. 7 or 8

10.4 and 9

Embase Ovid
1974 to March 2019

1. exp benzoic acid/

2. exp phenylacetic acid/

3. exp 4 phenylbutyric acid/

4. exp glycerol phenylbutyrate/

5. exp ornithine phenylacetate/

6. exp activated carbon/

7. ((sodium and (benzoate or phenylacetate or phenylbutyrate)) or glycerol phenylbutyrate or ornithine phenylacetate or spherical carbon absorbant or activated charcoal or ammonul or buphenyl or ravicti or AST-120 or polyethylene* glycol or PEG or (ammoni* and scaveng*)).mp. [mp=title, abstract, heading word, drug trade name, original title, device manufacturer, drug manufacturer, device trade name, keyword]

8 . 1 or 2 or 3 or 4 or 5 or 6 or 7

9. exp hepatic encephalopathy/

10. exp liver cirrhosis/

11. 9 and 10

12. ((encephalopath* or HE) and cirrho*).mp. [mp=title, abstract, heading word, drug trade name, original title, device manufacturer, drug manufacturer, device trade name, keyword]

13. 11 or 12

14.8 and 13

\section{LILACS (Bireme)}

\begin{tabular}{l|}
\hline \\
\hline $\begin{array}{l}\text { Science Citation Index Expanded (Web of } \\
\text { Science) }\end{array}$
\end{tabular}

Science $\mathrm{Cit}$
Science)

\section{\#3 \#2 AND \#1}

\#2 TS=((encephalopath* or HE) and cirrho*)

\#1 TS=((sodium and (benzoate or phenylacetate or phenylbutyrate)) or glycerol phenylbutyrate or ornithine phenylacetate or spherical carbon absorbant or activated charcoal or ammonul or buphenyl or ravicti or AST-120 or polyethylene* glycol or PEG or (ammoni* and scaveng*))
Conference Proceedings Citation Index - 1990 to March 2019 Science

(Web of Science)
\#3 \#2 AND \#1

\#2 TS=((encephalopath* or HE) and cirrho*)

\#1 TS=((sodium and (benzoate or phenylacetate or phenylbutyrate)) or glycerol phenylbutyrate or ornithine phenylacetate or spherical carbon absorbant or activated charcoal or ammonul or buphenyl or ravicti or AST-120 or polyethylene* glycol or PEG or (ammoni* and scaveng*)) 


\section{WHAT'S NEW}

\begin{tabular}{|c|c|c|}
\hline Date & Event & Description \\
\hline 10 July 2019 & Amended & $\begin{array}{l}\text { Adjustment to the number of trials at low risk of bias following removal of the 'For-profit bias' category } \\
\text { The units of ammonia measurements provided } \\
\text { A table is added, specifying details of the ammonia measurements in the included trials }\end{array}$ \\
\hline
\end{tabular}

\section{H I S T O R Y}

Protocol first published: Issue 8, 2016

Review first published: Issue 6, 2019

\begin{tabular}{|c|c|c|}
\hline Date & Event & Description \\
\hline 30 June 2019 & Amended & Sumary of Findings tables amalgamated \\
\hline
\end{tabular}

\section{CONTRIBUTIONSOFAUTHORS}

HDZ drafted the review, and identified and selected trials, conducted the data extraction, analyses and interpretation of the results. APZ identified and selected trials and assisted with the data extraction. LLG and MYM identified and selected trials, contributed to the analyses and interpretation of the results, and revised the review.

All authors participated in the final revision of the review and have approved of the submitted version.

\section{DECLARATIONSOF INTEREST}

Harry Zacharias: none

Antony Zacharias: none

Lise L Gluud: none

Marsha Y Morgan: none 


\section{SOURCES OF SUPPORT}

\section{Internal sources}

- No funding, Other.

\section{External sources}

- No funding, Other.

\section{DIFFERENCES BETWEEN PROTOCOLANDREVIEW}

We changed the title to more precisely reflect the modes of action of the interventions included in the review and to make it clear that we only included adult participants, and we changed the wording of the review objectives to reflect the changes we had made to the title. We also updated the methods according to the current recommendations of Cochrane Hepato-Biliary. The updates include changes to the wording of the 'Risk of bias' assessment; obligatory inclusion of observational studies for the assessment of adverse events; and searching of the LILACS database. We did not include liver-related mortality as a secondary outcome as most trials do report this separately. We upgraded blood ammonia from an exploratory to a secondary outcome as these pharmacotherapies specifically target ammonia. There were insufficient data to include Number Connection Test results as an exploratory outcome. We did not undertake subgroup analyses because the number of randomised clinical trials identified was too small. We did not undertake sensitivity analyses because the outcome data sets were complete in the intervention and control groups in all of the included trials. We did not undertake Trial Sequential Analyses because the number of events, participants, and trials was insufficient.

Pharmacotherapies that specifically target ammonia for the prevention and treatment of hepatic encephalopathy in adults with cirrhosis 